\title{
Synthesis of Bisindole Alkaloids from the Apocynaceae Which Contain a Macroline or Sarpagine Unit: A Review
}

\author{
Md Toufiqur Rahman, Veera V. N. Phani Babu Tiruveedhula and James M. Cook* \\ Department of Chemistry and Biochemistry, University of Wisconsin-Milwaukee, 3210 N. Cramer Street, \\ Milwaukee, WI 53201, USA; mdrahman@uwm.edu (M.T.R.); tiruvee2@uwm.edu (V.V.N.P.B.T.) \\ * Correspondence: capncook@uwm.edu; Tel.: +1-414-229-5856; Fax: +1-414-229-5530 \\ Academic Editor: Michael Wink \\ Received: 29 September 2016; Accepted: 4 November 2016; Published: 14 November 2016
}

\begin{abstract}
Bisindole natural products consist of two monomeric indole alkaloid units as their obligate constituents. Bisindoles are more potent with respect to their biological activity than their corresponding monomeric units. In addition, the synthesis of bisindoles are far more challenging than the synthesis of monomeric indole alkaloids. Herein is reviewed the enantiospecific total and partial synthesis of bisindole alkaloids isolated primarily from the Alstonia genus of the Apocynaceae family. The monomeric units belong to the sarpagine, ajmaline, macroline, vobasine, and pleiocarpamine series. An up-to-date discussion of their isolation, characterization, biological activity as well as approaches to their partial and total synthesis by means of both synthetic and biosynthetic strategies are presented.
\end{abstract}

Keywords: Alstonia genus; Apocynaceae family; sarpagine; macroline; ajmaline; bisindole alkaloids; biomimetic synthesis; partial and total synthesis; enantiospecific and regiospecific synthesis of alkaloids; bioactive indole alkaloids

\section{Introduction}

Indole alkaloids are of extraordinary significance due to their structural diversity, medicinal properties and are an essential part of the drug discovery process (see the Merck Index for details) [1]. Their medicinal values are evident from folklore and their ethnopharmacological uses worldwide stem from ancient times [2-5]. Many of the alkaloids are marketed drugs [6], and other drugs are derived directly from natural products or they serve as lead compounds for further development [7] into clinical candidates ranging from anti-bacterial to anti-cancer agents [8-15].

The activity and structures of bisindole alkaloids have been reviewed and the number of isolated bisindole alkaloids are increasing [16-19]. This review is focused on the partial and total synthesis of bisindoles, as well as some dimeric indole alkaloids wherein at least one of the following monomeric units contains, as its obligate constituent, the sarpagine, macroline, ajmaline, vobasine, or pleiocarpamine systems. Because of the complexity of their structures, which are comprised of more than one alkaloidal partner, a convergent approach toward their synthesis is logical synthetically, as well as biosynthetically. This breaks down to synthesis of the monomeric alkaloidal units, followed by a biomimetic-type condensation to arrive at the bisindole framework. The number of isolated bisindoles has increased recently because of modern spectroscopic techniques (e.g., Mass spectrometry, ${ }^{13} \mathrm{C}$ and 2D NMR, HMQC, HMBC, NOESY, and X-ray crystallography) which enable accurate structure determination on milligram quantities of the bisindole. The synthesis of these complex natural products can begin only when their structures are accurately confirmed [20]. Consequently, the synthesis of bisindole alkaloids, of course, must lag behind the synthesis of monomers which 
comprise them. An important approach, defined as partial synthesis, is to combine any monomeric alkaloid available, either by synthesis (including the synthesis from a natural product) or by isolation, with the other natural monomeric unit usually in a biosynthetic strategy. This process is commonly termed the biomimetic synthesis of bisindole alkaloids pioneered by Schmid, LeQuesne, Kutney, Magnus, and others.

In many studies, it has been shown that bisindole alkaloids exhibit more potent biological, pharmacological and medicinal properties than the corresponding monomers which comprise them [21,22], as mentioned above. There are many theories as to why this pattern of activity is observed but, to date, no concrete evidence as to the mechanism of action (MOA) has emerged. However, this is not surprising for one would not expect the same MOA in each case. As always one of the main hurdles in natural product related drug-discovery is that many natural products are present in very small quantities and cannot be isolated in quantities high enough to study their biological activity let alone structure-activity relationships. This situation is exacerbated in the case of bisindole alkaloids. Consequently, it is essential to develop better and easier access to bisindole alkaloids either synthetically or biosynthetically. Partial and total synthesis, thereby require equal emphasis in this regard. If one can synthesize the natural products in a stereospecific, regiospecific and enantiospecific sense via a practical synthetic route, these alkaloids could be obtained in appropriate amounts for detailed studies of their biological activity. One could then condense the mismatched pairs as well (i.e., $(+)(-) ;(+)(+) ;(-)(-) ;(-)(+))$.

The discovery of the Vinca alkaloids vinblastine and vincristine, originally isolated from Madagascar periwinkle, Catharanthus roseus (formerly known as Vinca rosea) [23-26], marked a major milestone in natural product-based drug development as these two are the first clinically used alkaloidal anti-cancer agents. Moreover, it is well known that the bisindole nature of these alkaloids is the key for the bisindoles are much more active than the monomeric alkaloids which comprise them. These bisindole (indole-indoline) alkaloids are one of the best treatment options in various types of cancers and have been successfully used in combination therapies since the early 1960s [27-29]. Besides, their MOA (interaction with tubuline, microtubule assembly inhibition, and mitosis inhibition) is one of the most effective treatment against cancer, which promoted rigorous research and development of vinblastine and vincristine resulting in many (derivatives of vincristine and vinblastine) clinical candidates to date [6,8-15,30-36]. As a consequence, these have profoundly stimulated the search and development of alkaloidal natural product based drugs.

The bisindoles (-)-accedinisine 1 and (-)- $N^{\prime}$-demethylaccedinisine 2 exhibit anti-leishmanial activity, as well as moderate antibacterial activity against gram-positive B. subtilis [37,38]. Antimalarial activity of numerous indole alkaloids against Palsmodium falciparum (cerebral) malaria have been reported, many of which are bisindole alkaloids [21,39-41]. (-)-Macrocarpamine 3 and (+)-villalstonine 5 were the most active bisindoles isolated from Alstonia macrophylla against both Entamoeba histolytica and Plasmodium falciparum [21,42]. These alkaloids 3 and 5 also exhibited potent anti-cancer activity against lung cancer cell lines as well as melanoma, renal cell carcinoma, breast, and colon adrenocarcinoma [22,40]. Villalstonine 5 was also active against murine leukemia cell lines [43]. (+)-Dispegatrine 7 and its related monomer, (+)-spegatrine exhibited potent hypotensive activity, wherein the potency of the dimer was about an order of magniture greater than the monomer toward $\alpha_{1}$ and $\alpha_{2}$ adrenergic receptors [44]. (+)-Macralstonine 9 has been reported to have hypotensive activity $[45,46]$. In another study, by Keawpradub et al. on three Alstonia species from Thailand, bisindoles (+)-macralstonine 9, (+)-O-acetylmacralstonine 10, (+)-O-methylmacralstonine 11, $(+)$-villalstonine 5, and (-)-macrocarpamine 3 , as well as the monomeric alkaloids (+)-pleiocarpamine 14, (-)-alstonerine 15, and (-)-alstophylline 22 exhibited profound anti-Plasmodial activity [47]. It is important to note that a minor change in the structure of (+)-macralstonine 9 by conversion into the O-methyl ether 11 or $O$-acetyl ester 10, profoundly increased its anti-Plasmodial activity [47]. This increase in activity of $O$-acetyl and $O$-methyl derivatives of macralstonine may be due to the increased lipophilicity which facilitated their transport across cell membranes. Accedinisine-related 
monomeric indole alkaloids (+)-pericyclivine (92, see later), (-)-perivine (43, see later) and (-)-vobasine (not shown) exhibited significant cytotoxicity against P388 and KB cells but were less active than the bisindole alkaloids [20,48]. (+)-Pleiocarpamine $\mathbf{1 4}$ has recently been found to form an unprecedented dimeric structure, (+)-bipleiophylline 12, wherein two pleiocarpamine 14 units were linked together by means of an aromatic spacer (pyrocatechuic acid). This dimer was found to be very effective against drug-sensitive, vincristine resistant human KB and Jurkat cells [49]. This finding also supports the argument that bisindole alkaloids are more active than their progenitors since (+)-pleiocarpamine did not exhibit significant activity [21,22,47].

Illustrated in Figure 1 are representative bisindoles presented in this review. All of these alkaloids have originated from the combination of two monomeric indole alkaloids depicted in Figure 2.

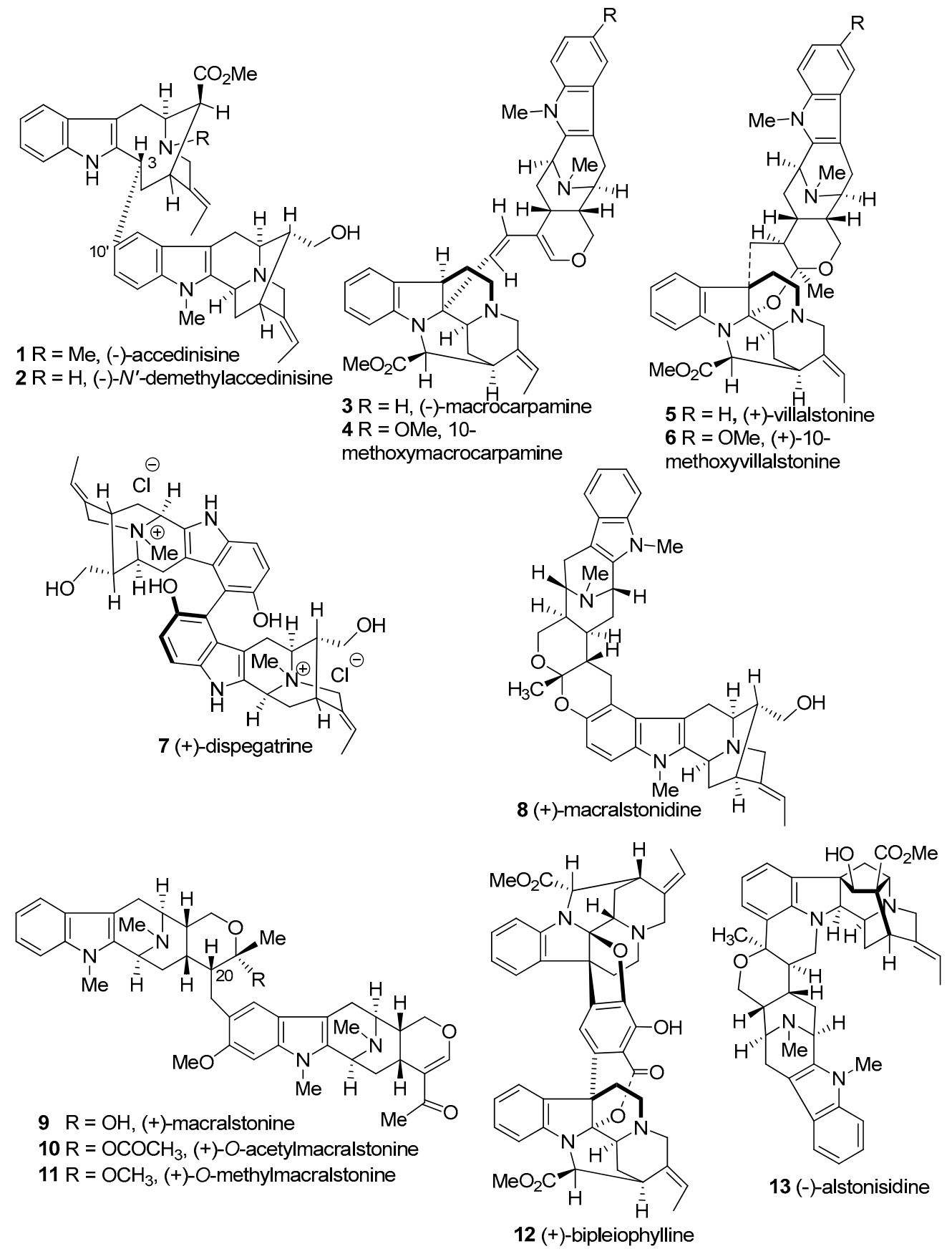

Figure 1. Representative examples of bioactive bisindole alkaloids. 

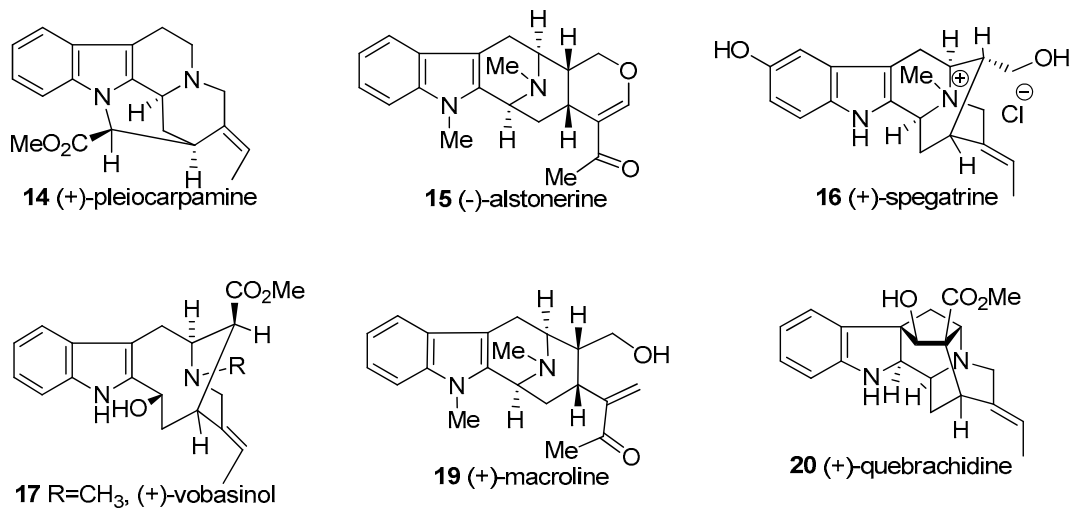

$18 \mathrm{R}=\mathrm{H}$, perivinol
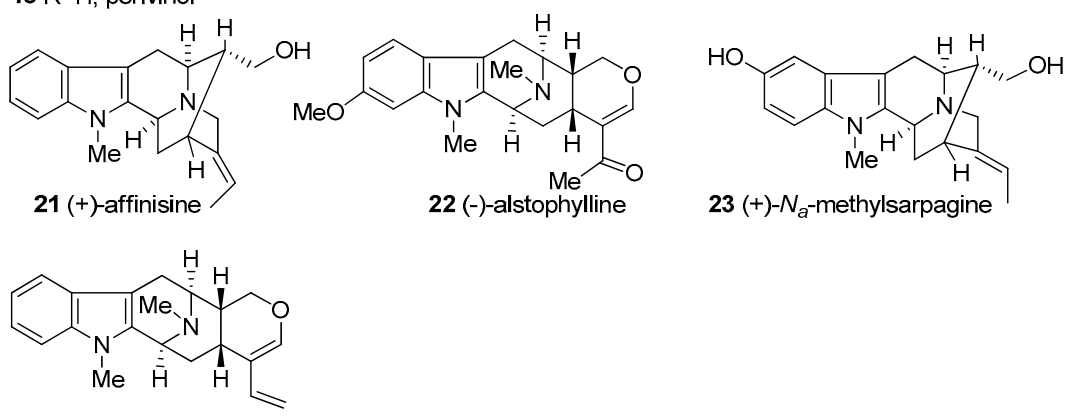

24 (-)-anhydromacrosalhine-methine

Figure 2. Monomeric units present in the bisindole alkaloids reviewed herein.

\section{Biogenetic Relationship between Sarpagine/Macroline/Ajmaline Alkaloids}

The macroline 19 and sarpagine 25 natural products are contained in one of the major classes of indole alkaloids that originated from common biogenetic intermediates. Although macroline $\mathbf{1 9}$ has not been isolated as an alkaloid itself, it is believed to be a biogenetic precursor for numerous alkaloids in this class. (+)-Ajmaline 26, a clinically and historically important alkaloid [20,50-52], is structurally related to the sarpagine alkaloids. These three major types of indole alkaloids are inter-related through their biogenetic origin. To date, this group consists of more than 300 alkaloids which contain more than 80 bisindole alkaloids [53,54]. A general strategy has been developed to access a common intermediate to this series of natural products, the tetracyclic core of which consists of the azabicyclo[3.3.1]nonane system with the (S) configuration at both C-3 and C-5 (Figure 3).

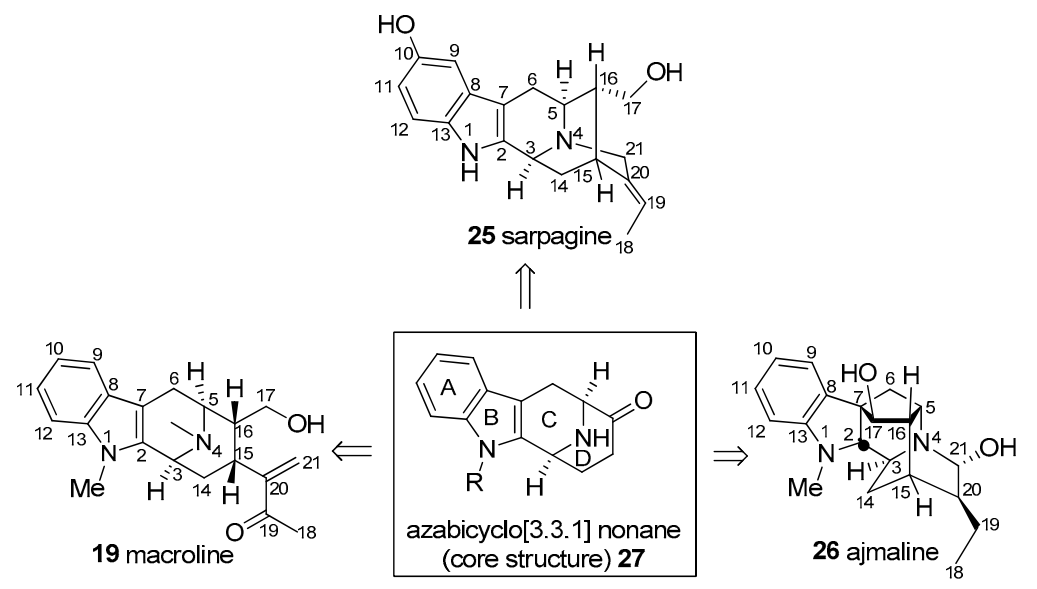

Figure 3. The sarpagine, macroline, and ajmaline indole alkaloids. The biogenetic numbering of LeMen and Taylor has been followed [55]. 
In a synthetic sense, sarpagine alkaloids could originate from a Michael-type reaction of the $N(4)$ nitrogen atom of macroline 19 onto the $\alpha, \beta$-unsaturated carbonyl system at C-21 either by a 1,2 or a 1,4-type addition reaction, as illustrated in Figure 4 [54,56]. On the other hand, the sarpagine 32 can be converted into macroline 19 by a retro-Michael process, reported in a biomimetic sense originally by LeQuesne et al. [57].

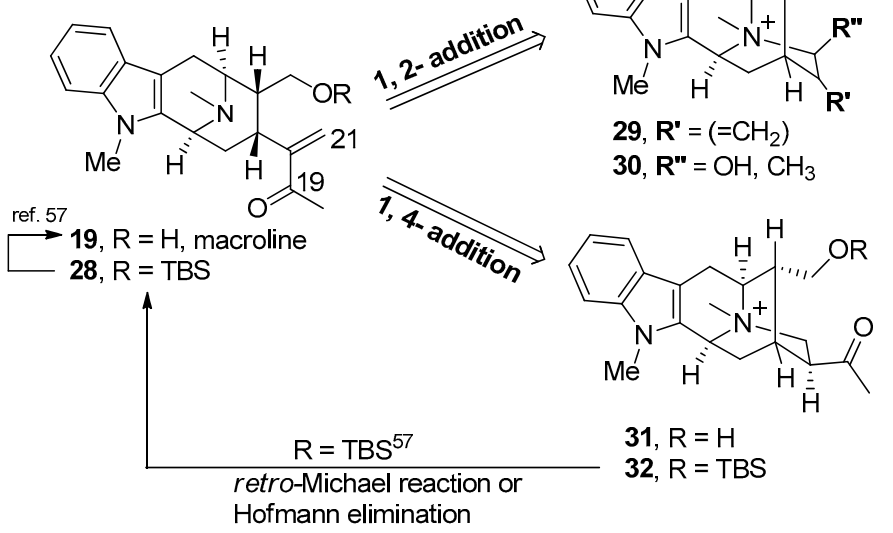

Figure 4. Interconversion of macroline 19 and sarpagine 25.

The biogenetic relationship between these series of alkaloids has been reported previously [58-61]. Stöckigt et al. converted 16-epi-vellosimine 33a into vinorine 35a via deacetylvinorine 34 using acetyl CoA dependent vinorine synthase [62-64]. This study confirmed the conversion of the endo-aldehyde containing sarpagine skeleton (33) into the ajmaline skeleton (35) under acidic conditions, as suggested earlier by Woodward (Figure 5) [58].

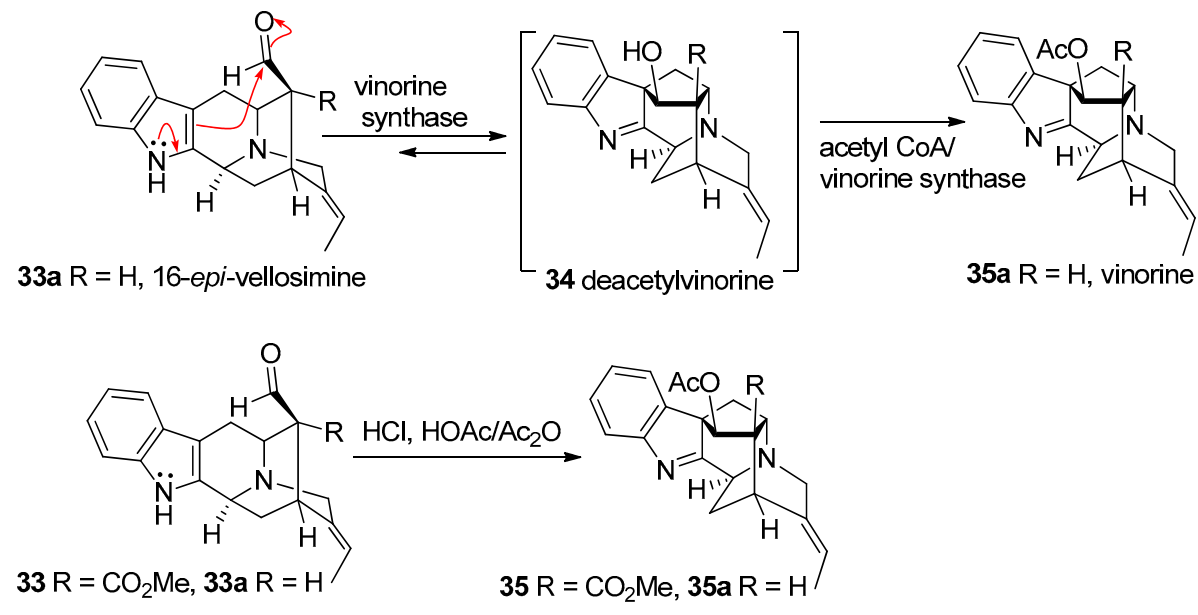

Figure 5. Biosynthetic relationship between sarpagine and ajmaline reported by Stöckigt et al. [62-64].

\section{General Strategy to Access the Tetracyclic Core 27 of the Sarpagine/Macroline/Ajmaline Related Indole Alkaloids}

An azabicyclo[3.3.1]nonane core system 27 is a common feature of the macroline/sarpagine/ ajmaline type indole alakaloids. Thus, a general synthetic strategy for the synthesis of these alkaloids involved the synthesis of this core structure with the correct stereochemistry at positions C-3, C-5 and appropriate functional groups at C-15 and C-16 for further functionalization. To date, methods for accessing the $( \pm)$-azabicyclo[3.3.1]nonane 27 system has been reported by Yoneda [65], Mashimo [66], Kluge [67] and on large scale by Soerens et al. [68]. 
The synthesis of the optically active (-)-tetracyclic core was achieved by Zhang et al. [69] in 1988 in a stereospecific fashion which employed the asymmetric Pictet-Spengler reaction. Numerous adjustments have been made to better access this moiety with both $N_{\mathrm{a}}-\mathrm{H}$ and $N_{\mathrm{a}}$-Me functionalities over the years. The present strategy is illustrated in Scheme 1. Currently, the Pictet-Spengler reaction is carried out in one pot under conditions that permit epimerization at $\mathrm{C}-1$ to provide only the desired trans-diastereomer 38. D-(+)-tryptophan methyl ester 37 is commercially available but can also be prepared from D-(+)-tryptophan 36 by Fischer esterification on 400 gram scale.
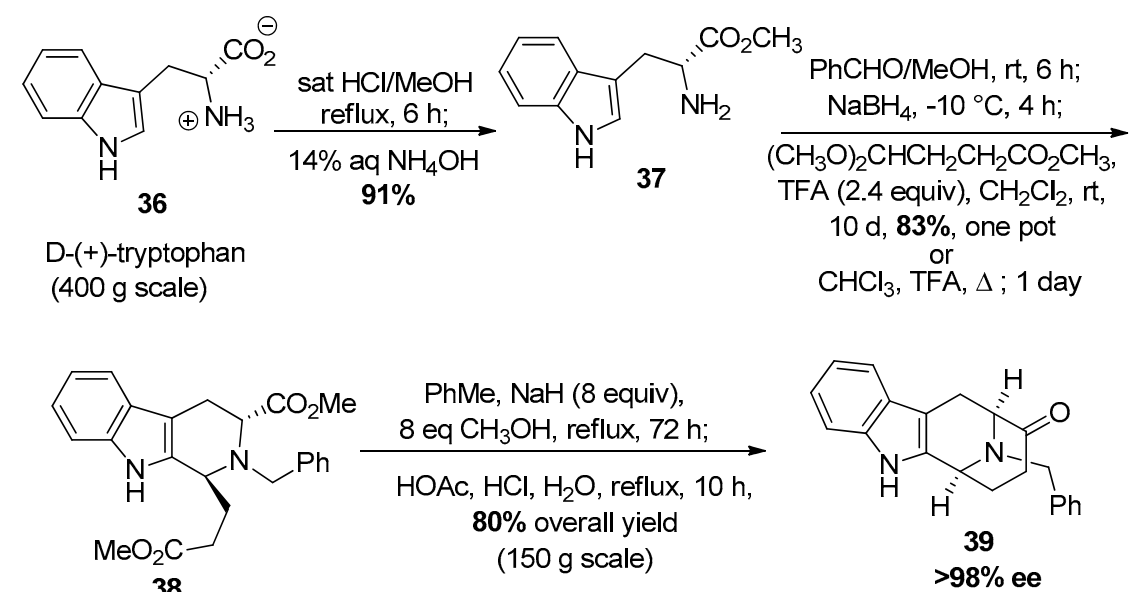

38
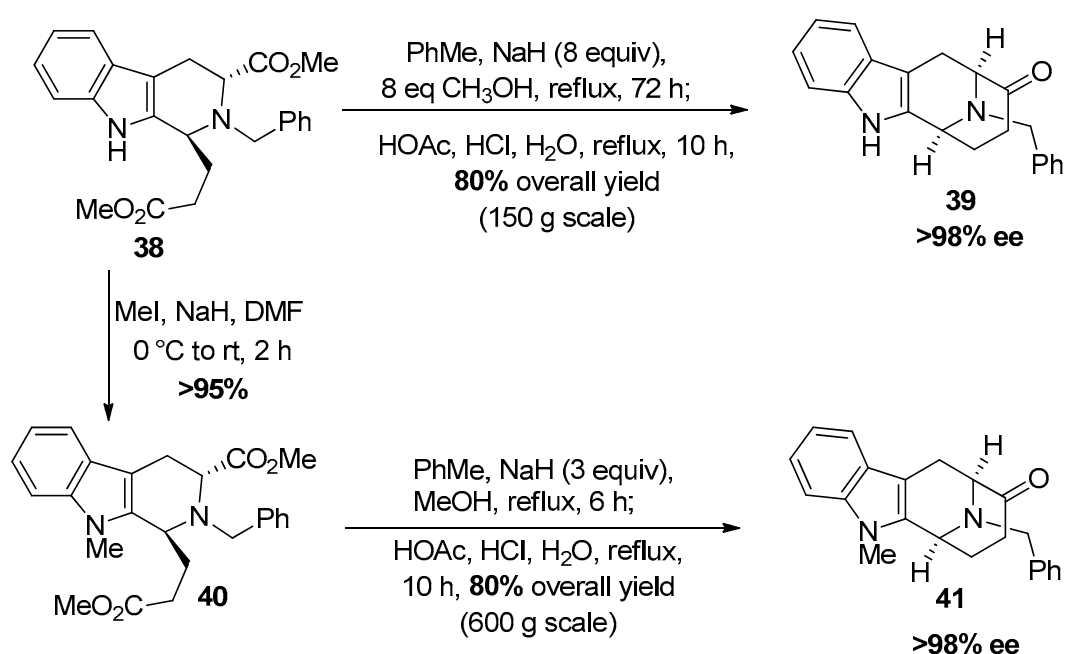

Scheme 1. General strategy to access the tetracyclic ketones which contain the azabicyclo[3.3.1]nonane system.

The $N_{\mathrm{b}}$-benzylation was done on amine 37 with benzaldehyde in methanol at room temperature, followed by reduction of the so formed iminium ion salt with sodium borohydride added slowly to the mixture at $-10{ }^{\circ} \mathrm{C}$. Subsequently, trifluoroacectic acid was added to the mixture at $0{ }^{\circ} \mathrm{C}$ to bring the $\mathrm{pH}$ to 7 . After removal of the solvent, methylene chloride, trifluoroacetic acid (TFA) and 4,4-dimethoxybutyrate were added to the mixture at $0{ }^{\circ} \mathrm{C}$ and this was stirred for 10 days at room temperature to yield the trans-diester 38 in $83 \%$ yield as the sole product [70]. This could be accomplished in refluxing chloroform in one day in slightly lower yield. Next, the Dieckmann cyclization was done in the presence of a large excess of $\mathrm{NaOMe}$ and methanol in toluene at reflux for $72 \mathrm{~h}$ ( $6 \mathrm{~h}$ for the $N_{\mathrm{a}}$-Me indole) to yield the cyclized product. At the completion of the reaction, the reaction mixture was cooled to $0{ }^{\circ} \mathrm{C}$ and the excess base was neutralized with glacial acetic acid and the solvent was removed under reduced pressure. After that, glacial acetic acid and aqueous hydrochloric acid as well as water were added to the mixture and it was allowed to reflux under these strongly acidic conditions to furnish the product of decarboxylation. This gave $N_{b}$-benzyl tetracyclic ketone 39 , in $80 \%$ overall yield on large scale. For the $N_{\mathrm{a}}$-Me series, the trans-diester 38 was methylated using iodomethane and sodium hydride in DMF to yield the $N_{\mathrm{a}}$-Me trans-diester 40 in $>95 \%$ yield, which under the same conditions as $\mathbf{3 8}$ gave the $N_{\mathrm{a}}$-Me tetracyclic ketone $\mathbf{4 1}$ in a one-pot process. This route is still one of the best routes since reactions can be done on multi-hundred gram scales and do not require protection of the $N_{\mathrm{a}}-\mathrm{H}$ function. This is an enantioselective and regioselective 
process in $>98 \%$ ee. This route with two one pot conversions also requires fewer steps than previous routes [69-71]. In addition, the availability of D-(+)-tryptophan and the (-)-enantiomer provides a route to both enantiomers of the alkaloids including the ability to condense mismatched pairs, as mentioned.

\section{Partial and Total Synthesis of Bisindole Alkaloids}

\section{1. (-)-Alstonisidine}

(-)-Alstonisidine was isolated from the bark of Alstonia muelleriana Domin, along with several other alkaloids by Elderfield et al. and LeQuesne et al. [72,73]. The structure of (-)-alstonisidine 13 was reported in 1972 by LeQuesne et al. [74,75]

The structure of $\mathbf{1 3}$ was proposed, in a biomimetic sense, for (-)-alstonisidine from its constituent monomeric units, (+)-quebrachidine 20 and (+)-macroline 19. The crystal structure of (-)-alstonisidine was ultimately reported by Hoard in 1977 which confirmed the structure as $\mathbf{1 3}$ (Figure 6) [76]. When the mixture of 19 and 20 was stirred in $0.2 \mathrm{~N}$ aqueous $\mathrm{HCl}$, the labile hemiketal 42 formed, as indicated by examination of the spectral data. The tentative stereochemistry was based on the structure of the bulky quebrachidine unit which bore a $-\mathrm{CH}_{2}-$ group which should occupy the equatorial position. The hemiketal was treated with boron trifluoride etherate to yield alstonisidine which suggested the structure 42 as an intermediate, since no reaction occurred under the same conditions between (+)-quebrachidine 20 and (+)-macroline 19 [75].

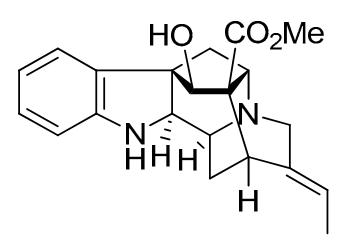

$(+)-20$

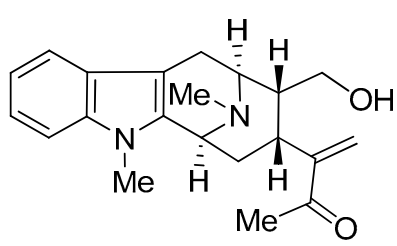

$(+)-19$

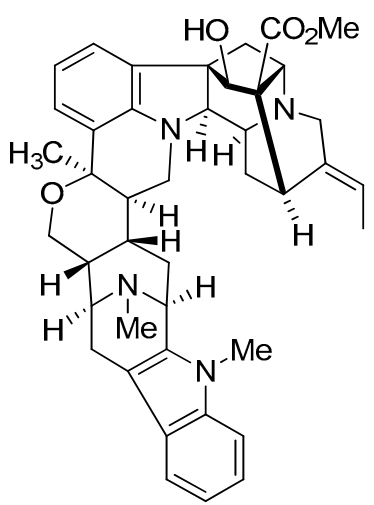

13 (-)-alstonisidine

Figure 6. Structures of (+)-quebachidine (20), (+)-macroline (19), and (-)-alstonisidine (13).

This biomimetic synthesis of (-)-alstonisidine 13 employed the biogenetic precursors (+)-macroline 19 and (+)-quebrachidine 20. Although macroline has never been isolated as a natural product, it is widely agreed to be a biogenetic precursor for (-)-alstonerine [77], (-)-alstophylline [78], and (+)-alstonisine [72] and may be present in very small steady-state concentrations in plants. Furthermore, the isolation of traces of $(+)$-quebrachidine from A. muelleriana further strengthened this proposed biogenetic route. (+)-Quebrachidine 20 has been isolated from Vinca libanotica [79], Ochrosia acuminate [80], Alstonia muelleriana [77], and the leaves of Aspidosperma quebracho blanco Schletch [81] and its structure was proposed to be 20 based on the studies by NMR and mass spectroscopy [82]. Four aromatic proton multiplets ( $\delta=6.6$ to 7.2) indicated it contained an unsubstituted aromatic ring, accompanied by an ethylidene group. Examination of the Infrared spectrum indicated the presence of $N-\mathrm{H}\left(3590 \mathrm{~cm}^{-1}\right), \mathrm{O}-\mathrm{H}\left(3370 \mathrm{~cm}^{-1}\right)$ and a carbomethoxyl (1722, $1235 \mathrm{~cm}^{-1}$ and ${ }^{1} \mathrm{H}$ singlet at $\left.\delta=3.6\right)$ group. Upon acetylation, the compound gave a diacetate. Analysis of the NMR, IR and UV spectra of the diacetate indicated the presence of a secondary alcohol and a dihydroindole nitrogen atom. Analysis of the mass spectrum further strengthened the proposed structure of (+)-quebrachidine to be 20 [82]. 
In the biomimetic partial synthesis of (-)-alstonisidine 13 [83], (+)-macroline 19 was prepared by degradation of villamine (not shown) by the method of Schmid et al. [84]. (+)-Macroline 19 reacted with naturally occurring (+)-quebrachidine 20 under mildly acidic conditions at $20{ }^{\circ} \mathrm{C}$ (Scheme 2 ). Initially macroline underwent a Michael reaction with the indoline nitrogen atom of quebrachidine and subsequently underwent intramolecular cyclization to form the amino hemiketal 42. This hemiketal species was found to be highly labile to acid since it reversed to the starting materials 19 and 20 upon warming, as well as under stronger acidic conditions and during chromatography. Fortunately, no other compounds were observed except the starting materials 19 and 20. The new indole 42 had a molecular weight of 690 and examination of the IR spectrum indicated the presence of only one carbonyl peak $\left(1735 \mathrm{~cm}^{-1}\right)$ which indicated that after the initial 1,4-conjugate addition had occured, the so formed ketone on the macroline unit reacted intramolecularly with the $-\mathrm{CH}_{2} \mathrm{OH}$ group to form the corresponding hemi-ketal present in $\mathbf{4 2}$. When hemiketal 42 was treated with boron trifluoride at $0{ }^{\circ} \mathrm{C}$ for $6 \mathrm{~h}$, the electrophilic aromatic substitution took place, ortho to the amino group of quebrachidine to form the tetrahydropyran which was indistinguishable from the naturally occurring alstonisidine 13 (Scheme 2) from A. muelleriana [77,83].

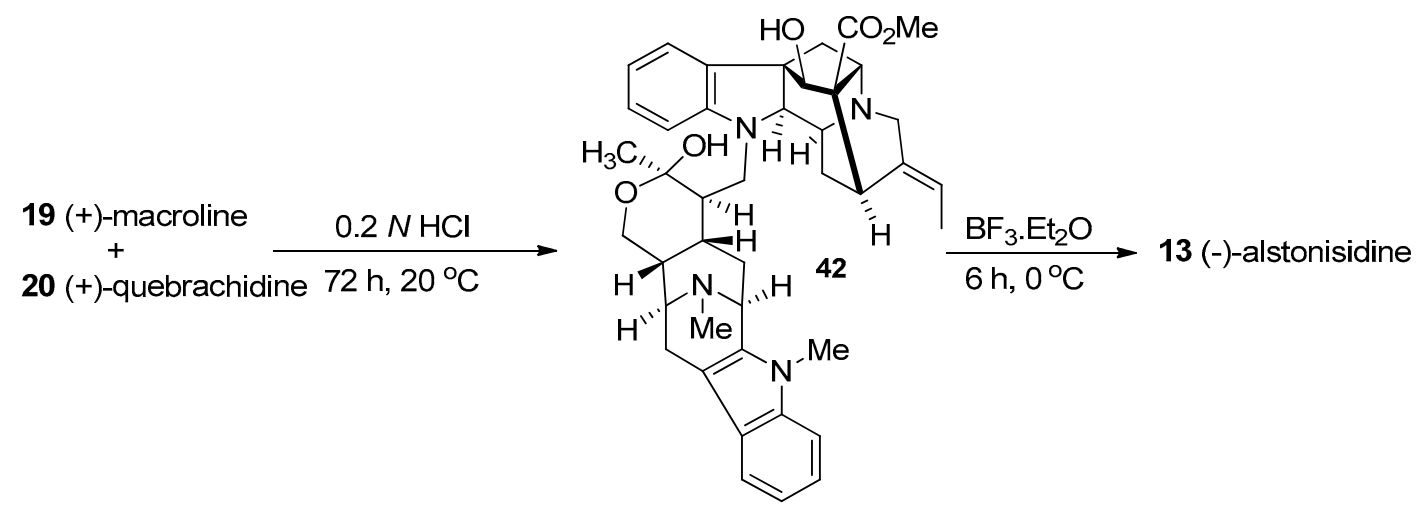

Scheme 2. Biomimetic partial synthesis of (-)-13 by LeQuesne et al. [75].

The total synthesis of (-)-alstonisidine has not been reported yet. Extensive work has been done toward its monomeric constituents 19 and 20. To date, The Milwaukee group has achieved the total synthesis of (+)-macroline 19 [85-88] and the enantiomer of macroline as well [89]. Besides an advanced intermediate for $\mathbf{2 0}$, the synthesis of quebrachidine diol (not shown) has been reported as well [90]. The partial synthesis of (-)-alstonisidine has been completed, to date, from synthetic (+)-macroline 19 and natural (+)-quebrachidine 20. The total synthesis of bisindole $\mathbf{1 3}$ awaits the total synthesis of 20 .

The earliest synthesis of (+)-macroline 19, a biomimetic synthesis, was done by LeQuesne et al. in 1980 [57] and the absolute configuration had been confirmed by X-ray crystallography by Hesse in 1981 [91]. In this synthesis, LeQuesne et al. converted (-)-perivine 43 to (+)-normacusine 44, according to the reported procedure by Gorman et al. (Scheme 3) [92]. The protection of the hydroxyl group (in 44) as the tert-butyldimethylsilyl ether, was followed by $N_{\mathrm{a}}$-methylation to furnish the sarpagine system 45 . Osmylation of olefin 45 with $\mathrm{OsO}_{4}$ and pyridine in THF gave an inseparable mixture which contained the diol 46, along with a related spirooxindole byproduct. The bulky TBDMS function rendered the osmylation sequence stereoselective, although marred by the formation of the spirooxindole side-product. This mixture was treated with $\mathrm{TsCl}$ and $\mathrm{Py}$, followed by $\mathrm{NaH}$ in $\mathrm{THF}$ to give the epoxide 47 that could be purified by crystallization. The epoxide underwent rearrangement on treatment with freshly prepared $\mathrm{MgBr}_{2}$ to furnish the ketone 48. The methylation of the $\mathrm{N}_{\mathrm{b}}$ function was performed with dimethyl sulfate and potassium carbonate, in refluxing benzene. This was followed by the retro-Michael reaction in base followed by desilylation with TBAF to provide (+)-macroline 19 [57]. 


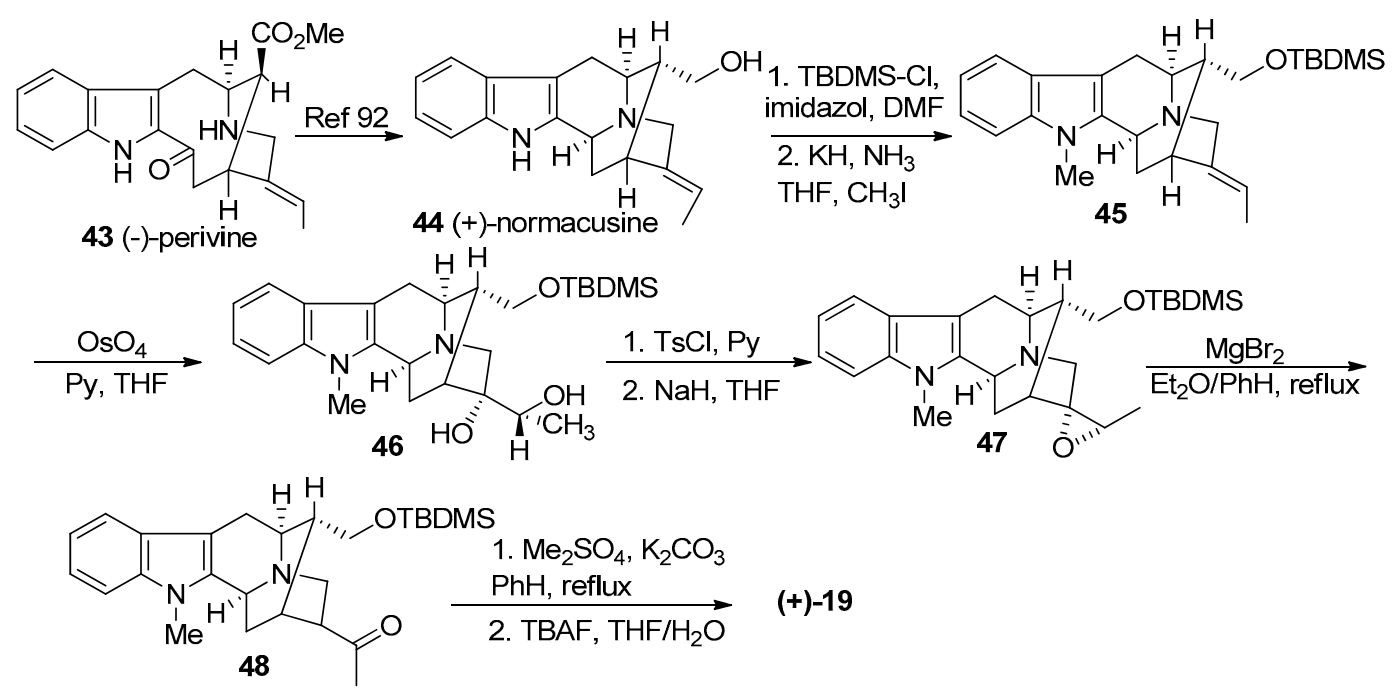

Scheme 3. Biomimetic partial synthesis of (+)-19 by LeQuesne et al. [57].

In an enantiospecific synthetic approach to (+)-macroline $[85,86]$, the readily available $N_{\mathrm{b}}$-benzyl tetracyclic ketone [93-95] intermediate 41, available on 300 gram scale, was converted into the corresponding $N_{\mathrm{b}}$-methyl indole compound 49 by methylation with methyl triflate followed by catalytic debenzylation to form the $N_{\mathrm{b}}$-methyl system in $84 \%$ yield (Scheme 4 ). The ketone 49 was reacted with the anion of chloromethyl phenyl sulfoxide (LDA, THF, $-78{ }^{\circ} \mathrm{C}$ ) to generate the corresponding chlorohydrin. This chlorohydrin, upon stirring in a heterogeneous solution of $10 \mathrm{~N} \mathrm{KOH}$ in THF at $25^{\circ} \mathrm{C}$ for $24 \mathrm{~h}$ produced the corresponding spirooxirane and this was followed by treatment with $\mathrm{LiClO}_{4}$ and $\mathrm{PO}(n-\mathrm{Bu})_{3}$ in refluxing toluene to produce the $\alpha, \beta$-unsaturated aldehyde 50 [96]. Chemo-selective reduction of the aldehyde with lithium aluminum hydride in ether at $-20{ }^{\circ} \mathrm{C}$ gave the allylic alcohol 51. Michael addition of the alcohol to 3-butyn-2-one 52 provided the desired enone ether 53 in $92 \%$ yield. The Claisen rearrangement of the enone ether produced the $\beta$-dicarbonyl compound 54, which was subsequently reduced with sodium borohydride to give the corresponding diol 55. The 1,3-diol functionality was protected as an acetonide $\mathbf{5 6}$ using acetone dimethyl acetal in the presence of $p$-toluenesulfonic acid. The hydroboration of the olefin in $\mathbf{5 6}$ with 9-BBN occurred in a stereospecific fashion and this was followed by oxidation with a basic solution of hydrogen peroxide, under classical conditions, to furnish the C-17 primary alcohol 57. The hydroxyl group of monol 57 was protected as the $t$-butyldimethylsilyl ether, and subsequent selective removal of the acetonide was done using $p$-toluenesulfonic acid in dry methanol to provide diol 58. To access the $\alpha, \beta$-unsaturated carbonyl system in macroline, it was planned to use the tosylate of the C-18 hydroxyl group as the leaving group. But the tosylation with tosyl chloride and pyridine in DCM was not successful, and mesylation took place with very poor regioselectivity. Based upon a precedent by Helquist et al. [97], acetylation with acetic anhydride worked both as a protecting group and leaving group. The so formed monoacetate was subjected to PDC oxidation. The acetate group underwent elimination spontaneously upon oxidation to provide the stable TBDMS protected macroline equivalent 59a, which could be stored in a vial. The silyl ether was deprotected with tetrabutylammonium fluoride in THF to provide (+)-macroline 19 identical to the natural material obtained from villamine by Schmid et al. [84]. 

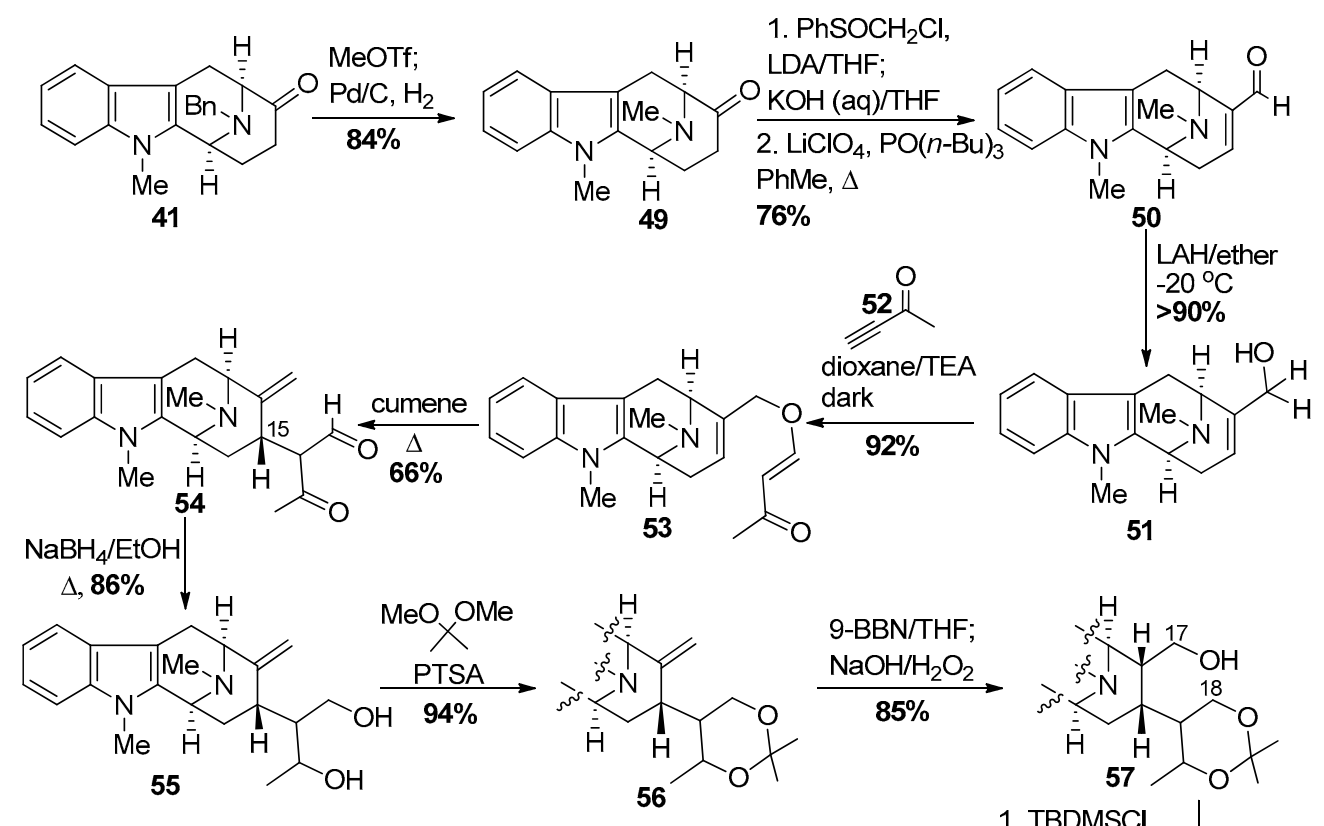

51

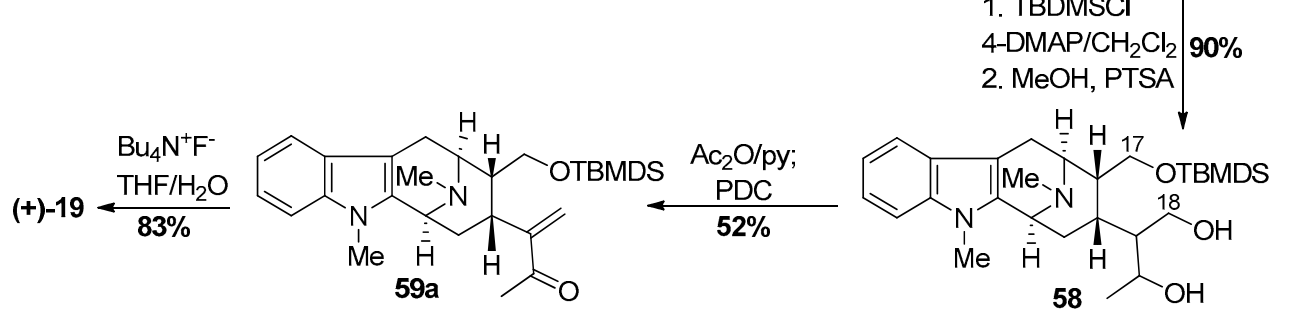

Scheme 4. Enantiospecific total synthesis of (+)-19 by Bi et al. [85].

In another more recent and improved approach (Scheme 5) $[87,88], N_{\mathrm{b}}$-alkylation via $\mathrm{S}_{\mathrm{N}} 2$ substitution on (Z)-1-bromo-2-iodo-2-butene $\mathbf{6 1}$ in the presence of $\mathrm{K}_{2} \mathrm{CO}_{3}$ in refluxing THF gave the vinyl iodide 62. The palladium catalyzed intramolecular cyclization of the enolate anion with the vinyl iodide took place in a stereospecific manner to yield the pentacyclic ketone 63 . A one-carbon homologation via Wittig olefination with methoxymethyl triphenylphosphonium chloride with potassium tert-butoxide in benzene, followed by hydrolysis of the so formed enol ether 64 in aqueous $\mathrm{HCl} / \mathrm{THF}$ furnished the $\alpha$-aldehyde $65\left((+)-N_{\mathrm{a}}\right.$-methylvellosimine; an alkaloid isolated from Alstonia nitida [98]). The aldehyde was reduced with sodium borohydride to provide (+)-affinisine 66, another alkaloid obtained from A. macrophylla [99]. The protection of the primary alcohol as the TIPS ether with triisopropylsilyl triflate and 2,6-lutidine gave indole 67 . The hydroboration-oxidation of the olefin in 67 went smoothly to provide the secondary alcohol 68 in very good yield, accompanied by a small amount of the corresponding tertiary alcohol. An equivalent of $\mathrm{BH}_{3}$ is known to complex with the $N_{b}$-nitrogen function which alters the electronic character in the vicinity of the olefin, which presumably resulted in the formation of the small amount of tertiary alcohol. The Dess-Martin periodinane-mediated oxidation of the alcohol 68 to the ketone 69 took place in high yield. The quaternization of the $N_{\mathrm{b}}$-nitrogen with methyl iodide in THF at $0{ }^{\circ} \mathrm{C}$, was followed by treatment of the so formed $N_{\mathrm{b}}$-methiodide salt with potassium tert-butoxide in ethanol under modified conditions to provide the stable macroline equivalent $59 \mathrm{~b}$. Again, this intermediate can be easily stored. The de-silylation with tetrabutylammonium fluoride resulted in the synthesis of (+)-macroline 19 identical to that obtained above in much higher overall yield and fewer steps. These reactions could be scaled up with ease as well. 

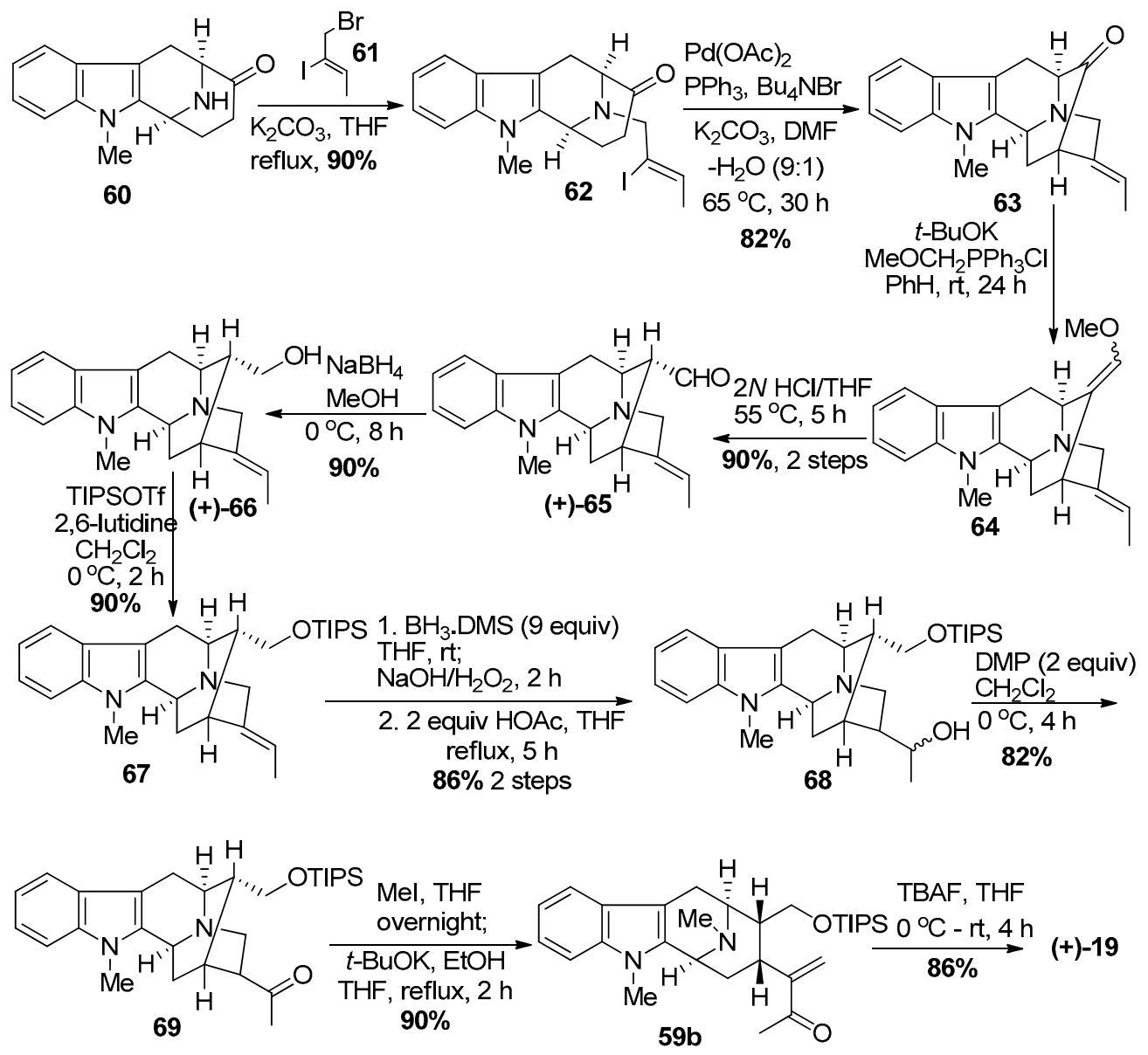

Scheme 5. Improved total synthesis of (+)-macroline (19) by Liao et al. [87].

Kwon recently reported a formal synthesis of (+)-macroline 19 as well, which employed a phosphine-catalyzed [4 +2] annulation process (Scheme 6) [100]. This route began from commercially available phosphorene $\mathbf{7 0}$ or $\mathbf{7 1}$; the first step of which was to generate the phosphonium salt $\mathbf{7 2}$ by reaction with the bromoacetate. Treatment of $\mathbf{7 2}$ with acetyl chloride in the presence of trimethylamine furnished the allene $\mathbf{7 3}$ or $\mathbf{7 4}$, individually. The condensation of $o$-nitrobenzenesulfonamide with either of the indole-2-carboxaldehydes 75 or $\mathbf{7 6}$ in the presence of $\mathrm{TiCl}_{4}$ and $\mathrm{Et}_{3} \mathrm{~N}$ gave the imines 77 in very good yield, respectively. The allene (73 or 74 ) was then reacted with the imine 77 in the presence of tributylphosphine in methylene chloride to yield the [4+2] annulation products as inseparable mixtures with moderate diastereoselctivity ( $\mathrm{dr} 3: 1$ when $\mathrm{R}_{1}=\mathrm{Et}, \mathrm{R}_{2}=\mathrm{Me}$ and $\mathrm{dr}$ 1.1:1 when $\mathrm{R}_{1}=\mathrm{Bn}$, $\mathrm{R}_{2}=\mathrm{Boc}$ ). The $\mathrm{C}-5$ carboxylic acid ester was epimerized under acidic conditions to facilitate the intramolecular Friedel-Crafts acylation to provide the bridged bicyclic compounds $\mathbf{8 0}$ or $\mathbf{8 1}$.

The nosyl group on the $N_{b}$-nitrogen atom in $\mathbf{8 0}$ was removed by the method of Fukuyama [101] and proceeded smoothly to provide the $N_{\mathrm{b}}-\mathrm{H}$ free base 82 in excellent yield (Scheme 6). An Eschweiler-Clarke reaction [102,103] gave the otherwise troublesome $N_{b}$-methylated product 83 in quantitative yield. The deoxygenation at C-6 under standard reductive conditions either did not react or gave the C- 6 alcohol. However, the use of $\mathrm{ZnI}_{2}-\mathrm{NaCNBH}_{3}$, gave the desired aryl alkane as an $N_{\mathrm{b}}$-complex 84 with cyanoborane, which upon heating in refluxing ethanol gave the free amine 85. Reduction of 85 with DIBAL in toluene gave the allylic alcohol 51, a known intermediate toward (+)-macroline 19 and (-)-alstonerine 15 previously reported [86] by The Milwaukee group and hence this completed a formal synthesis of (+)-macroline 19. 

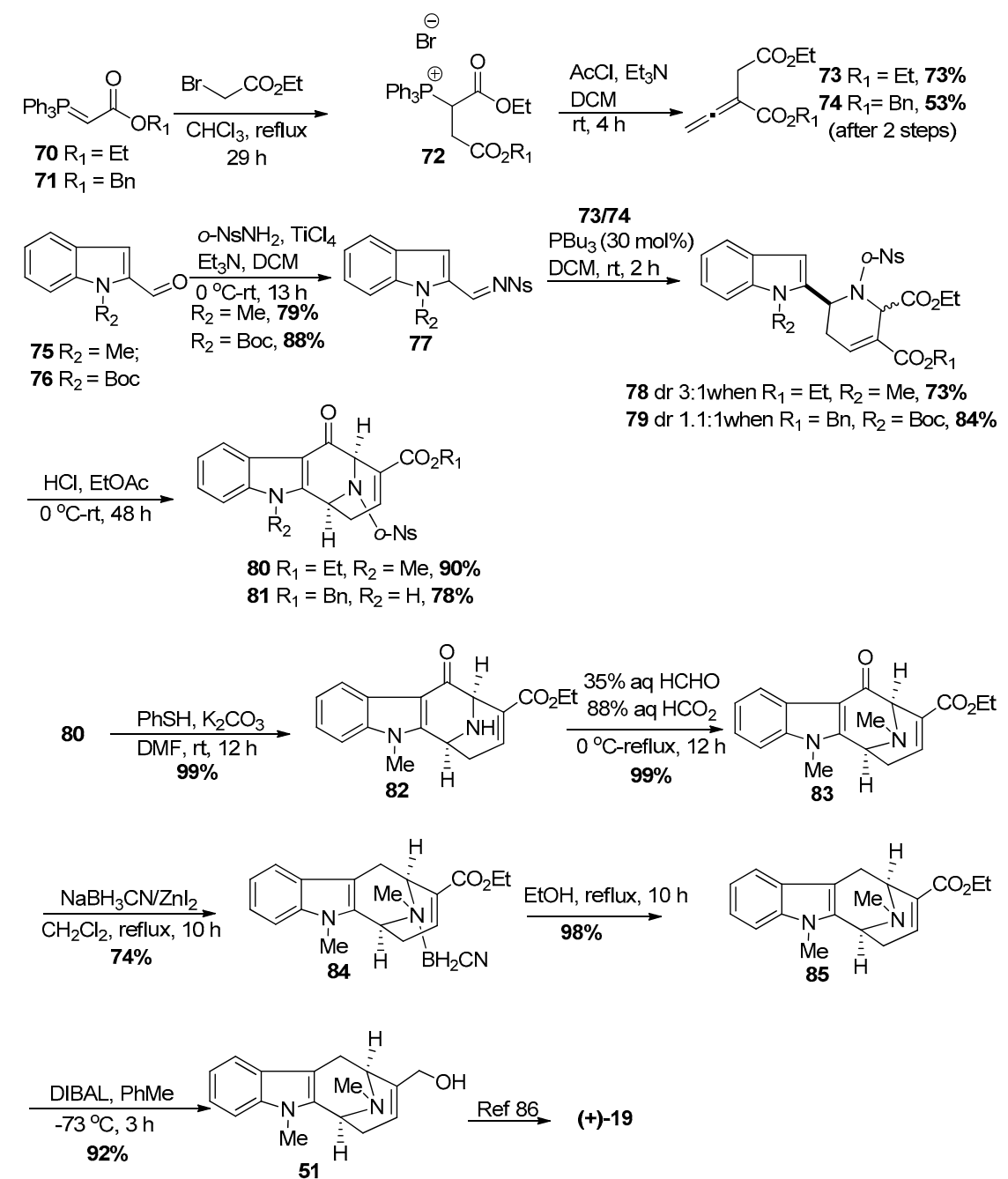

Scheme 6. Formal synthesis of (+)-macroline (19) by Kwon et al. [100].

\section{2. (-)-Accedinisine and (-)- $N^{\prime}$-demethylaccedinisine}

(-)-Accedinisine 1 was isolated along with several other bisindole alkaloids from Tabernaemontana accedens Muell. Arg. (Apocynaceae) and Peschiera van heurkii [38,104]. This dimeric indole alkaloid contained both a vobasine and a sarpagine unit. Upon treatment with hydrochloric acid, natural accedinisine $\mathbf{1}$ yielded cycloaffinisine $\mathbf{8 6}$ which could also be prepared from affinisine 21 under the same conditions. This clearly indicated the presence of an affinisine $\mathbf{2 1}$ unit in this dimeric alkaloid. Extensive studies of $\mathbf{1}$ by NMR and mass spectroscopy of the bisindole suggested the presence of a vobasinol unit as the remaining part of the molecule which was confirmed by the condensation of (+)-vobasinol 17 with (+)-affinisine 21 in aqueous $\mathrm{HCl}$ to yield a compound identical to natural (-)-accedinisine 1 (Scheme 7) [104]. Another vobasine-sarpagine (perivinol $18+$ affinisine 21) bisindole alkaloid (-)- $N^{\prime}$-demethylaccedinisine 2 (demethylaccedinisine) was isolated from Peschiera buchtieni [105] and Peschiera van heurkii [38]. The structure was confirmed by methylation of (-)-2 to yield the identical compound to the authentic sample of (-)-accedinisine $\mathbf{1}$ [105]. Both of this dimeric indole alkaloids have the constituent monomeric alkaloids linked from the C-3 position of the vobasine unit (vobasinol 17 or perivinol 18) to the C-10' of the sarpagine unit (affinisine 21), as indicated by NMR spectroscopy and partial synthesis $[104,105]$. Both of these bisindoles are active against leishmaniasis. It is of interest that these alkaloids are purportedly active against only one of the strains of leishmaniasis that were studied indicating selectivity. 


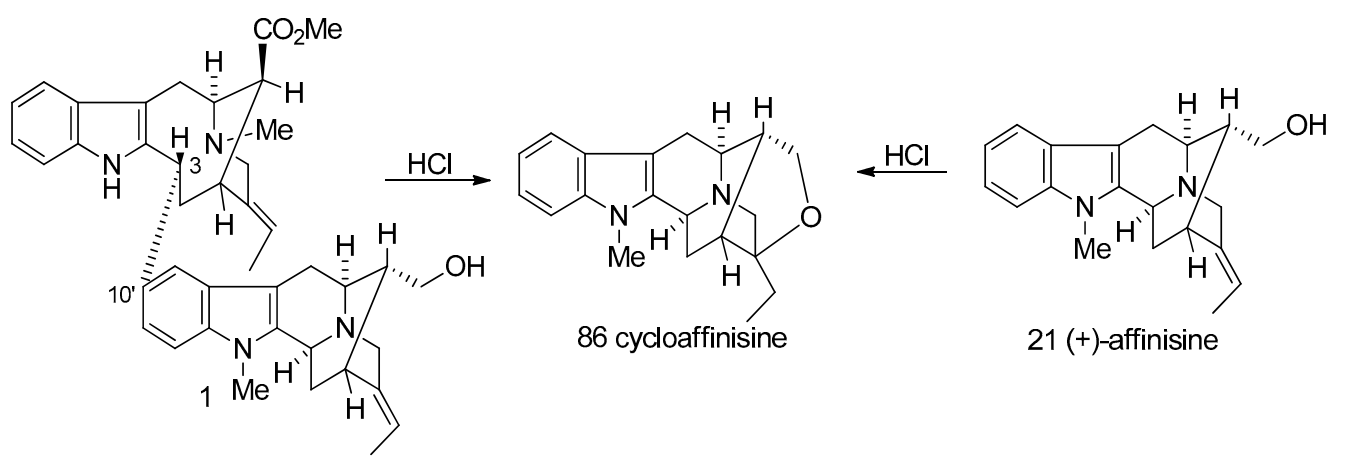

Scheme 7. Formation of cycloaffinisine from (-)-accedinisine (1) and (+)-affinisine (21) under acidic conditions.

The vobasine portion of these alkaloids originated from $\mathrm{C}(3)-N_{\mathrm{b}}$ disconnection of the sarpagine skeleton of (+)-peicyclivine (see later) and similar to the other unit, (+)-affinisine 21, could be accessed by a general and efficient approach from commercially available D-(+)-tryptophan methyl ester 37 (Scheme 8). Yang et al. achieved a total synthesis of (-)-accedinisine $\mathbf{1}$ and (-)-N'-demethylaccedinisine 2 [106-109].

The synthesis of the northern vobasine fragment was accomplished from the previously synthesized (+)-16-epi-vellosimine (from D-(+)-tryptophan [110]). The E-ethylidene ketone 87 was available in an enantiospecific manner in five steps starting from commercially available D-(+)-tryptophan (Scheme 8) [111]. The Wittig olefination with methyltriphenylphosphonium bromide in the presence of potassium tert-butoxide in benzene provided the olefin 88 in excellent yield. Improved access to the aldehyde from the olefin via hydroboration with 9-BBN was followed by Kabalka oxidation with $\mathrm{NaBO}_{3} \cdot 4 \mathrm{H}_{2} \mathrm{O}$ to furnish (+)-16-epi-normacusine 90 in excellent yield. This was followed by Dess-Martin oxidation to yield the $\beta$-aldehyde, in (+)-16-epi-vellosimine 33 in $>95 \%$ yield in the absence of any epimerization. The aldehyde was treated with hydroxylamine hydrochloride and subsequesnt dehydration of the so formed oxime which resulted in the corresponding cyano-compound 91 in $90 \%$ yield. The cyano function was converted into the corresponding methyl ester, (+)-pericyclivine 92, under the conditions $\left(\mathrm{HCl}(\mathrm{g}), \mathrm{CH}_{2} \mathrm{Cl}_{2}, \mathrm{CH}_{3} \mathrm{OH}\right)$ reported by Warmuth et al. [112]. In an alternative approach, (+)-16-epi-vellosimine 33 was converted into (+)-pericyclivine via a cyanohydrin that resulted from nucleophilic attack of the cyano group onto the bisulfite adduct of 16-epi-vellosimine analogous to a previous report by Wender et al. [113]. The cyanohydrin 93 was oxidized to the ketone at low temperature under Corey-Kim oxidation conditions, which yielded the ester (+)-pericyclivine 92 in $80 \%$ yield, on treatment with methanol. This constituted the first enantiospecific total synthesis of the indole alkaloid (+)-pericylivine.

The $\mathrm{C}(3)-N_{\mathrm{b}}$ bond cleavage [114-121] was carried out analogous to the procedure reported by Bonjoch et al. [114]. Pericyclivine 92 when heated to reflux in methanol, and reacted with benzyl chloroformate, to furnish the carbamate $\mathbf{9 4}$ in 75\% yield (Scheme 9). The Cbz-group was removed by standard hydrogenolysis with hydrogen and palladium on carbon in methanol. This was followed by methylation of the $N_{\mathrm{b}}$-group to provide the vobasine unit 96 required for (-)-accedinisine. The key to this synthesis was the formation of the 9-membered ring in $\mathbf{9 4}$ for the pseudo-axial ester and the pseudo-equatorial ester are similar in energy so there is no driving force for epimerization. This was in contrast to the $\beta$-ester function in 92, which can undergo epimerization to the $\alpha$-configuration upon chromatography on silica gel.

(+)-Affinisine $\mathbf{2 1}$ is a sarpagine-type indole alkaloid isolated from Alstonia macrophylla [99] Wall, Peschiera affinis [122], and Ervatamia hirta [123]. In 2000, Liu et al. reported an enatiospecific total synthesis of the enatiomer of affnisine from L-(-)-tryptophan [124]. In 2006, Liao et al. completed the total synthesis of (+)-affinisine as an intermediate in the total synthesis of $(+)$-macroline and $(-)$-alstonerine [87]. 


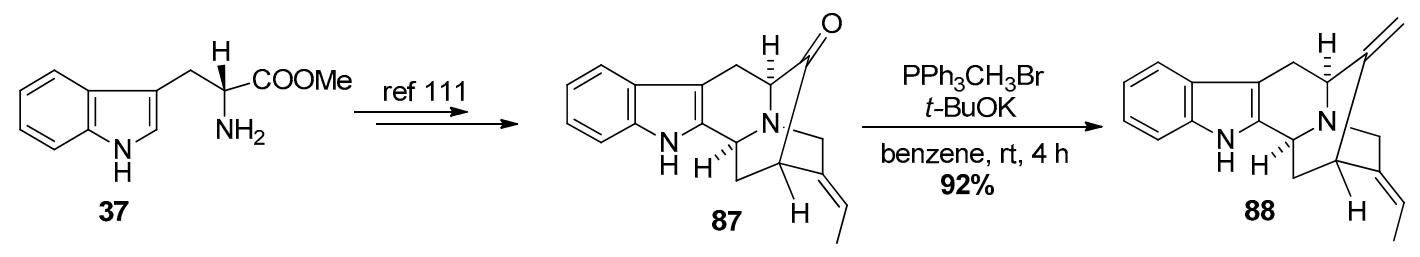

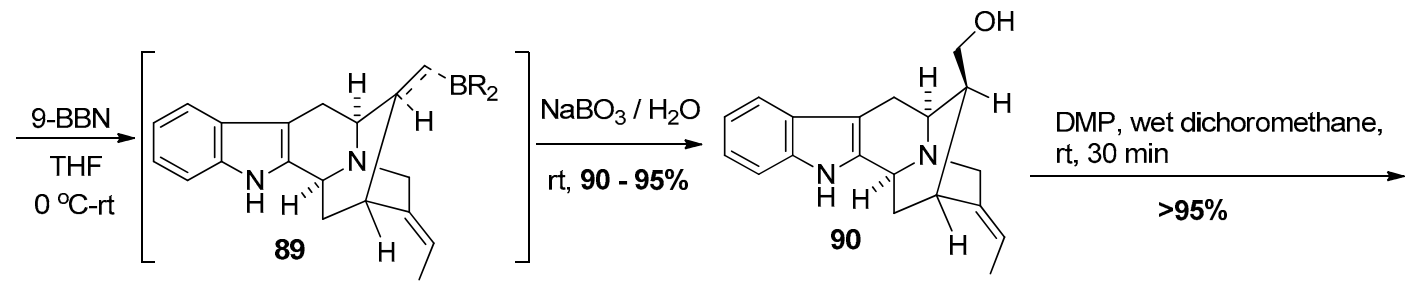

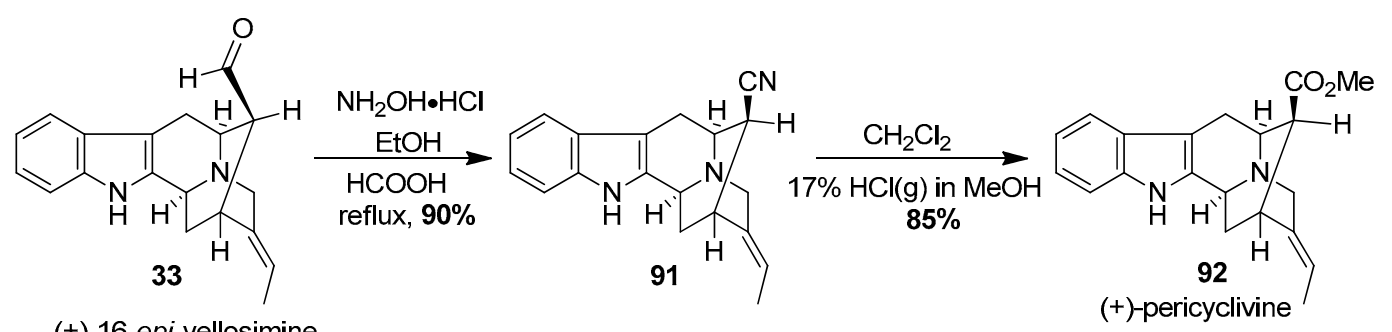

(+)-16-epi-vellosimine

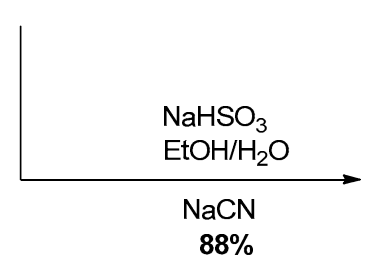

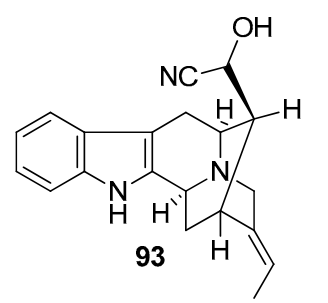

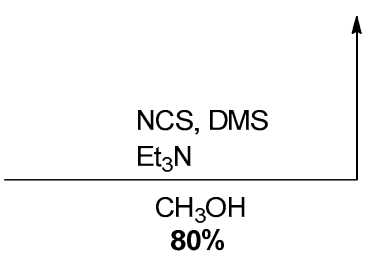

Scheme 8. Enantiospecific total synthesis of (+)-16-epi-vellosimine (33) and (+)-pericyclivine (92) by Yang et al. [106,107].

The $N_{\mathrm{b}}-\mathrm{Cbz}$ derivative 94 and $N_{\mathrm{b}}$-methyl derivative 96 provided the northern hemispheres of $(-)-N^{\prime}$-demethyl accedinisine 2 and (-)-accedinisine 1, respectively. The coupling of (+)-affininsine 21 with $N_{\mathrm{b}}$-methyl intermediate 96 in $6 \%-7 \%$ methanolic $\mathrm{HCl}$ or with $N_{\mathrm{b}}-\mathrm{Cbz}$ intermediate 94 in $6 \%-7 \%$ methanolic methanesulfonic acid or $\mathrm{HCl}(\mathrm{g})[125,126]$ provided the corresponding bisindoles in stereospecific fashion with an un-optimized yield of $>35 \%$ (Scheme 9 ). There was one major component on TLC (silica gel) with a trace of a material too little to isolate with no starting materials left and no baseline material. Both of these dimers were run on milligram scale and were purified by preparative TLC on an actual thin layer plastic backed plate. The recovery was very poor. It is clear only one diastereomer was formed and from TLC the yield of the bisindoles appeared to be greater than $70 \%$. 

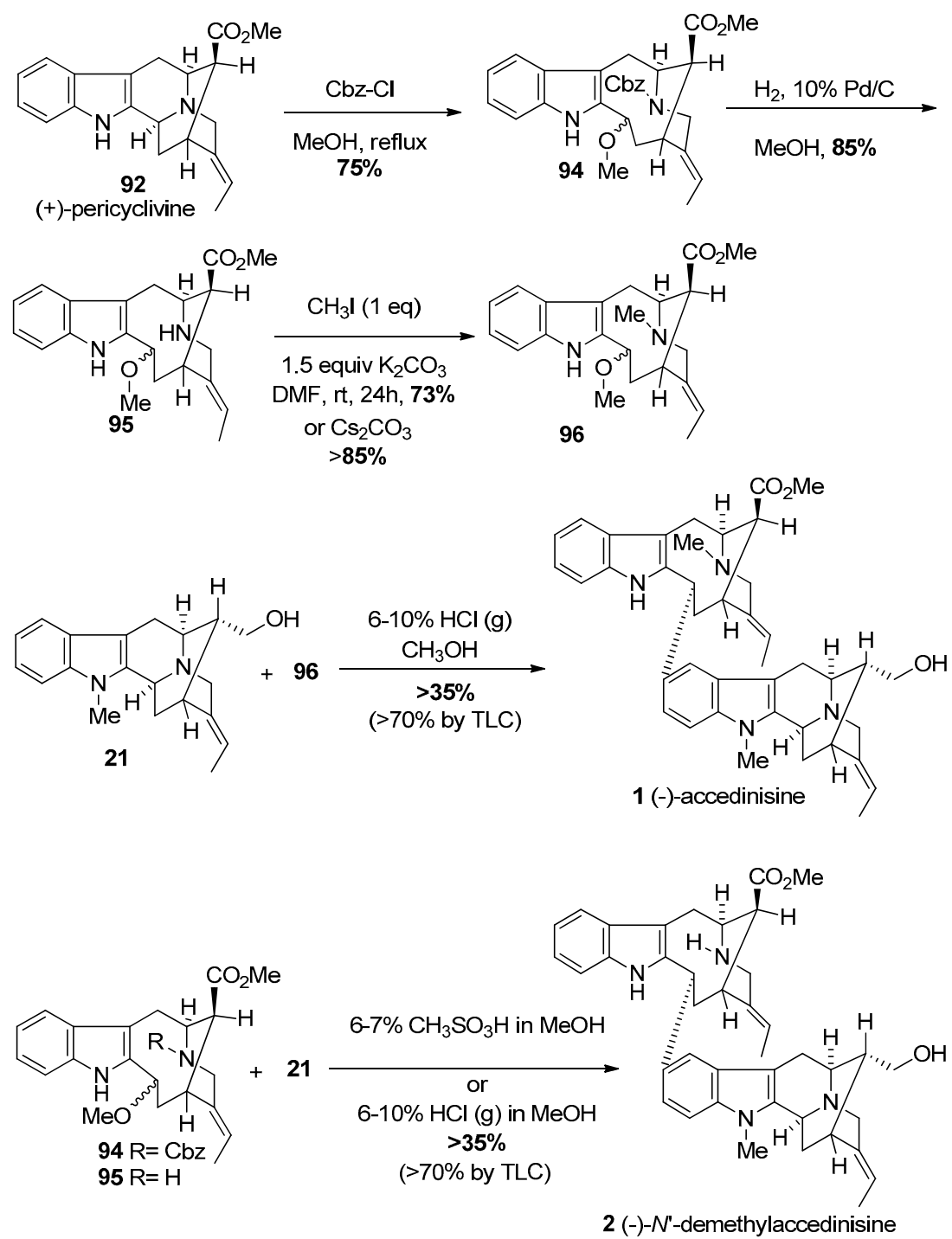

Scheme 9. Completion of the total synthesis of bisindole alkaloids (-)-1 and (-)-2.

\section{3. (+)-Macralstonine}

(+)-Macralstonine 9 is a dimeric alkaloid which consists of two macroline cores which belong to the Alstonia alkaloids (-)-alstophylline 22 and (+)-macroline 19. This bisindole was isolated from Alstonia macrophylla [22,127-130], Alstonia angustifolia [131], Alstonia muelleriana [132], and Alstonia glabriflora Mgf. [133]. Several related bisindoles (natural or semi-synthetic) with potent antimalarial activity, (+)-O-methylmacralstonine [22], (+)-O-acetylmacralstonine [40], and (+)-des- $N^{\prime}{ }_{\mathrm{a}}$-methylanhydromacralstonine 97 [73] were also known. In their studies, Schmid et al. [128] reported that (+)-macralstonine underwent ring opening and existed in an equilibrium mixture of the acyclic ketone 9a (Figure 7) and the cyclic hemiketal 9 in chloroform solution. This has been confirmed recently by Kam et al. by the analysis of high field NMR $(600 \mathrm{MHz})$ spectroscopy that the ratio of acyclic to cyclic macralstonine was 2.32:1, 1.14:1, and 0:1 in $\mathrm{CDCl}_{3}, \mathrm{CD}_{2} \mathrm{Cl}_{2}$, and THF- $d_{8}$ respectively. In their NMR (NOESY) spectroscopic studies of the O-methyl congener 11 during its isolation from A. macrophylla $[22,130]$, Keawpradub et al. and Changwichit et al. concluded the stereochemistry at $\mathrm{C}-20$ to be $R(\beta-\mathrm{H})$. In the case of macralstonine [129], NOESY was not feasible. Fortunately, it was possible to trap the acyclic form as the $O$-acetyl derivative $\mathbf{9 b}$ (Figure 7 ) which clearly indicated the $\mathrm{C}-20$ to be in $R(\beta-\mathrm{H})$ configuration after spectroscopic analysis. This was further confirmed by $\mathrm{X}$-ray analysis of (+)-macralstonine which was crystallized as the hemiketal 9 [129]. 


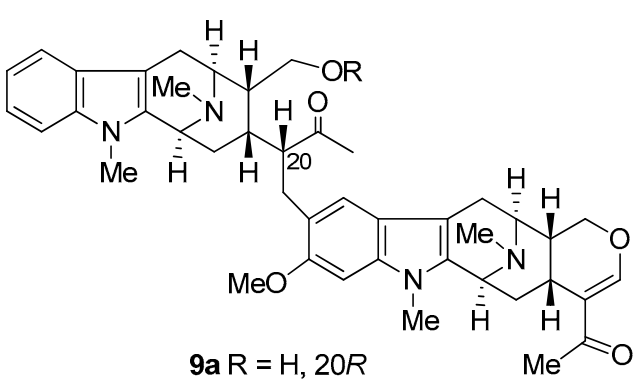

$9 \mathrm{~b} R=\mathrm{Ac}, 20 R$

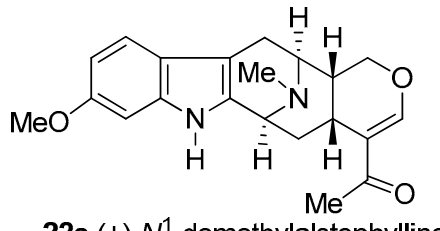

22a (+)-N $N^{1}$-demethylalstophylline

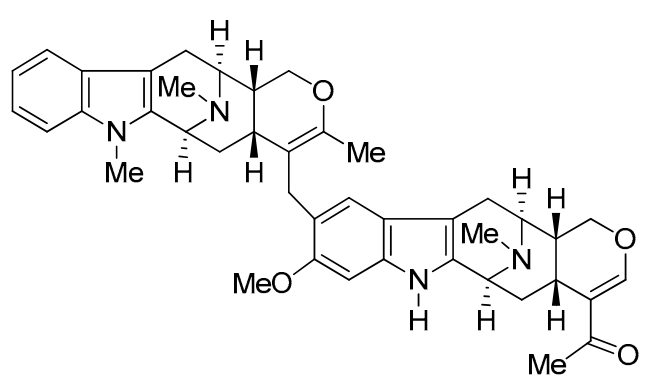

97 des- $N N_{\mathrm{a}}^{\prime}$-methylanhydromacralstonine

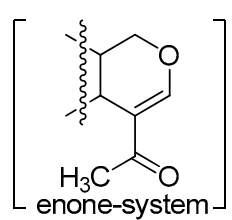

22b

Figure 7. Structures of the cyclic ketone form (9a) of (+)-macralstonine and its $O$-acetyl derivative (9b); des- $N^{\prime}{ }_{\text {a }}$-methylanhydromacralstonine (97) as well $N^{1}$-demethylalstophylline (22a), and the enone system (22b).

One possible biosynthetic route to (+)-macralstonine 9 was proposed by Schmid [134], which was confirmed in a biomimetic partial synthesis by LeQuesne et al. [135] by coupling (+)-macroline 19 with (-)-alstophylline 22 in dilute $0.2 \mathrm{~N}$ aqueous $\mathrm{HCl}$ solution (Scheme 10).

This $0.2 \mathrm{~N}$ aqueous hydrochloric acid solution which contained alstophylline and excess (+)-macroline was stirred at $20{ }^{\circ} \mathrm{C}$ for 5 days. (+)-Macralstonine 9 was isolated in $40 \%$ yield after chromatographic separation. Examination of the product by thin layer chromatography and infrared spectroscopy indicated this material was identical to the natural (+)-macralstonine and the analysis of the ${ }^{1} \mathrm{H}$ NMR spectrum indicated the alkaloid was a mixture of C-20 epimers. Upon acetylation with actetic anhydride in pyridine, the C-20 epimer of macralstonine underwent epimerization to provide only $(+)-O$-acetylmacralstonine $\mathbf{1 0}$ indistinguishable from the acetyl derivative of natural (+)-macralstonine (Scheme 10) [40].

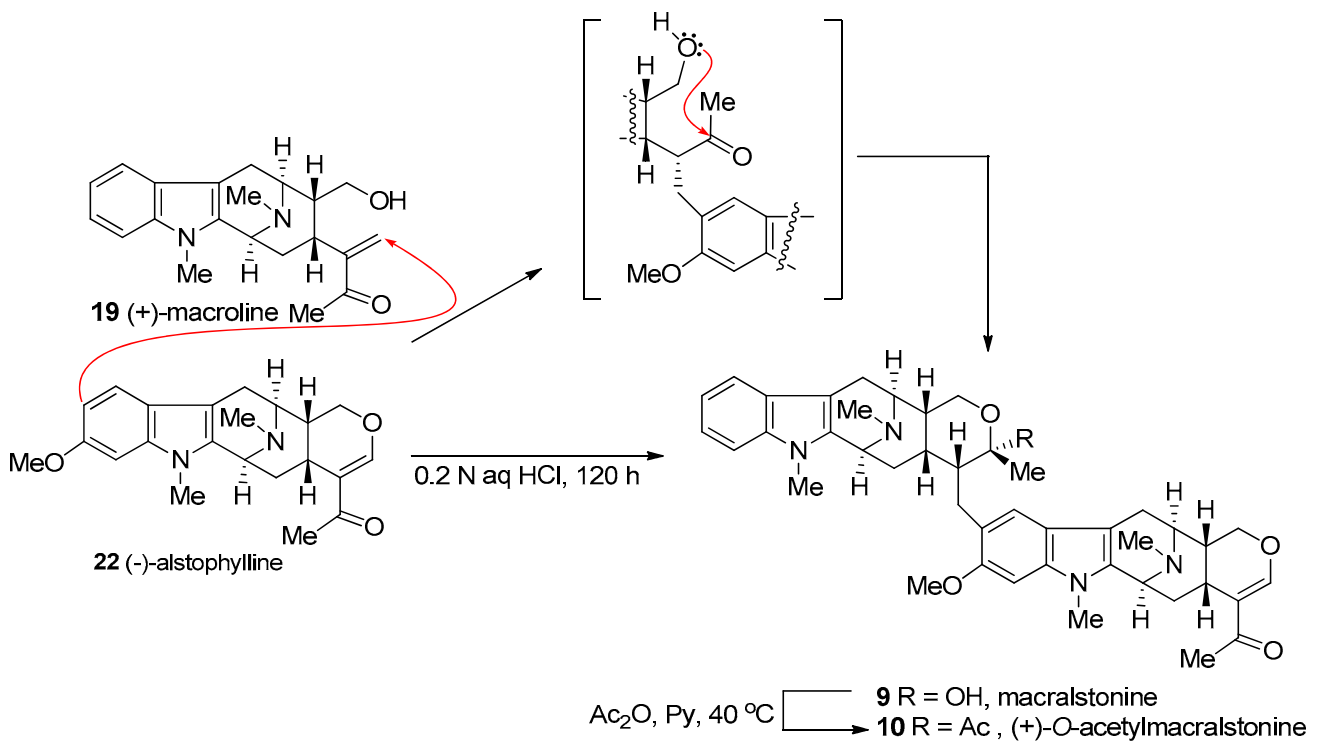

Scheme 10. The biomimetic partial synthesis of macralstonine (9) and its $O$-acetyl derivative (10) by LeQuesne et al. [135]. 
At least two mechanisms are possible for the formation of macralstonine 9 by the acid catalyzed coupling of macroline and the ring-A oxygenated macroline-type indole base (-)-alstophylline 22. One possible mechanism was the earlier described Michael process [135]; however another potential mechanism is a Friedel-Crafts alkylation process stabilized by the oxonium ion [136]. The Michael addition followed by cyclization is straight-forward, as shown in Scheme 10. The electron-rich aromatic ring adds nucleophiliclly in a 1,4-fashion to form the alkylated product ortho to the methoxy group, followed by nucleophilic addition of the C-17 hydroxy group to the carbonyl carbon atom to form the cyclic hemiketal present in macralstonine 9. On the other hand, alternatively, acid catalyzed intra-molecular cyclization of (+)-macroline, which involves the nucleophilic attack of the C-17 hydroxyl group on to the carbonyl carbon atom (1,2-fashion) would provide the cyclic hemiketal 98. This intermediate can then lose a molecule of water to form the oxonium ion species 99 (Figure 8). Electrophilic attack of the electron rich aromatic ring onto the oxonium ion electrophile would furnish the cyclic enol-ether 100, as suggested by Fukuyama. The cyclic enol-ether would then isomerize to an oxonium ion, only to be attacked by water to provide the cyclic hemiketal present in macralstonine 9.
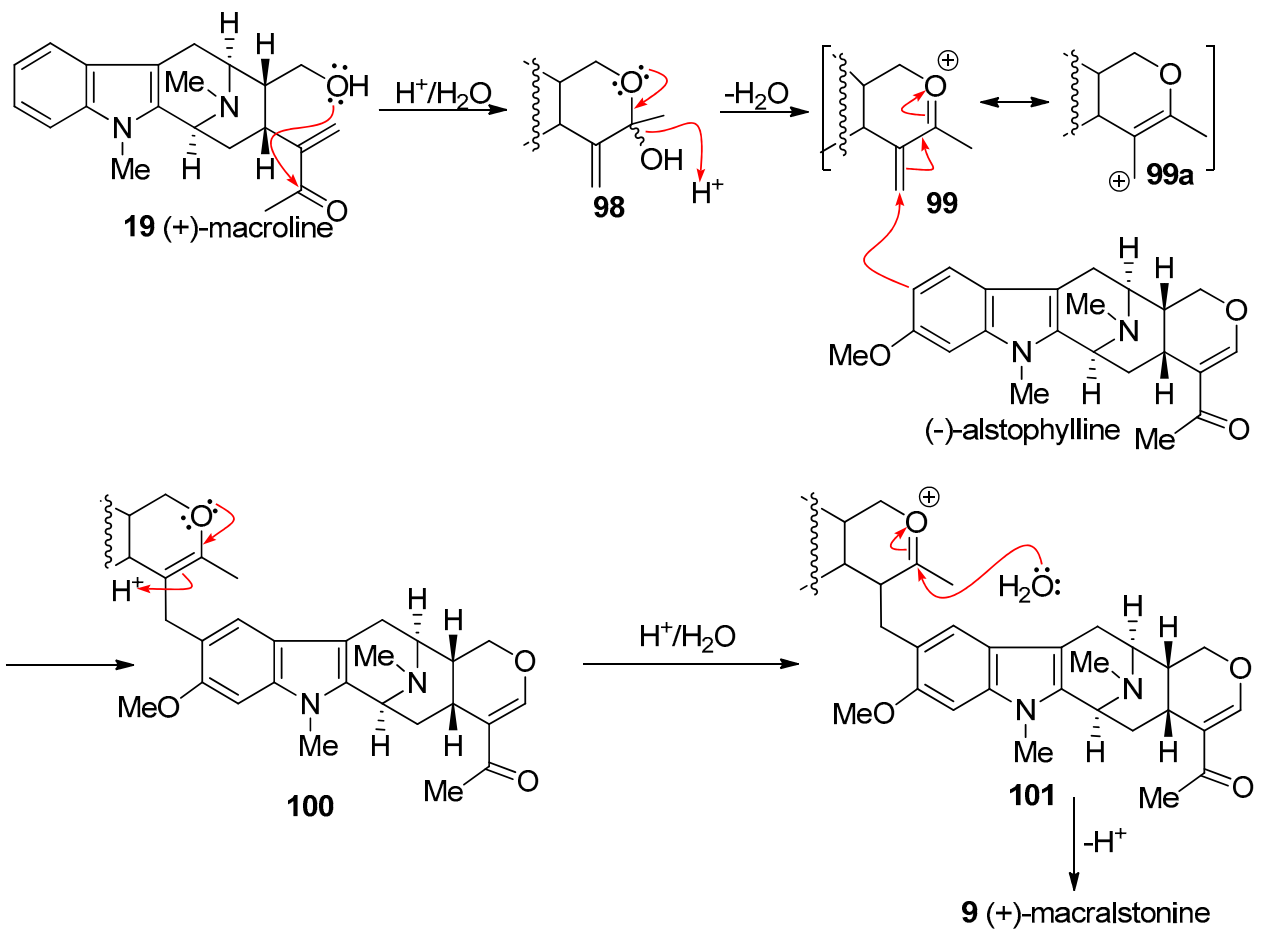

Figure 8. The possible alternative mechanism for the formation of (+)-9 via a Friedel-Crafts alkylation process.

(-)-Alstophylline 22, as described above comprises one unit of the antimalarial bisindoles macralstonine and the related $O$-acetyl and $O$-methyl macralstonine bases. This alkaloid was originally isolated from Alstonia macrophylla WALL by Kishi, Schmid et al. [78,128], from Alstonia glabriflora Mgf. by Hart [133] and from Alstonia angustifolia by Ghedira et al. [131]. In addition, the related $N_{\mathrm{a}}-\mathrm{H}$ analog (+)-N $N^{1}$-demethylalstophylline 22a has recently been isolated from Alstonia macrophylla by Kam [43].

The total synthesis of (-)-alstophylline required facile access to the optically active 6-methoxy tryptophan 105 which was no easy task. It was developed by Huang, Wearing, Liu et al. [137,138] on large scale. In the initial approach towards several 11-methoxy macroline-related indole alkaloids, Liu et al. completed a total synthesis of (-)-alstophylline [139].

The readily available iodoaniline $\mathbf{1 0 2}$ and propargyl substituted Schöllkopf chiral auxiliary 103 [138] were coupled under Larock heteroannulation conditions regiospecifically to provide the 6-methoxyindole derivative 104 (Scheme 11). The Schöllkopf chiral auxiliary severved as 
a protecting group which prevented epimerization of the chiral center in strong base. The required $N_{\mathrm{a}}$-methylation was executed with sodium hydride and iodomethane in dimethyl formamide to furnish the $\mathrm{N}_{\mathrm{a}}$-methylated 6-methoxytryptophan derivative, in greater than $98 \%$ ee. The hydrolysis of the dihydropyrazine moiety with aqueous $2 \mathrm{~N} \mathrm{HCl}$ in THF and concomitant removal of the triethylsilyl group resulted in the formation of $N_{\mathrm{a}}$-methyl-6-methoxy-D-(-)-tryptophan ethyl ester 105 in excellent yield. The primary amine 105 was converted into the benzyl protected amine by reduction of the phenyl substituted imine with sodium borohydride, which had formed by condensation of benzaldehyde with the primary amine. The asymmetric Pictet-Spengler reaction of the so formed $N_{\mathrm{b}}$-benzyl protected tryptophan derivative with the aldehyde, ethyl 4-oxobutanoate under acidic conditions (HOAC in DCM) resulted in an almost quantitative yield of the di-ester 106 in a 72:28 (trans:cis) diastereomeric ratio. The same reaction in trifluoroacetic acid in DCM resulted in decomposition of the product. However, after the Pictet-Spengler reaction had been completed in acetic acid, the addition of a small amount of TFA was found to be effective for the epimerization of the diester at C-1 to the correscponding trans-diester isolated as a single diastereomer ( $>98 \%$ ee). The trans-diester 106 was subjected to a one-pot Dieckmann cyclization and this was followed by a base-mediated hydrolysis/decarboxylation process to provide the required 11-methoxy- $N_{\mathrm{b}}$-benzyl protected tetracyclic ketone $\mathbf{1 0 7}$ in excellent yield. The catalytic hydrogenation on palladium on carbon under acidic conditions, removed the benzyl group to provide the desired the $N_{\mathrm{b}}-\mathrm{H}$ tetracyclic ketone 108, as shown on Scheme 11.

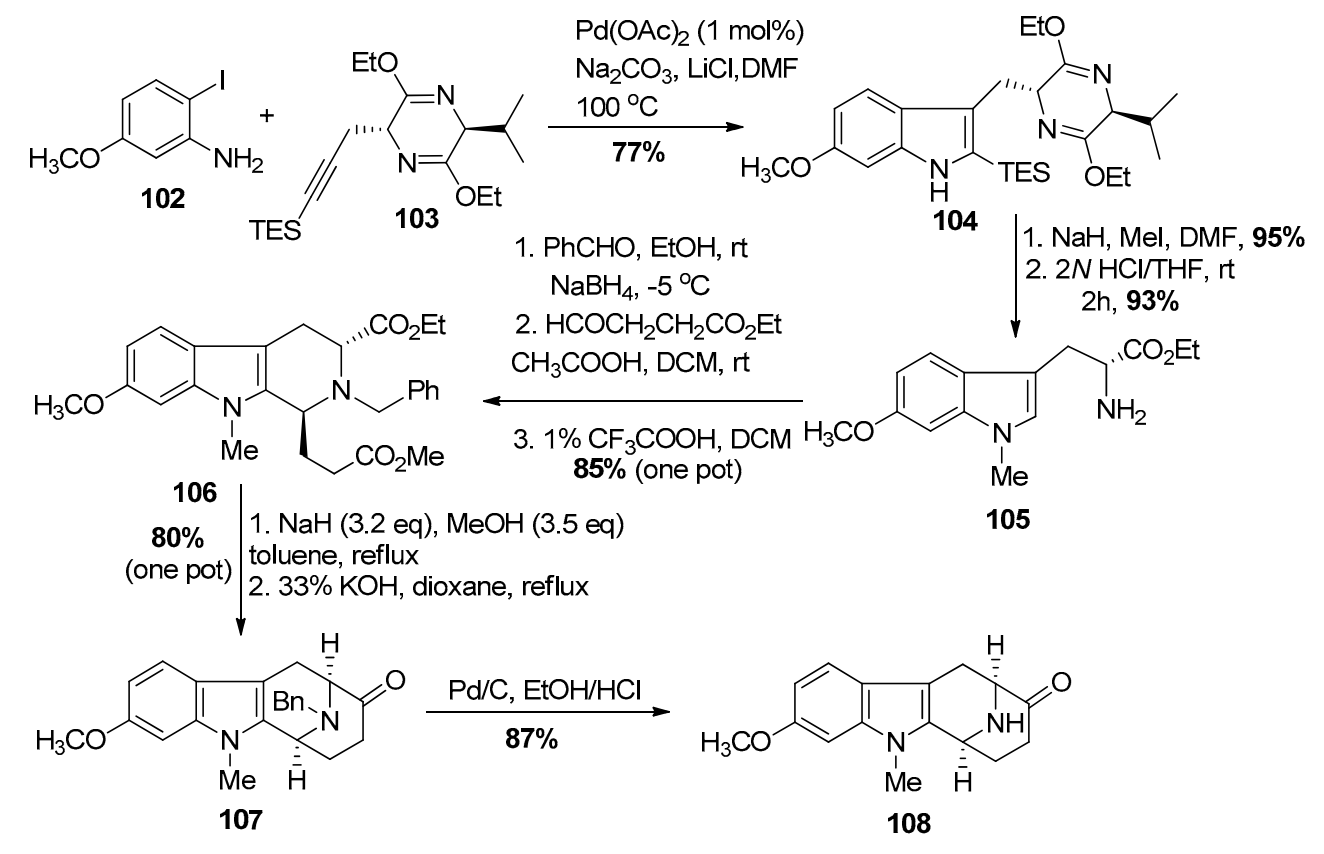

Scheme 11. Large scale enantiospecific access to the 11-methoxy substituted tetracyclic core structure present in (-)-alstophylline (22).

The $N_{\mathrm{b}}-\mathrm{H}$ function in amine 108 was re-alkylated via an $\mathrm{S}_{\mathrm{N}} 2$ substitution with (Z)-1-bromo2-iodo-2-butene 61 in the presence of $\mathrm{K}_{2} \mathrm{CO}_{3}$ in THF to provide the $\mathrm{N}_{\mathrm{b}}$-alkylated ketone 109 in good yield (Scheme 12) analogous to previous work. The iodo-2-butene $\mathbf{6 1}$ can now be prepared in 3 steps in stereospecific fashion on 500 gram scale. A palladium-catalyzed enolate-driven intramolecular cross-coupling process resulted in the pentacyclic ketone $\mathbf{1 1 0}$ in stereospecific fashion. A Wittig olefination was followed by hydrolysis of the enol ether which had resulted to yield the one-carbon homologated aldehyde $\mathbf{1 1 1}$ in excellent yield. The reduction of the aldehyde to the primary alcohol 112, to generate 11-methoxy affinisine was executed smoothly with sodium borohydride in ethanol. This constituted the first total synthesis of $\mathbf{1 1 2}$ (11-methoxy affinisine). Protection of the primary alcohol 
as a silyl ether $\mathbf{1 1 3}$ was done under standard conditions with triisopropylsilyl chloride in the presence of base. The hydroboration of the E-ethylidene function with borane-dimethyl sulfide and oxidation with basic hydrogen peroxide went smoothly to furnish the secondary alcohol 114, accompanied by a small amount of the corresponding tertiary alcohol. The Swern-oxidation conditions were employed to convert the mixture of secondary alcohols into the corresponding ketone 115 . The $N_{\mathrm{b}}-\mathrm{BH}_{3}$ adduct which had formed, could be converted into the free amine $\mathbf{1 1 6}$ by treating it with 1.5 equivalents of aqueous $\mathrm{HCl}$ in refluxing THF. On the other hand, in the presence of 10 equivalents of $\mathrm{HCl}$ in refluxing THF the cyclic hemiacetal 117 (11-methoxy- $N_{\mathrm{a}}$-methyl-trinervine) was isolated in 85\% yield, which could be converted into 120 by quaternization of the $N_{\mathrm{b}}$ nitrogen atom with iodomethane. This was followed by treatment with base to provide a retro-Michael reaction which underwent recyclization to dihydroalstophylline $\mathbf{1 2 0 .}$

Alternatively, the ketone 116 underwent the ring opening process under conditions similar to LeQuesne et al. [140] to 120. The dihydroalstophylline upon treatment with IBX and $p$-TSA in toluene and DMSO gave (-)-alstophylline 22, albeit the yield of this step was only moderate.
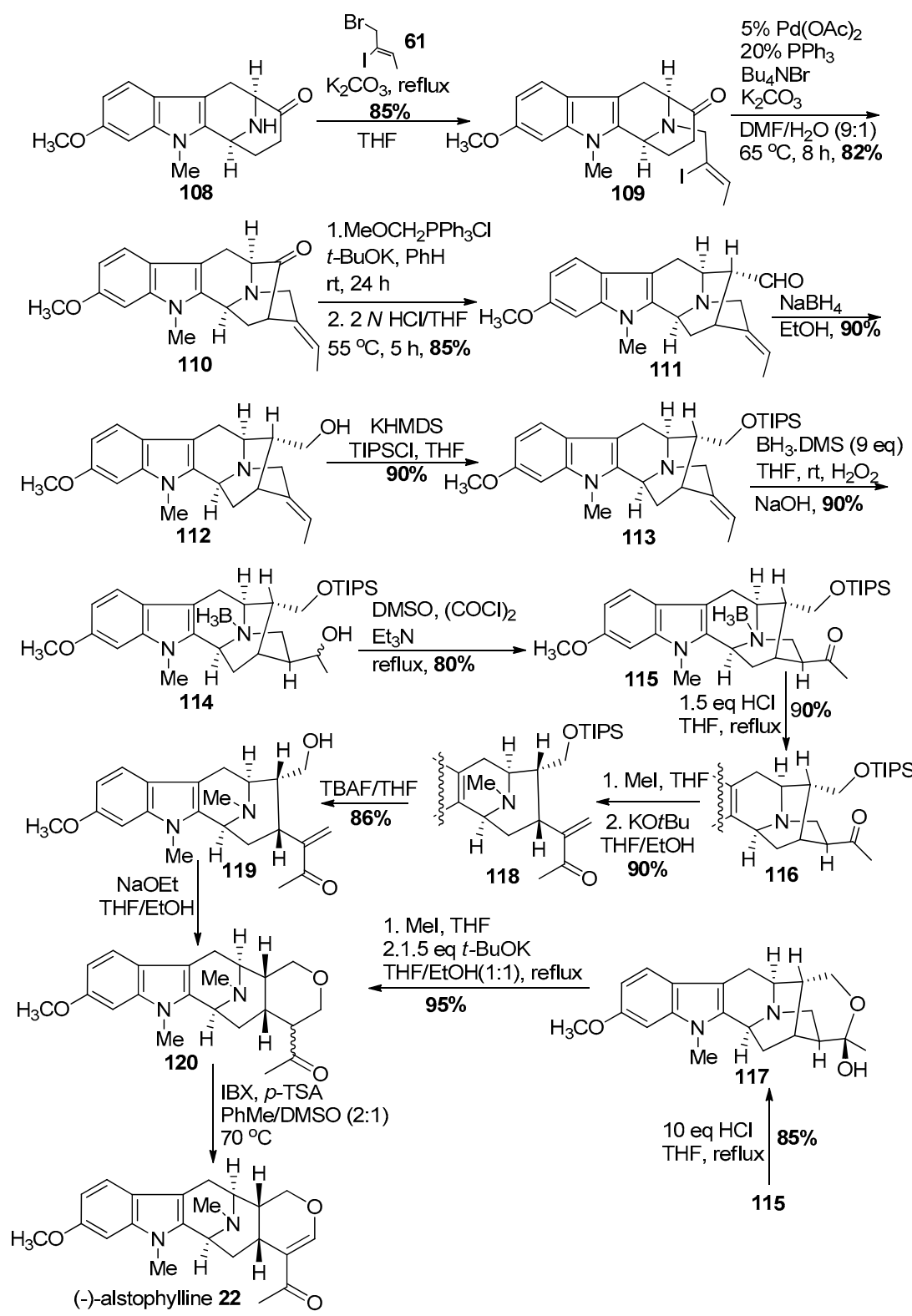

Scheme 12. Enantiospecific total synthesis of (-)-22 by Liu et al. [139]. 
In an improved approach, Liao et al. in Milwaukee developed a modified Wacker reaction to gain quick access to several macroline-type indole alkaloids (Scheme 13) [141]. The $N_{\mathrm{b}}-\mathrm{BH}_{3}$ adduct 114 (Scheme 13) was accessed in similar fashion in better yield than the previous report by Liu et al. [139]. However, in this case, the $N_{\mathrm{b}}-\mathrm{BH}_{3}$ group was removed alternatively by refluxing the complex with sodium carbonate in methanol to provide 121. The conditions of K.C. Nicolaou with IBX [142] were employed to oxidize the secondary alcohol to a ketone $116(1 \mathrm{~h})$ in 85\% yield with the first equivalent of IBX. This was followed by addition of another 3 equivalents of IBX after the initial transformation and the mixture was heated to $80^{\circ} \mathrm{C}$. This promoted the radical process with IBX, as reported by Nicolaou et al. at the C-6 benzylic position to provide access to the 6-oxoalstophylline intermediate 122. This method permitted access to both alstophylline and its 6-oxo variant simply by changing the number of equivalents of IBX. The ring opening of the ketone 116 by a retro-Michael reaction under conditions modified from those of LeQuesne et al. gave the $\alpha, \beta$-unsaturated system in 118. The ketone, under the modified Wacker conditions [143], effected the novel cyclization to provide (-)-alstophylline 22 directly. The total synthesis of alstophylline, accompanied by the total synthesis of (+)-macroline 19 by the group in Milwaukee constituted a total synthesis of (+)-macralstonine 9 . In addition, the unique indole alkaloid 6-oxoalstophylline was synthesized for the first time, as well as a much improved route to (-)-alstonerine via this modified Wacker (Pd (II)) process. This process can be employed to prepare a number of enone systems $(\mathbf{2 2 b}$, Figure 7$)$ found in indole alkaloids, as well as flavones (Lorenz, Cook et al.).

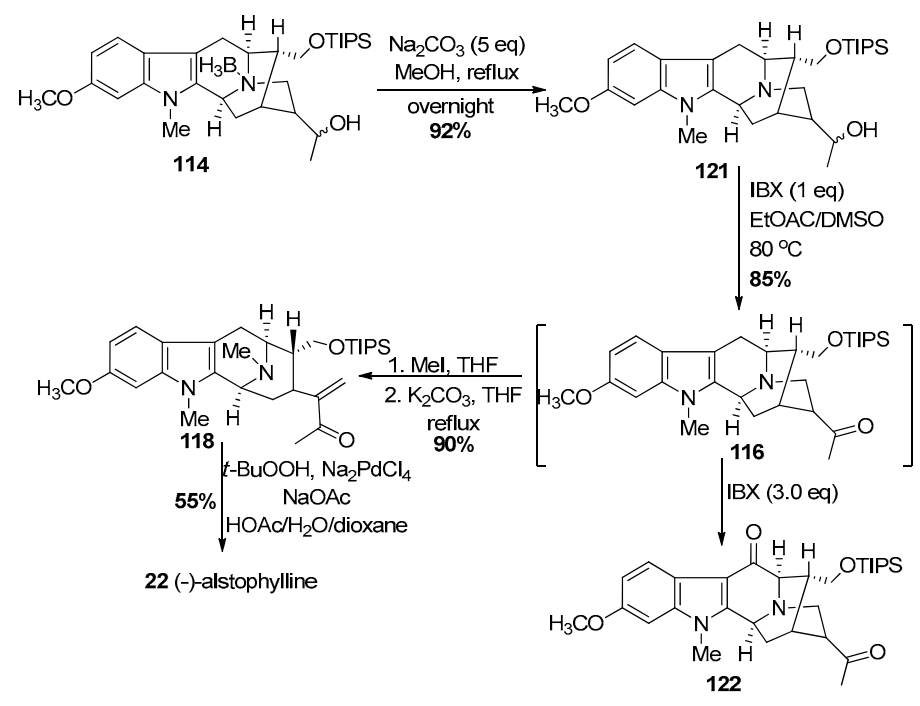

Scheme 13. An improved synthesis of (-)-22 by Liao et al. [141].

\section{4. (+)-Macralstonidine}

(+)-Macralstonidine 8 represents another dimeric indole alkaloid which consists of a macroline and a sarpagine obligate monomeric unit. It has been isolated from Alstonia macrophylla [127,128], Alstonia somersentenis [127], and Alstonia spectabilis [133]. The alkaloid, $N_{\mathrm{a}}$-methylsarpagine (23) is a natural product isolated from Alstonia spectabilis by Hart et al. [133]. Zhao et al. reported the first total synthesis of (+)- $N_{\mathrm{a}}$-methylsarpagine, as well as the total synthesis of (+)-macralstonidine, along with several other indole alkaloids $[144,145]$. The synthesis of $(+)-N_{\mathrm{a}}$-methylsarpagine accompanied by the total synthesis of (+)-macroline vide supra by the group in Milwaukee [85,86] constituted a total synthesis of this bisindole alkaloid.

Synthesis of the desired sarpagine unit 23 began from $p$-anisidine 123 (Scheme 14) [145]. The 5-methoxy-3-methylindole-2-carboxylate was prepared on 600 gram scale via a Japp-Klingmann azo-ester intermediate [146]. The subsequent saponification was followed by a copper/quinoline-mediated decarboxylation process executed again on large scale in excellent yield. In this process only 
2 equivalents of distilled quinoline were employed in contrast to the previous methods, which require a very large excess of quinoline. This latter route was difficult because the excess quinoline was hard to remove. The $N_{\mathrm{a}}-\mathrm{H}$ group was protected with a Boc function by treating it with Boc-anhydride and dimethyl amino pyridine to provide $\mathbf{1 2 4}$ in $95 \%$ yield. The regiospecific bromination of the C-3 alkyl group was done carefully under radical conditions with $\mathrm{N}$-bromosuccinimide and AIBN (admixed and added in portions) in carbon tetrachloride on large scale and in excellent yield to furnish 125. This radical reaction was also executed in refluxing cyclohexane with similar results. The 3-bromomethyl indole was found to be very unstable and was used without further purification. It was treated with the anion of the Schöllkopf chiral auxiliary 126 at $-78{ }^{\circ} \mathrm{C}$ to afford a single diastereomer $\mathbf{1 2 7}$ in $93 \%$ yield. The Boc group was removed under thermal conditions and this was followed by $N_{\mathrm{a}}$-methylation with iodomethane and sodium hydride in DMF to provide the $N_{\mathrm{a}}$-methyl tryptophan precursor 128. The dihydropyrazine moiety present in the Schöllkopf unit was hydrolyzed under acidic conditions in ethanol to furnish the 5-methoxy- $N_{\mathrm{a}}$-methyl D-(+)-tryptophan ethyl ester 129 on large scale. The usual subsequent transformations e.g., $N_{\mathrm{b}}$-benzylation, asymmetric Pictet-Spengler condensation, diastereospecific Dieckmann cyclization-decarboxylation reaction and catalytic debenzylation on palladium/carbon to remove the $N_{\mathrm{b}}$-benzyl group afforded the 5-methoxy tetracyclic ketone $\mathbf{1 3 0}$ in excellent overall yield. The $N_{\mathrm{b}}$-nitrogen atom was re-alkylated with the vinyl iodide, (Z)-1-bromo-2-iodo-2-butene 61 (prepared regiospecifically on 500 gram scale) to give iodo olefin 131, which underwent the enolated-driven palladium-catalyzed cross-coupling to provide the $\alpha$-vinylated intermediate, the key pentacyclic ketone 132 [144,145]. The conversion of the $E$-ethylidene intermediate 132 into the $\alpha$-aldehyde [(+)-majvinine] 133 was effected using a one-carbon homologation sequence by Wittig olefination followed by hydrolysis/epimerization as employed previously in Milwaukee. The C-10 methoxy alkyl group was removed using 6.0 equivalents of boron tribromide in DCM at $-78^{\circ} \mathrm{C}$ to yield the 10-hydroxy intermediate 134 and this was followed by reduction of the aldehyde with sodium borohydride in ethanol to the primary alcohol in (+)- $N_{\mathrm{a}}$-methylsarpagine 23 in $90 \%$ yield over the two steps. This constituted the first enantiospecific total synthesis of (+)-majvinine and of $(+)-N_{\mathrm{a}}$-methylsarpagine 23 [144,145].

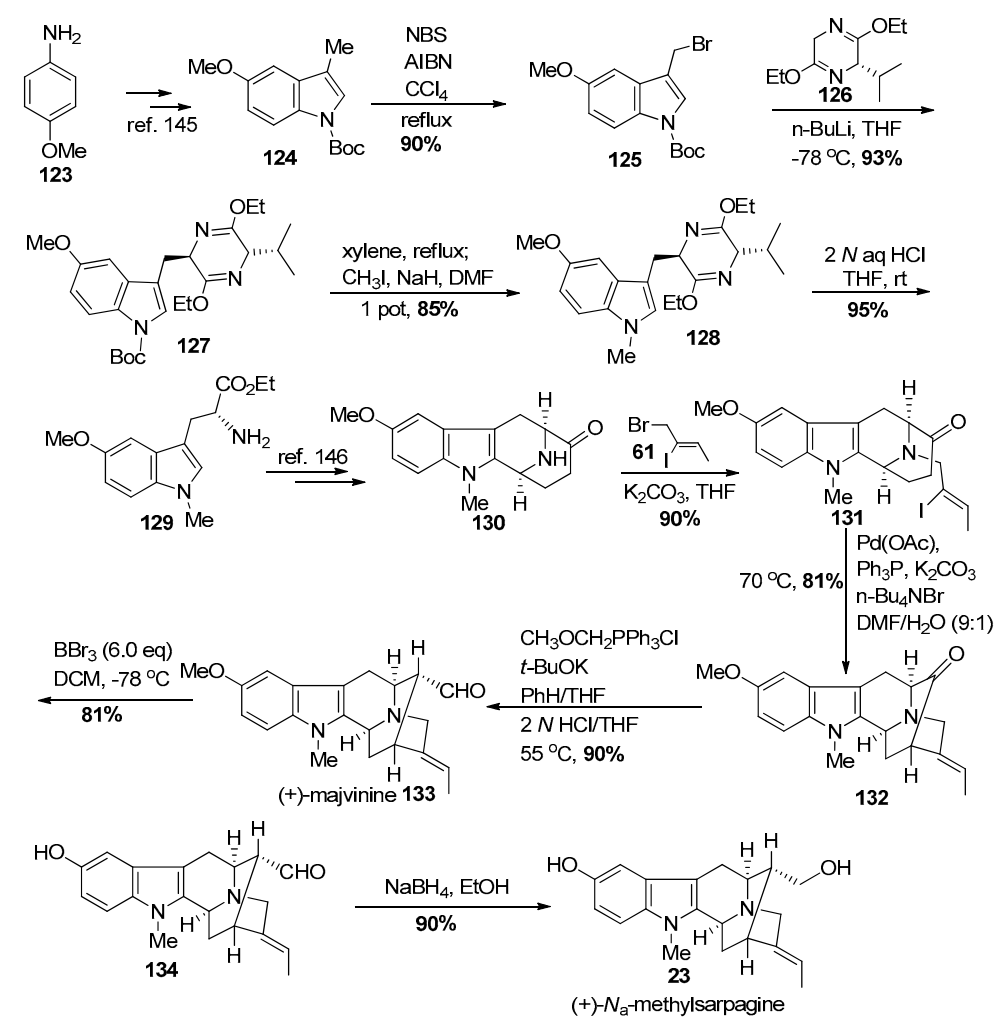

Scheme 14. Enantiospecific total synthesis of (+)-23 by Zhao et al. [144,145]. 
The condensation of (+)-macroline 19 and $(+)-N_{\mathrm{a}}$-methylsarpagine 23 under mildly acidicconditions provided the bisindole alkaloid, (+)-macralstonidine 8 (Scheme 15) [133]. In similar fashion to the case of macralstonine, there are at least two possible mechanisms of the coupling process. The first is the straight forward biomimetic coupling via a Michael reaction (Scheme 15) pioneered by LeQuesne [135], while the second is the Friedel-Crafts alkylation process [136,147], as illustrated in Figure 9. From a biological perspective the Michael reaction is the most reasonable, however, from a chemical perspective the Friedel-Crafts alkylation (Figure 9) is more likely. What is of significance here is that the alkylation took place soley at the C-9 position. No alkylation at C-11 was observed under these conditions.

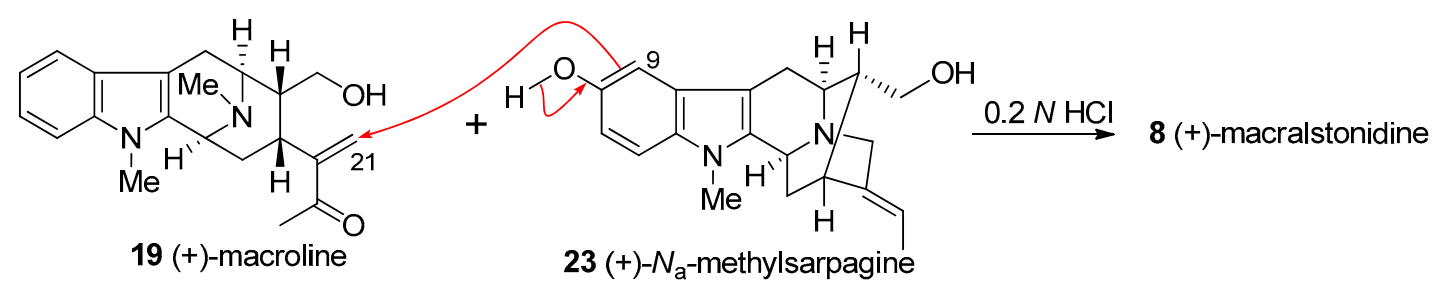

Scheme 15. Synthesis of (+)-8 by condensing (+)-macroline (19) and (+)- $\mathrm{N}_{\mathrm{a}}$-methylsarpagine (23) under acidic conditions.

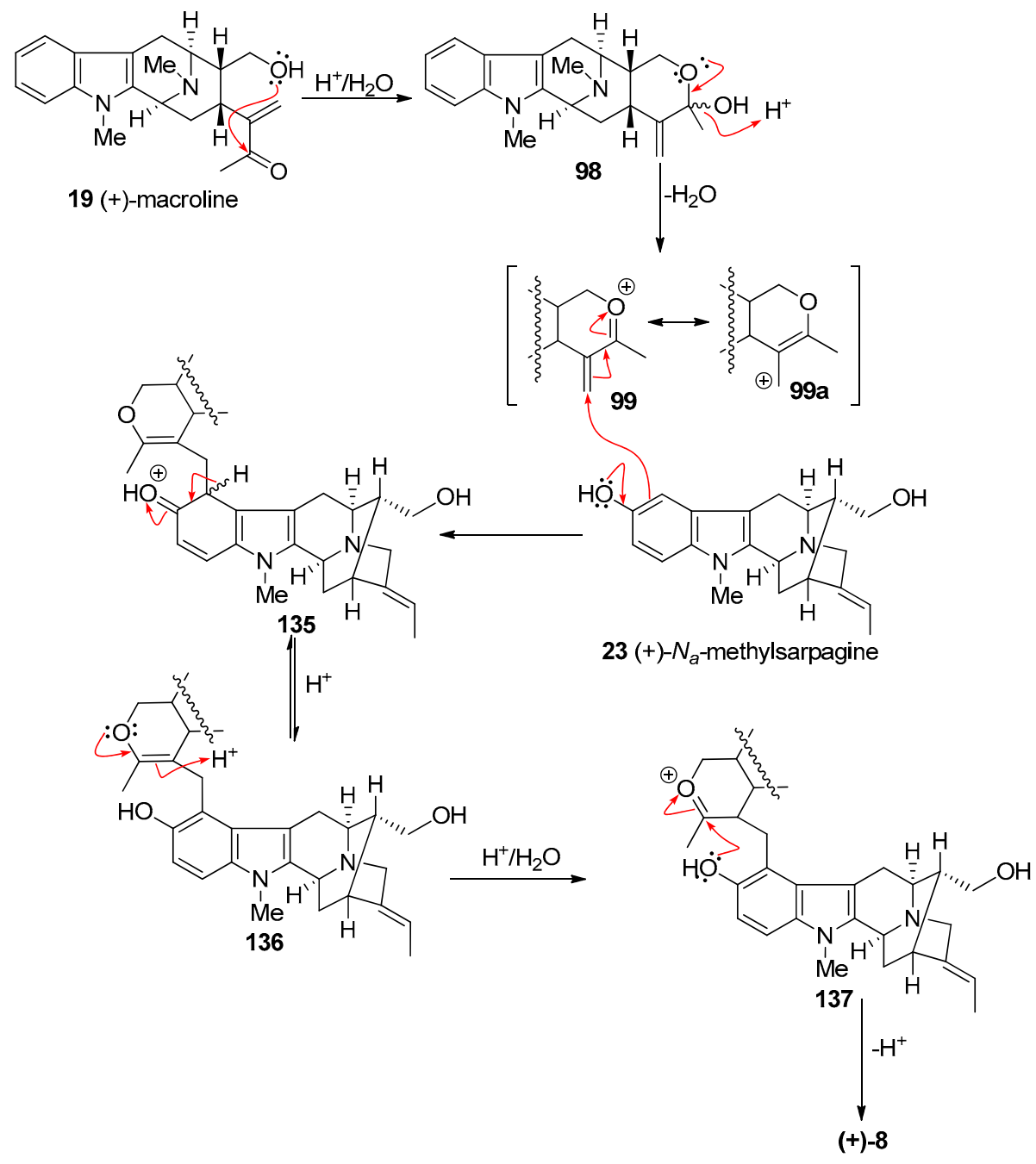

Figure 9. The possible alternative mechanism for the formation of (+)-8 via a Friedel-Crafts alkylation process. 


\section{5. (+)-Villalstonine}

Villalstonine $\mathbf{5}$ is a bisindole alkaloid consisting of two monomeric indole alkaloid units and Schmid et al. concluded from their study of the degradation of (+)-villalstonine that the monomeric components were (+)-macroline 19 and (+)-pleiocarpamine 14 [148]. Villalstonine has been isolated from the leaves and stem bark of Alstonia angustifolia [131,149], Alstonia macrophylla [22,128,148], Alstonia muelleriana [77], and Alstonia spectabilis [127]. The structure was deduced by Schmid et al. and confirmed by Nordman et al. by X-ray crystallography [150]. (+)-Pleiocarpamine, one unit, has been isolated from many Apocynaceae plants. To date, it has been isolated from Alstonia macrophylla [22], Alstonia angustifolia [131], Pleiocarpa mutica [151], Pleiocarpa pycnantha [152], Pleiocarpa tubicina [151], Kopsia dasyrachis [152], and from Hunteria eburnean Pichon [153] as well as Alstonia muelleriana [73]. The structure was based on examination of the NMR spectra, as well as in depth studies via mass spectrometry [154].

LeQuesne et al. executed a biomimetic synthesis of (+)-villalstonine 5 from condensation of (+)-macroline with (+)-pleiocarpamine 14 [83]. Macroline was obtained by degradation of villamine (not shown) and stirred with (+)-pleiocarpamine 14 in $0.2 \mathrm{~N}$ aqueous hydrochloric acid solution at $20{ }^{\circ} \mathrm{C}$ for $18 \mathrm{~h}$. This was followed by basic workup to furnish (+)-villalstonine 5 indistinguishable from the natural product [83].

This biomimetic synthesis [83] of (+)-villalstonine is believed to consist of the initial electrophilic addition of the macroline enone 19 function onto pleiocarpamine $\mathbf{1 4}$ from the less hindered $\alpha$-face to give intermediate 138. This intermediate undergoes facile transformation via hemiacetal formation and subsequent or concerted attack on the iminium ion of the indoline $\mathbf{1 3 8}$ to form the acetal-aminoactetal function in (+)-villalstonine 5, as illustrated in Scheme 16.

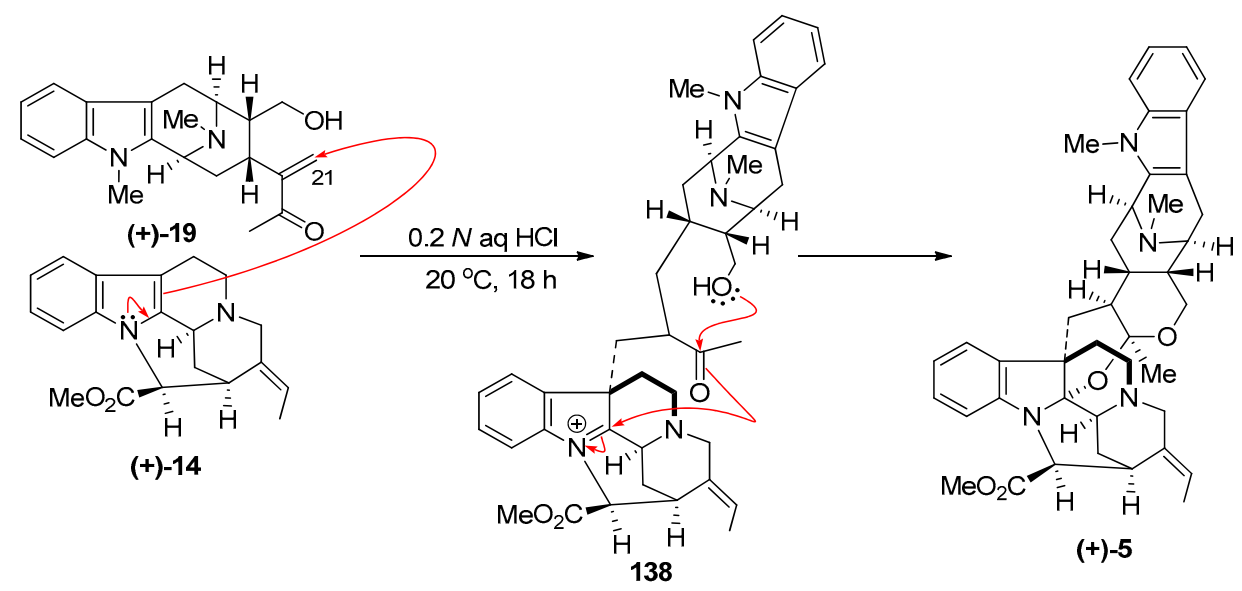

Scheme 16. The biomimetic partial synthesis of (+)-5 by LeQuesne et al. [83].

Since the total synthesis of (+)-pleiocarpamine $\mathbf{1 4}$ has not been successfully executed to date, the total synthesis of (+)-villalstonine $\mathbf{5}$ has still not been reported. In a partial synthesis of villalstonine, the Milwaukee group employed the more stable macroline equivalent 140, which served as a better alternative than macroline 19 itself, for the condensation with another monomeric unit to access bisindole alkaloids. This is because (+)-macroline tended to cyclize to form dihydroalstonerine 139 and limited the shelf life of macroline in storage (Scheme 17) [86].

The stable macroline equivalent 140 was stirred with natural (+)-pleiocarpamine 14, obtained from Professor LeQuesne, in $0.2 \mathrm{~N}$ aqueous hydrochloric acid along with tetrabutylammonium fluoride at $20^{\circ} \mathrm{C}$ for $24 \mathrm{~h}$. (+)-Villalstonine 5 was obtained as the sole product and was indistinguishable from the natural (+)-villalstonine. It has not been confirmed whether the desilylation of the macroline equivalent 140 occurred to form macroline 19 before the condensation or the condensation took place 
similar to that depicted in Scheme 18. It is significant that the stable dihydroalstonerine $\mathbf{1 3 9}$ was not obtained in this process.

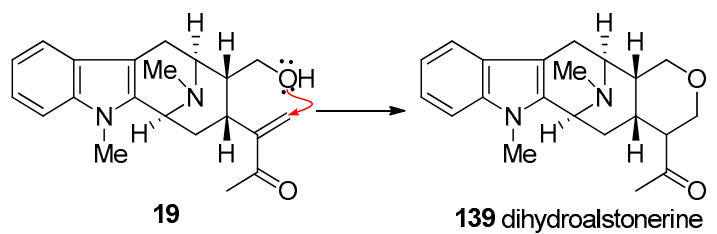

Scheme 17. Intramolecular cyclization of macroline (19) to form 139 which is responsible for its limited shelf life.

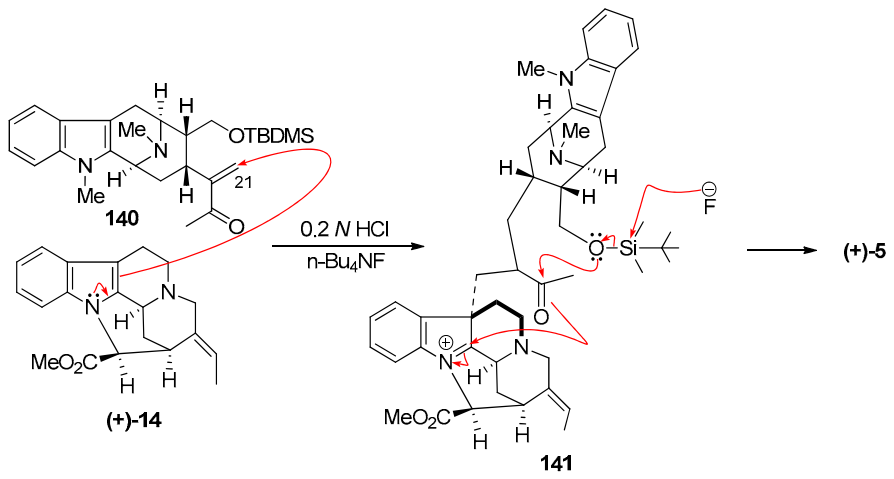

Scheme 18. An improved partial synthesis of (+)-villalstonine (5) using the stable macroline equivalent (140) by Bi et al. [86].

\section{6. (-)-Macrocarpamine}

(-)-Macrocarpamine 3 is a bisindole arising from the condensation of (+)-pleiocarpamine 14 and the indole base (-)-anhydromacrosalhine-methine 24, according to the biogenetic pathway proposed by Hesse et al. [155]. It has been found in Alstonia macrophylla WALL [40,155], and Alstonia angustifolia [21,156]. (-)-Anhydromacrosalhine-methine $\mathbf{2 4}$ was first reported as a degradation product of (+)-macrosalhine 142 [157], as well as (-)-macrocarpamine 3 [155] (Scheme 19). The partial synthesis of macrocarpamine was carried out by Wang et al. from the condensation of natural (+)-pleiocarpamine 14 and semi-synthetic (see Scheme 19) (-)-anhydromacrosalhine-methine 24 [158-160].

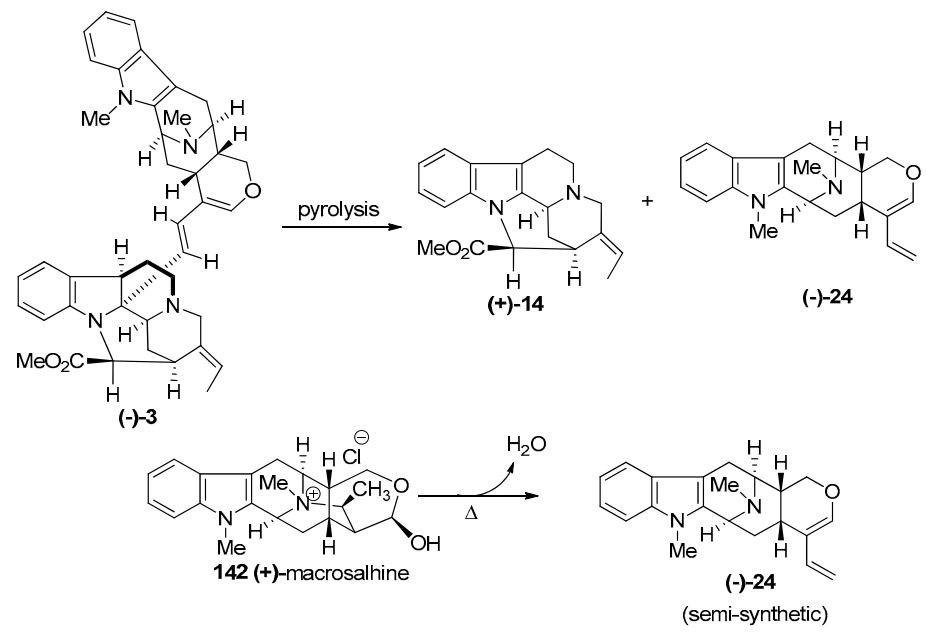

Scheme 19. Semi-synthetic access to (+)-14 and (-)-24 by the pyrolysis of (-)-macrocarpamine (3) and (+)-macrosalhine (142). 
In the partial synthesis of (-)-macrocarpaine 3, an authentic sample of (-)-anhydromacrosalhinemethine 24 (a relay compound) was first prepared semi-synthetically from natural (+)-ajmaline 26 (Scheme 20) [160]. The hemiacetal 143 was prepared from ajmaline 26, according to the reported procedure by Sakai [161] and also carried out by Wearing et al. [162] which involved generation of the indole from the indoline, epimerization at C-16 and cleavage of $N_{\mathrm{b}}-\mathrm{C} 21$ bond. This yielded the E ring in macrosalhine methine 24. In this sequence the hemiacetal 143 underwent a dehydration to form deoxyalstonerine 144 upon heating with $p$-toluenesulfonic acid in refluxing benzene. Oxyselenation of 144 to provide 146 was carried out using $\mathrm{N}$-(phenylseleno)phthalimide in $\mathrm{CH}_{2} \mathrm{Cl}_{2}$ in the presence of 2-3 equivalents of water and 1.3 equivalents of $p$-toluenesulfonic acid. Elimination of the selenoxide upon treatment of 146 with $\mathrm{NaIO}_{4}$ provided the allylic alcohol 147. The 1,4-elimination in 147 of water was executed by stirring it with $p$-toluenesulfonic acid in THF to provide (-)-anhydromacrosalhine-methine 24 in $85 \%$ yield [160].

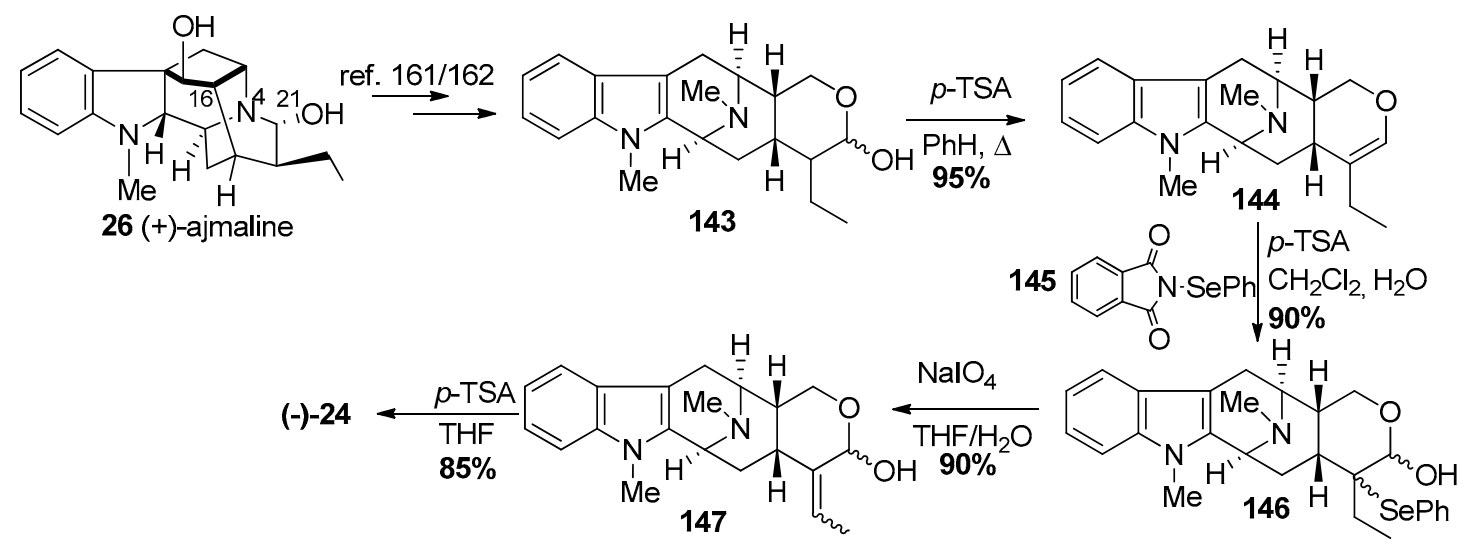

Scheme 20. Semi-synthetic access to (-)-24 from relay compound (+)-ajmaline (26) [160].

The enantiospecific total synthesis of (-)-anhydromacrosalhine-methine 24 began from D-(+)-tryptophan. The tetracyclic ketone 49 was prepared in $>98 \%$ ee using the reported method (Scheme 21) [95] on large scale. (-)-Alstonerine 15 which was converted into (-)-24, was prepared from 49 following the same procedure reported for the total synthesis of alstonerine 15 by Bi et al. [86]. The enone ether 53 was synthesized from the $N_{\mathrm{b}}$-methyl tetracyclic ketone 49 in four steps following the reported procedure [163] as described in brief here. The Claisen rearrangement of enone 53 took place from the desired $\alpha$-face with at least $4: 1$ diastereoselectivity to provide 54 in $66 \%$ yield. Reduction of the carbonyl functions with sodium borohydride in ethanol was followed by stereospecific hydroboration-oxidation of the olefin with 9-BBN/THF and $\mathrm{H}_{2} \mathrm{O}_{2} / \mathrm{NaOH}$ which furnished the triol 147. The regioselective cyclization of $\mathbf{1 4 7}$ by using the tosylate as a leaving group generated the tetrahydropyran which was subsequently oxidized to the enone 15 [(-)-alstonerine] in $51 \%$ yield. The enone was accompanied by $31 \%$ of dihydroalstonerine 139 which could be transformed into the enone 15 through reduction and re-oxidation. Reduction of (-)-alstonerine 15 with sodium borohydride to the allylic alcohol 150 was followed by dehydration using $p$-TSA in excellent yield to complete the enantiospecific total synthesis of (-)-anhydromacrosalhine-methine 24. 


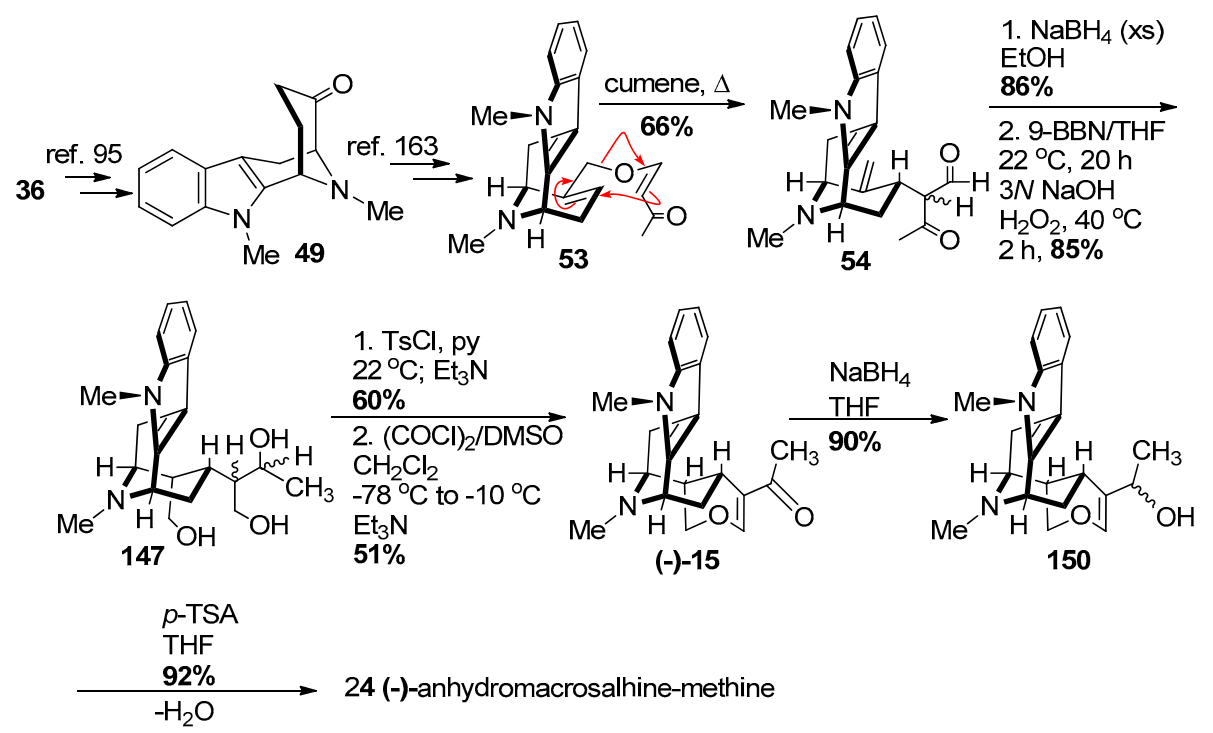

Scheme 21. Enantiospecific total synthesis of (-)-24 by Gan et al. [158].

When (-)-anhydromacrosalhine-methine $\mathbf{2 4}$ was condensed under mildly aqueous acidic conditions $(0.2 \mathrm{~N}$ aqueous $\mathrm{HCl})$ with natural pleiocarpamine 14, the enol ether was converted into its hydrated form preventing it from undergoing the coupling reaction to yield (-)-macrocarpamine 3 [159]. However, under anhydrous conditions $(0.2 \mathrm{~N} \mathrm{HCl}(\mathrm{g}) / \mathrm{THF})$, when 6 equivalents of 24 were added in portions over $48 \mathrm{~h}$ to (+)-pleiocarpamine, (-)-macrocarpamine 3 was formed in $75 \%$ yield (Scheme 22). A possible mechanism for the coupling reaction has been proposed by Wang et al. [159]. The proton acted as an electrophile to form the readily reversible iminium ion $\mathbf{1 5 1}$. The diene $\mathbf{2 4}$ was added portionwise in acidic solution to immediately quench the iminium ion upon its formation and to prevent the decomposition of the diene. The so formed (-)-macrocarpamine 3 was identical to the natural product reported by Hesse et al. by comparison of the spectral data [155].

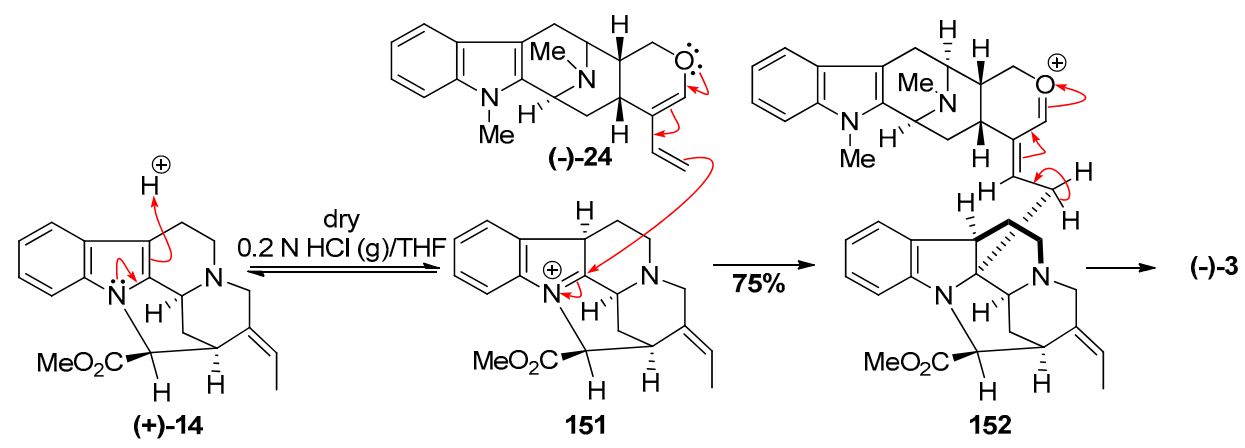

Scheme 22. Partial synthesis of (-)-macrocarpamine (3) by Gan et al. [159].

\section{7. (+)-Dispegatrine}

(+)-Dispegatrine 7 is a dimeric indole alkaloid isolated from the water-soluble fraction of the root extract of Rauwolfia verticillata (Lour.) Bail. var. hainanensis Tsiang [164,165]. It is a bisphenolic as well as a bisquaternary sarpagine indole alkaloid which makes it a unique alkaloid since the occurrence of these types of alkaloids are very rare [18]. (-)-Blumeanine (not shown) [166] is the only other alkaloid of this class among more than 300 or so bisindole alkaloids isolated to date. The monomer, spagatrine $\mathbf{1 6}$ is a major alkaloid isolated from Aspidosperma spegazzinii [167], R. sprucei [168], R. verticillata var. hainanesis [164], and from $R$. verticillata var. rubrocarpa [165]. 
A biomimetic partial synthesis of (+)-dispegatrine 7 had been carried out from the monomer spegatrine 16 by Yu et al. [164] via an oxidative phenolic coupling in a negligible yield of $0.25 \%$ (Scheme 23). Although most of the structure of (+)-dispegatrine was determined based on the analysis of the NMR spectra and mass spectra, the partial synthesis by Yu confirmed the structure [164]. Moreover, no other diastereomer was reported. However, the isolation chemists were unable to determine the important axial chirality at the C9-C9' bond [164]. In spite of that, formation of only one atropodiastereomer in that dehydrodimerization process suggested internal chiral induction was responsible for the atroposelectivity at the C9-C $9^{\prime}$ bond. This strategy was employed in the total synthesis of (+)-dispegatrine $\mathbf{7}$ and its monomer, (+)-spegatrine $\mathbf{1 6}$ in a convergent fashion, by Edwankar et al. [169,170].

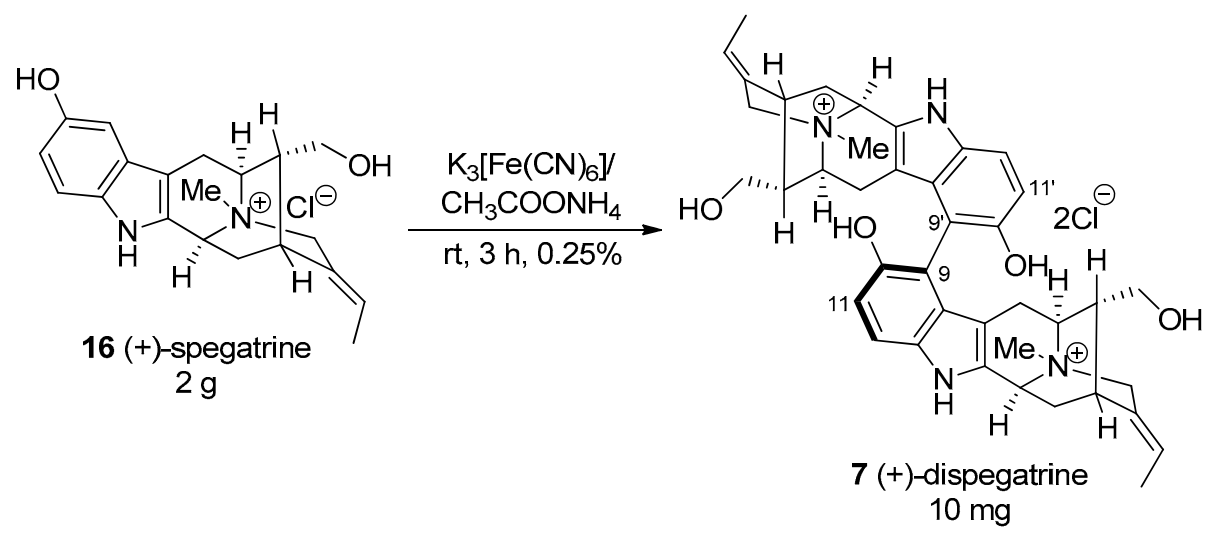

Scheme 23. Biomimetic partial synthesis of dispegatrine by Yu et al. [164].

In a biomimetic total synthesis of the $(P)$-atropodiestereomer of $(+)$-dispegatrine $[169,170]$, the tetracyclic ketone core $\mathbf{1 6 3}$ was accessed via the general process for ring-A oxygenated indole alkaloids, which began from 5-methoxy-D-(+)-tryptophan via the asymmetric Pictet-Spengler condensation and diastereospecific Dieckmann cyclization process.

The enatiospecific synthesis of 5-methoxy tryptophan was done on large scale using a regiospecific bromination [145] and Larock heteroannulation [171-173] process. The L-valine in the Schöllkopf chiral auxiliary served both as the starting material and the source of chirality in the route. The Schöllkopf chiral auxiliary 154 was prepared on large scale (500 g) from L-valine 153 and glycine ethyl ester using an earlier method (Scheme 24) [174-176].

The $o$-iodoaniline 156 was synthesized by employing known methods (Scheme 24) $[177,178]$. The amino group in $\mathbf{1 2 3}$ was protected with a Boc group and subjected to a Snieckus ortho-lithiation [179] with 2.2 equivalents of tert-butyllithium at $-78{ }^{\circ} \mathrm{C}$ and quenched with diiodoethane to afford the Boc protected iodoaniline $\mathbf{1 5 6}$ in 86\% yield, required for the Larock heteroannulation. With the TMS-substituted alkyne 155 and iodoaniline 156 in hand, the heteroannulation was carried out using conditions developed by Ma et al. [176] which furnished the Schöllkopf analogs 157 and 158 in a combined yield of $81 \%$. Using a bulkier silyl TES-substituted alkyne did not improve the regioselectivity of the cyclization. Hydrolysis of indole 157 under acidic conditions removed the Schöllkopf unit, as well as the silyl group to provide optically active 5-methoxy-D-tryptophan ethyl ester 159 in $86 \%$ yield. 

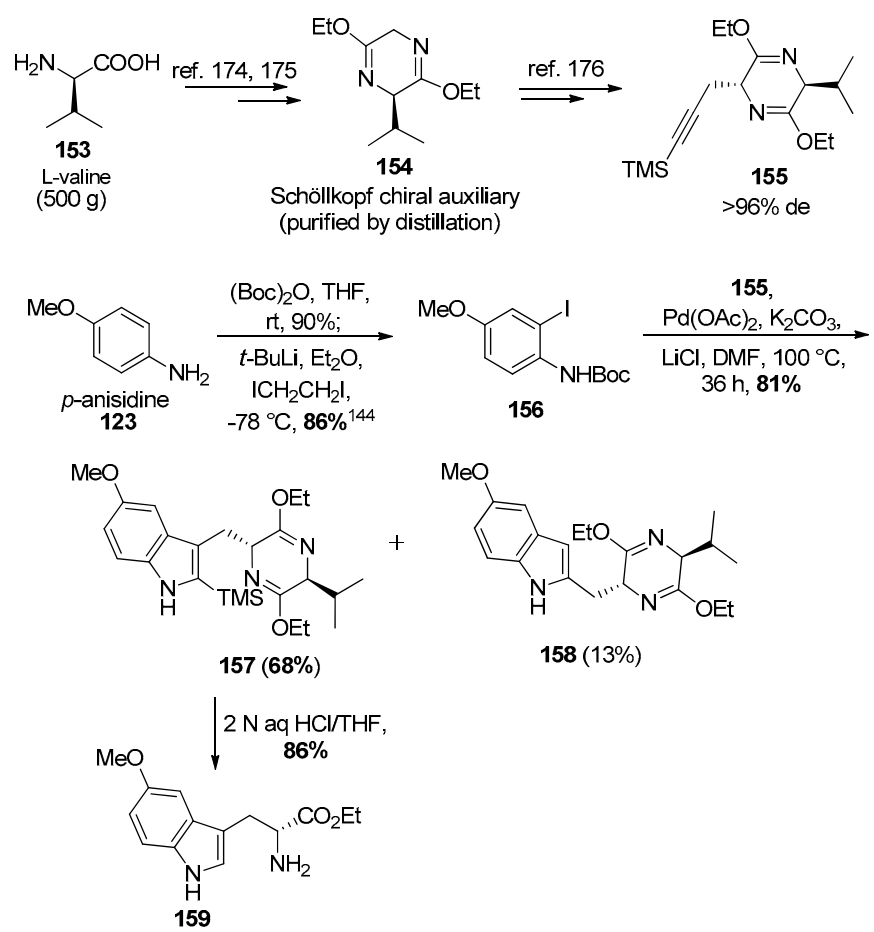

Scheme 24. Enantiospecific access to 5-methoxy tryptophan (159) by The Larock heteroannulation process.

Due to the failure to improve the diastereoselectivity of the Larock heteroannulation (68:13) using the TMS-substituted alkyne $\mathbf{1 5 5}$ and the $\mathrm{N}$-Boc protected ortho-iodo aniline $\mathbf{1 5 6}$ under the previously reported conditions $[90,180]$, an alternative route involving a Japp-Klingemann/Fischer indole processes was also employed. This was developed by Abramovitch and Shapiro and was used here for the large-scale (>600 g) preparation of 3-methyl-5-methoxyindole 161 (Scheme 25) [181,182].

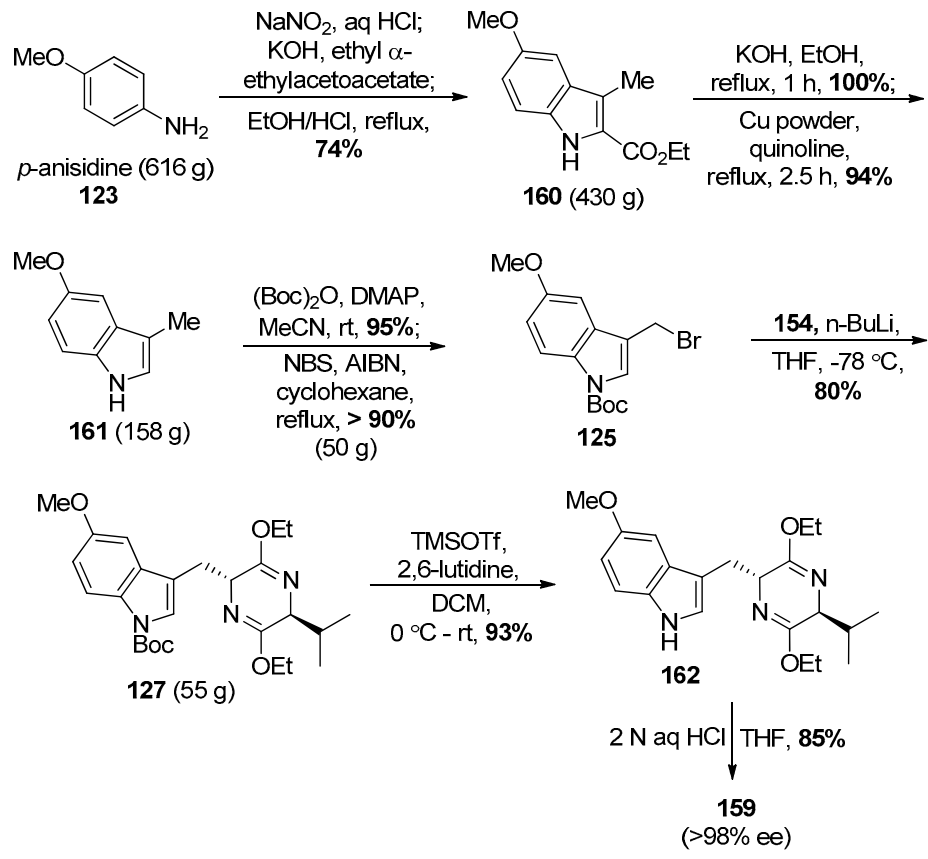

Scheme 25. Alternative approach toward enantiopure 159 via the Japp-Klingemann/Fischer esterification process. 
As mentioned above, the 5-methoxy-3-methylindole-2-carboxylate 160 was prepared on large scale via The Japp-Klingemann azo-ester intermediate (Scheme 25) [146]. The subsequent saponification was followed by a copper/quinoline-mediated decarboxylation executed on large scale to provide $\mathbf{1 6 1}$ in excellent yield. In order to carry out this decarboxylation in high yield only 2 equivalents of distilled quinoline were employed. The indole $\mathrm{N}-\mathrm{H}$ group was then protected with a Boc group by treatment of 161 with Boc-anhydride and 4-(dimethylamino) pyridine in 95\% yield. The subsequent regiospecific bromination of the C-3 alkyl group was done under radical conditions with $\mathrm{N}$-bromosuccinimide and AIBN (admixed) in carbon tetrachloride on large scale in excellent yield to furnish bromide 125. This radical reaction could be carried out in refluxing cyclohexane with the same result. Alkylation of bromide 125 with the anion of the Schöllkopf chiral auxiliary (154) provided 127 on multigram scale. An improved and milder condition for the removal of the Boc group using TMSOTf/2,6-lutidine [183] was used in place of refluxing xylene [145]. The hydrolysis of the Schöllkopf analog 162 with $2 \mathrm{~N}$ aqueous $\mathrm{HCl}$ in THF provided the optically active $\mathrm{N}_{\mathrm{a}}-\mathrm{H}$, 5-methoxy-D-(-)-tryptophan ethyl ester (159) in excellent yield and diastereoselectivity ( $>98 \%$ ee).

The tetracyclic ketone 163 was prepared on large scale from ester 159 which involved the asymmetric Pictet-Spengler reaction [37,145,184-186], and diastereospecific Dieckmann cyclization [111]. This was followed by base mediated decarboxylation and catalytic debenzylation of the $N_{\mathrm{b}}$-benzyl function under acidic conditions (Scheme 26).<smiles></smiles>

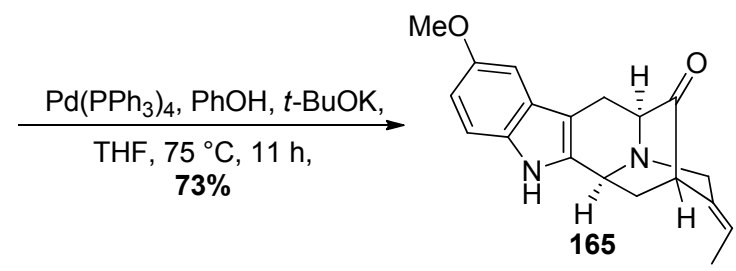

Scheme 26. Synthesis of the 10-methoxy pentacyclic core system 165 from 159.

The $N_{\mathrm{b}}$-alkylation was carried out by heating (Z)-1-bromo-2-iodo-2-butene 61 [187] with 163 in the presence of potassium carbonate in MeCN to provide the desired vinyl iodide 164 (Scheme 26) [111,145]. Because this route to $\mathbf{1 6 4}$ was somewhat longer, the Larock heteroannulation was often employed to prepare 5-methoxy-D-(+)-tryptophan. The enolate mediate palladium-catalyzed intramolecular cross-coupling of the vinyl iodide $\mathbf{1 6 4}$ was carried out under the conditions of Bonjoch [188] which employed PhOK/Pd( $\left(\mathrm{PPh}_{3}\right)_{4}$ to effect the coupling in $73 \%$ yield (Scheme 26). Initial attempts with the modified conditions ( $t$-BuOK only) resulted in the pentacyclic ketone 165 in only $50 \%$ yield [87]. This was because the acetylene by product was formed in the presence of the stronger base $t$-BuOK versus the Bonjoch sodium phenoxide.

The E-ethylidene pentacyclic ketone 165 was subjected to a one-carbon homologation via a Wittig olefination- hydrolysis process employed many times in Milwaukee in a one pot sequence. This provided the desired $\alpha$-aldehyde, the natural product (+)-10-methoxyvellosimine 166, in excellent yield (Scheme 27). The reduction of $\mathbf{1 6 6}$ with sodium borohydride yielded another natural product, (+)-lochnerine (167). Upon treatment with $\mathrm{BBr}_{3}$ in methylene chloride at $-78{ }^{\circ} \mathrm{C}$, demethylation of 167 occurred in $80 \%$ yield to furnish the hydroxyindole natural product (+)-sarpagine 25 . The quaternization of $\mathbf{2 5}$ at the $\mathrm{N}_{\mathrm{b}}$-function using an excess of iodomethane was followed by simple iodide halide exchange with silver chloride in ethanol to furnish (+)-spegatrine chloride (16) $[169,170]$. 
In addition to (+)-lochnerine, when it was treated with an excess of iodomethane in methanol at $\mathrm{rt}$ for $24 \mathrm{~h}$ this provided the natural product (+)-lochneram 168 in 85\% yield. These monomeric indole alkaloids were synthesized for the first time, the chemical and physical properties of which were very important in the final assault on (+)-dispegatrine. One could determine the chemical and chromatography characeteristics of these monomers to help with the isolation and purification of (+)-dispegatrine.

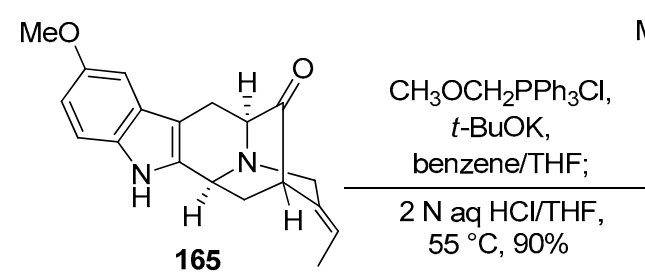

(+)-10-methoxyvellosimine

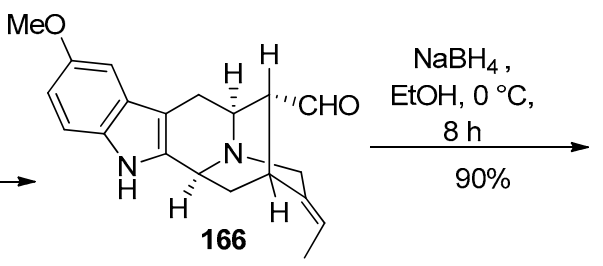

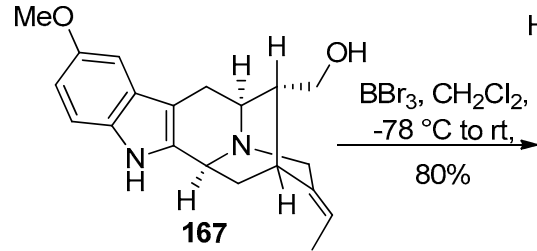

(+)-lochnerine

Mel (xs)

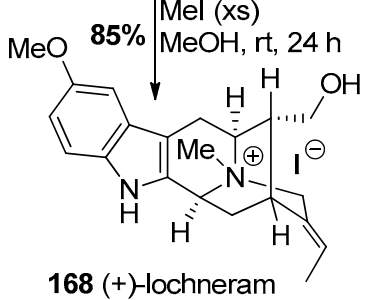

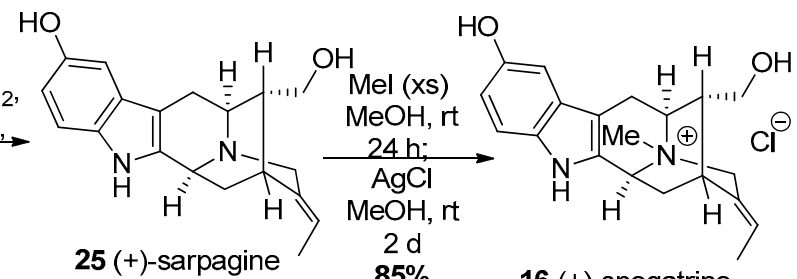

$85 \%$
$16(+)-$ spegatrine

Scheme 27. Enantiospecific total synthesis of (+)-10-methoxyvellosimine (166), (+)-lochnerine (167), (+)-sarpagine (25), (+)-spegatrine (16), and (+)-lochneram (168) by Edwankar et al. [169,170].

Numerous attempts were undertaken (including Ullmann coupling and Suzuki-Miyaura coupling) to effect the biaryl cross-coupling in model substrates while avoiding the very poor yields in the oxidative phenolic coupling reported in the partial synthesis of (+)-dispegatrine 7 by Yu et al. [170]. Eventually, a thallium(III) mediated Scholl-type dimerization [189] of (+)-lochnerine 167 was successfully executed wherein the chirality of the $\mathrm{C} 9-\mathrm{C} 9^{\prime}$ bond was determined by the chirality inherent in the sarpagine system, as planned (Scheme 28).

As shown in Scheme 28, The monomeric sarpagine alkaloid lochnerine 167, under the modified conditions of Taylor et al. [190,191] underwent Tl(III) mediated oxidative dimerization (a 0.65 equvalent of thallium (III) acetate with 3 equivalents of borontrifluoride etherate in $\mathrm{MeCN}$ at $-40{ }^{\circ} \mathrm{C}$ ) to furnish the key C9-C9' biaryl coupling and provided the $P(\mathrm{~S})$-atropodiastereomer 169 (confirmed by X-ray crystallographic analysis at low temperature wherein all the chiral centers were determined with the MoK $\alpha$ source) as the sole product and with complete regioselectivity [169]. This process was accompanied by a competing byproduct, an electrophilic thallation product $\mathbf{1 7 0}$ and its origin could be understood by the mechanistic studies of Kochi et al. [192,193]. 

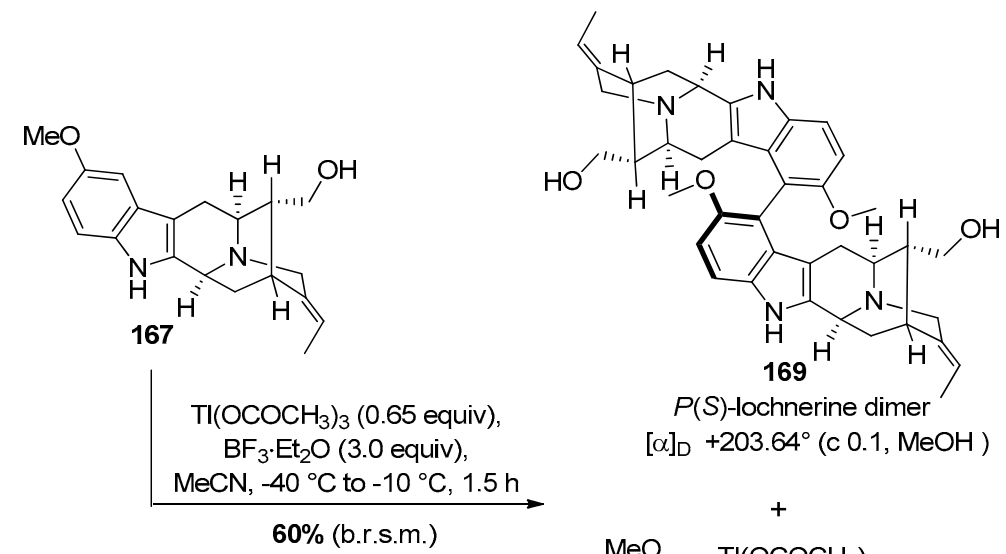

$[\alpha]_{D}+203.64^{\circ}(\mathrm{c} 0.1, \mathrm{MeOH})$

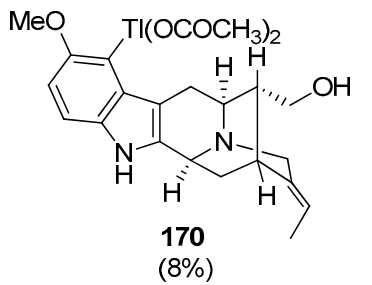

Scheme 28. Thallium (III) mediated oxidative dimerization process to provide $P(\mathrm{~S})$-atropodiastereomer of the dimer lochnerine (169).

The methoxy group in $\mathbf{1 6 9}$ was demethylated using an excess of boron tribromide in methylene chloride at $-78{ }^{\circ} \mathrm{C}$ to provide the sarpagine dimer $\mathbf{1 7 1}$ followed by $N_{\mathrm{b}}$-quaternization using excess iodomethane in methanol at $40{ }^{\circ} \mathrm{C}$ to provide the dispegatrine diiodide salt (Scheme 29). Treatment of the diiodide salt with silver chloride in methanol provided (+)-dispegatrine 7 in $85 \%$ yield. Although the $(P)$-atropoisomer here could be correlated back to the configuration in the $P(S)-(+)$-lochnerine dimer, the stereochemistry was confirmed by examination of extensive NMR studies. This strategy completed the first total synthesis of the monomer spegatrine as well as the dimer $P(S)-(+)$-dispegatrine in a nature inspired and convergent manner in $8.3 \%$ yield starting from commercially available material. Moreover 6 other monomeric 10-methoxy substituted indole alkaloids were synthesized, enantiospecifically, for the first time.

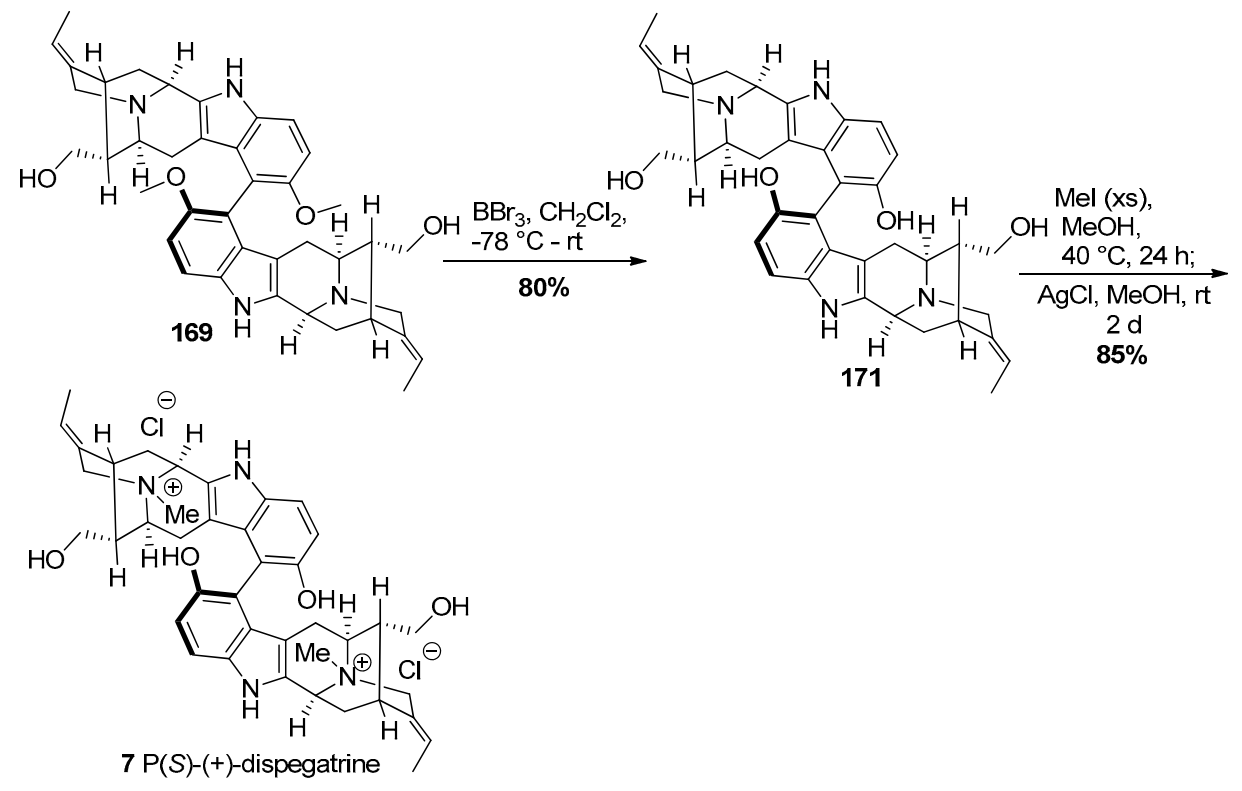

Scheme 29. Completion of the first total synthesis of $P(S)-(+)$-dispegatrine (7) by Edwankar et al. [170]. 


\section{Conclusions}

Indole alkaloids of different classes and sub-classes have been a promising source of new drugs since the search for new molecular entities with profound biological activity from natural sources was initiated. It is sure to continue. The pace of natural product-based drug development from plants to patients has necessarily been rather moderate because of the difficulty in isolation of sufficient material for adequate structure determination, initial screening for a target, followed by preclinical and clinical studies. The anticancer properties of the important bisindole alkaloids, vincristine and vinblastine, prompted chemists including Potier, Kutney, Kuehne, Magnus, Rawal, and Fukuyama to execute elegant work in this area. In addition, natural product derivatives are an equally important area of further improvements in drug development. In the case of bisindoles, the bisindole itself continues to be more potent in most cases in comparison to the monomeric alkaloids which comprise them. It is this phenomenon that stimulated the interest in the synthesis of the antimalarial and antileishmanial bisindoles described herein. In order to accelerate the development of the drugs from natural sources, modern, practical, and efficient synthetic strategies capable of scale up to multigram quantities are of utmost importance. Illustrated in this review is the versatility of the asymmetric Pictet-Spengler reaction in the enantiospecific total synthesis of many biologically active monomeric and bisindole alkaloids. In addition, there are many other new developments with 100\% diastereoselectivity derived from the coupling process of two monomeric alkaloids to provide the bisindole targets. Investigations of the synthesis of the monomeric unit has yielded many reactions capable of scale up, to date, to the 300-600 g levels.

Acknowledgments: This work was supported by NS 076517 and MH 096463.

Conflicts of Interest: The authors declare no conflict of interest.

\section{References}

1. O'Neil, M.J. The Merck Index: An Encyclopedia of Chemicals, Drugs, and Biologicals; RSC Publishing: London, UK, 2013.

2. Henry, T.A. The Plant Alkaloids, 4th ed.; I \& A Churchill Ltd.: London, UK, 1949.

3. Fabricant, D.S.; Farnsworth, N.R. The value of plants used in traditional medicine for drug discovery. Environ. Health Perspect. 2001, 109 (Suppl. S1), 69-75. [CrossRef] [PubMed]

4. Farnsworth, N.R.; Akerele, O.; Bingel, A.S.; Soejarto, D.D.; Guo, Z. Medicinal plants in therapy. Bull. World Health Organ. 1985, 63, 965-981. [CrossRef]

5. Wang, J.-F.; Wei, D.-Q.; Chou, K.-C. Drug candidates from traditional Chinese medicines. Curr. Top. Med. Chem. 2008, 8, 1656-1665. [CrossRef] [PubMed]

6. Newman, D.J.; Cragg, G.M. Natural products as sources of new drugs over the 30 years from 1981 to 2010. J. Nat. Prod. 2012, 75, 311-335. [CrossRef] [PubMed]

7. Butler, M.S. Natural products to drugs: Natural product-derived compounds in clinical trials. Nat. Prod. Rep. 2008, 25, 475-516. [CrossRef] [PubMed]

8. Cordell, G.A.; Quinn-Beattie, M.L.; Farnsworth, N.R. The potential of alkaloids in drug discovery. Phytother. Res. 2001, 15, 183-205. [CrossRef] [PubMed]

9. Tietze, L.F.; Bell, H.P.; Chandrasekhar, S. Natural product hybrids as new leads for drug discovery. Angew. Chem. Int. Ed. 2003, 42, 3996-4028. [CrossRef] [PubMed]

10. Mishra, B.B.; Tiwari, V.K. Natural products: An evolving role in future drug discovery. Eur. J. Med. Chem. 2011, 46, 4769-4807. [CrossRef] [PubMed]

11. Cragg, G.M.; Newman, D.J. Biodiversity: A continuing source of novel drug leads. Pure Appl. Chem. 2005, 77, 7-24. [CrossRef]

12. Haefner, B. Drugs from the deep: Marine natural products as drug candidates. Drug Discov. Today 2003, 8, 536-544. [CrossRef]

13. Butler, M.S. The role of natural product chemistry in drug discovery. J. Nat. Prod. 2004, 67, 2141-2153. [CrossRef] [PubMed] 
14. Butler, M.S. Natural products to drugs: Natural product derived compounds in clinical trials. Nat. Prod. Rep. 2005, 22, 162-195. [CrossRef] [PubMed]

15. Cragg, G.M.; Newman, D.J. Natural products: A continuing source of novel drug leads. Biochim. Biophys. Acta 2013, 1830, 3670-3695. [CrossRef] [PubMed]

16. Cordell, G.A.; Saxton, J.E. Bisindole Alkaloids. In The Alkaloids: Chemistry and Physiology; Rodrigo, G.A., Ed.; Academic Press: New York, NY, USA, 1981; Volume 20, pp. 3-295.

17. Cordell, G.A. The bisindole alkaloids. In Chemistry of Heterocyclic Compounds: Indoles, Part Four, the Monoterpenoid Indole Alkaloids; Saxton, J.E., Ed.; John Wiley \& Sons, Inc.: New York, NY, USA, 1983; Volume 25, pp. 539-728.

18. Kam, T.-S.; Choo, Y.-M. Bisindole alkaloids. In The Alkaloids: Chemistry and Biology; Cordell, G.A., Ed.; Academic Press: San Diego, CA, USA, 2006; Volume 63, pp. 181-337.

19. Kitajima, M.; Takayama, H. Chapter Four-Monoterpenoid Bisindole Alkaloids. In The Alkaloids: Chemistry and Biology; Knölker, H.-J., Ed.; Academic Press: San Diego, CA, USA, 2016; Volume 76, pp. 259-310.

20. Ban, Y.; Murakami, Y.; Iwasawa, Y.; Tsuchiya, M.; Takano, N. Indole alkaloids in medicine. Med. Res. Rev. 1988, 8, 231-308. [CrossRef] [PubMed]

21. Wright, C.; Allen, D.; Cai, Y.; Phillipson, J.; Said, I.; Kirby, G.; Warhurst, D. In vitro antiamoebic and antiplasmodial activities of alkaloids isolated from Alstonia angustifolia roots. Phytother. Res. 1992, 6, 121-124. [CrossRef]

22. Keawprdub, N.; Houghton, P.; Eno-Amooquaye, E.; Burke, P. Activity of extracts and alkaloids of Thai Alstonia species against human lung cancer cell lines. Planta Med. 1997, 63, 97-101. [CrossRef]

23. Johnson, I.S.; Wright, H.F.; Svoboda, G.H.; Vlantis, J. Antitumor principles derived from Vinca rosea Linn I. Vincaleukoblastine and leurosine. Cancer Res. 1960, 20, 1016-1022. [PubMed]

24. Noble, R.; Beer, C.; Cutts, J. Role of chance observations in chemotherapy: Vinca rosea. Ann. N. Y. Acad. Sci. 1958, 76, 882-894. [CrossRef] [PubMed]

25. Svoboda, G.H.; Johnson, I.S.; Gorman, M.; Neuss, N. Current status of research on the alkaloids of Vinca rosea Linn. (Catharanthus roseus G. Don). J. Pharm. Sci. 1962, 51, 707-720. [CrossRef] [PubMed]

26. Neuss, N.; Gorman, M.; Svoboda, G.; Maciak, G.; Beer, C. Vinca alkaloids. III. 1. Characterization of leurosine and vincaleukoblastine, new alkaloids from Vinca rosea LINN. J. Am. Chem. Soc. 1959, 81, 4754-4755. [CrossRef]

27. Johnson, I. Historical background of Vinca alkaloid research and areas of future interest. Cancer Chemother. Rep. 1968, 52, 455-461. [PubMed]

28. Neuss, N.; Neuss, M.N. Therapeutic use of bisindole alkaloids from catharanthus. Alkaloids Chem. Pharmacol. 1990, 37, 229-240.

29. Sieber, S.; Mead, J.; Adamson, R. Pharmacology of antitumor agents from higher plants. Cancer Treat. Rep. 1976, 60, 1127. [PubMed]

30. Carney, D.W.; Lukesh, J.C.; Brody, D.M.; Brütsch, M.M.; Boger, D.L. Ultrapotent vinblastines in which added molecular complexity further disrupts the target tubulin dimer-dimer interface. Proc. Natl. Acad. Sci. USA 2016, 113, 9691-9698. [CrossRef] [PubMed]

31. Kutney, J.P. Synthetic Vinblastine and Vincristine Derivatives. U.S. Patent 4144237 A, 13 March 1979.

32. Fahy, J.; Duflos, A.; Ribet, J.-P.; Jacquesy, J.-C.; Berrier, C.; Jouannetaud, M.-P.; Zunino, F. Vinca alkaloids in superacidic media: A method for creating a new family of antitumor derivatives. J. Am. Chem. Soc. 1997, 119, 8576-8577. [CrossRef]

33. Keglevich, P.; Hazai, L.; Kalaus, G.; Szántay, C. Modifications on the basic skeletons of vinblastine and vincristine. Molecules 2012, 17, 5893-5914. [CrossRef] [PubMed]

34. Zhou, J.; Giannakakou, P. Targeting microtubules for cancer chemotherapy. Curr. Med. Chem. Anticancer Agents 2005, 5, 65-71. [CrossRef] [PubMed]

35. Va, P.; Campbell, E.L.; Robertson, W.M.; Boger, D.L. Total synthesis and evaluation of a key series of C5-substituted vinblastine derivatives. J. Am. Chem. Soc. 2010, 132, 8489-8495. [CrossRef] [PubMed]

36. Ishikawa, H.; Colby, D.A.; Seto, S.; Va, P.; Tam, A.; Kakei, H.; Rayl, T.J.; Hwang, I.; Boger, D.L. Total synthesis of vinblastine, vincristine, related natural products, and key structural analogues. J. Am. Chem. Soc. 2009, 131, 4904-4916. [CrossRef] [PubMed]

37. Lorenz, M.; Van Linn, M.; Cook, J. The asymmetric Pictet-Spengler reaction. Curr. Org. Synth. 2010, 7, 189-223. [CrossRef] 
38. Munoz, V.; Moretti, C.; Sauvain, M.; Caron, C.; Porzel, A.; Massiot, G.; Richard, B.; Le Men-Olivier, L. Isolation of bis-indole alkaloids with antileishmanial and antibacterial activities from Perschiera van heurkii (Syn. Tabernaemontana van heurkii). Planta Med. 1994, 60, 455-459. [CrossRef] [PubMed]

39. Saxena, S.; Pant, N.; Jain, D.; Bhakuni, R. Antimalarial agents from plant sources. Curr. Sci. 2003, 85, 1314-1329.

40. Keawpradub, N.; Eno-Amooquaye, E.; Burke, P.; Houghton, P. Cytotoxic activity of indole alkaloids from Alstonia macrophylla. Planta Med. 1999, 65, 311-315. [CrossRef] [PubMed]

41. Wright, C.W.; Allen, D.; Phillipson, J.D.; Kirby, G.C.; Warhurst, D.C.; Massiot, G.; Le Men-Olivier, L. Alstonia species: Are they effective in malaria treatment? J. Ethnopharmacol. 1993, 40, 41-45. [CrossRef]

42. Wright, C.W.; Phillipson, J.D. Natural products and the development of selective antiprotozoal drugs. Phytother. Res. 1990, 4, 127-139. [CrossRef]

43. Kam, T.-S.; Choo, Y.-M.; Komiyama, K. Unusual spirocyclic macroline alkaloids, nitrogenous derivatives, and a cytotoxic bisindole from Alstonia. Tetrahedron 2004, 60, 3957-3966. [CrossRef]

44. Feng, Y.; Gao, H.; Zeng, G. Effect of higenamine on alpha-adrenoceptors. Acta pharmacol. Sin. 1986, 7 , 208-211.

45. Talapatra, S.; Aditya Chaudhury, N. Macralstonine, an alkaloid of the trunk bark of Alstonia macrophylla Wall. Sci. Cult. 1958, 24, 243.

46. Isidro, N.; Manalo, G.D. J. Phillipine Pharm. Assoc. 1967, 53, 8.

47. Keawpradub, N.; Kirby, G.; Steele, J.; Houghton, P. Antiplasmodial activity of extracts and alkaloids of three Alstonia species from Thailand. Planta Med. 1999, 65, 690-694. [CrossRef] [PubMed]

48. Kingston, D.G. Plant anticancer agents VI: Isolation of voacangine, voacamine, and epivoacorine from Tabernaemontana arborea sap. J. Pharm. Sci. 1978, 67, 271-272. [CrossRef] [PubMed]

49. Kam, T.-S.; Tan, S.-J.; Ng, S.-W.; Komiyama, K. Bipleiophylline, an unprecedented cytotoxic bisindole alkaloid constituted from the bridging of two indole moieties by an aromatic spacer unit. Org. Lett. 2008, 10, 3749-3752. [CrossRef] [PubMed]

50. Koskinen, A.; Lounasmaa, M. The sarpagine-ajmaline group of indole alkaloids. In Progress in the Chemistry of Organic Natural Products; Ingham, J.L., Ed.; Springer: Wien, Austria, 1983; Volume 43, pp. 267-346.

51. Brugada, J.; Brugada, P. What to do in patients with no structural heart disease and sudden arrhythmic death? Am. J. Cardiol. 1996, 78, 69-75. [CrossRef]

52. Creasey, W.A. Pharmacology, biochemistry, and clinical applications of the monoterpenoid alkaloids. In Chemistry of Heterocyclic Compounds: Indoles, Part Four, The Monoterpenoid Indole Alkaloids; Saxton, J.E., Ed.; John Wiley \& Sons, Inc.: New York, NY, USA, 1983; Volume 25, pp. 783-829.

53. Lounasmaa, M.; Hanhinen, P.; Westersund, M.; Halonen, N. The Sarpagine Group of Indole Alkaloids. In The Alkaloids: Chemistry and Biology; Cordell, G.A., Ed.; Academic Press: San Diego, CA, USA, 1999; Volume 52, pp. 103-195.

54. Namjoshi, O.A.; Cook, J.M. Chapter Two-Sarpagine and Related Alkaloids. In The Alkaloids: Chemistry and Biology; Knölker, H.-J., Ed.; Academic Press: San Diego, CA, USA, 2016; Volume 76, pp. 63-169.

55. Le Men, J.; Taylor, W.I. A uniform numbering system for indole alkaloids. Experientia 1965, 21, 508-510. [CrossRef] [PubMed]

56. Hamaker, L.K.; Cook, J.M. Chapter Two: The Synthesis of Macroline Related Sarpagine Alkaloids. In Alkaloids: Chemical and Biological Perspectives; Pelletier, S.W., Ed.; Elsevier Science: New York, NY, USA, 1995; Volume 9, pp. 23-84.

57. Esmond, R.W.; Le Quesne, P.W. Biomimetic synthesis of macroline. J. Am. Chem. Soc. 1980, 102, $7116-7117$. [CrossRef]

58. Woodward, R. Neuere entwicklungen in der chemie der naturstoffe. Angew. Chem. 1956, 68, 13-20. [CrossRef]

59. Bartlett, M.; Lambert, B.; Werblood, H.; Taylor, W. Rauwolfia alkaloids. XLIII. 1 A facile ring closure of deoxyajmalal-A to deoxyajmaline. J. Am. Chem. Soc. 1963, 85, 475-477. [CrossRef]

60. Van Tamelen, E.; Oliver, L. The biogenetic-type total synthesis of ajmaline. Bioorg. Chem. 1976, 5, 309-326. [CrossRef]

61. Koskinen, A.; Lounasmaa, M. Biogenesis of the Ajmaline Type Alkaloids. Planta Med. 1982, 45, $248-249$. [CrossRef] [PubMed]

62. Pfitzner, A.; Stöckigt, J. Biogenetic link between sarpagine and ajmaline type alkaloids. Tetrahedron Lett. 1983, 24, 5197-5200. [CrossRef] 
63. Mattern-Dogru, E.; Ma, X.; Hartmann, J.; Decker, H.; Stöckigt, J. Potential active-site residues in polyneuridine aldehyde esterase, a central enzyme of indole alkaloid biosynthesis, by modelling and site-directed mutagenesis. Eur. J. Biochem. 2002, 269, 2889-2896. [CrossRef] [PubMed]

64. Ruppert, M.; Woll, J.; Giritch, A.; Genady, E.; Ma, X.; Stöckigt, J. Functional expression of an ajmaline pathway-specific esterase from Rauvolfia in a novel plant-virus expression system. Planta 2005, 222, 888-898. [CrossRef] [PubMed]

65. Yoneda, N. Synthesis of 12-methyl-1,2,3,4,6,7,12,12b-octahydro-2, 6-methanoindolo[2,3-a]quinolizine. Chem. Pharm. Bull. 1965, 13, 622-625. [CrossRef] [PubMed]

66. Mashimo, K.; Sato, Y. On the synthesis of ajmaline. Tetrahedron Lett. 1969, 10, 905-906. [CrossRef]

67. Cloudsdale, I.S.; Kluge, A.F.; McClure, N.L. Synthetic studies in the ajmaline series. J. Org. Chem. 1982, 47, 919-928. [CrossRef]

68. Soerens, D.; Sandrin, J.; Ungemach, F.; Mokry, P.; Wu, G.; Yamanaka, E.; Hutchins, L.; DiPierro, M.; Cook, J. Study of the Pictet-Spengler reaction in aprotic media: Synthesis of the. beta.-galactosidase inhibitor, pyridindolol. J. Org. Chem. 1979, 44, 535-545. [CrossRef]

69. Zhang, L.-H.; Cook, J. Pictet-Spengler reactions in aprotic media: $N_{b}$-benzyl promoted retention of optical activity in the synthesis of an indolo substituted azabicyclo[3.3.1]nonane, a key template for the synthesis of macroline alkaloids. Heterocycles 1988, 27, 2795-2802. [CrossRef]

70. Li, J.; Wang, T.; Yu, P.; Peterson, A.; Weber, R.; Soerens, D.; Grubisha, D.; Bennett, D.; Cook, J. General approach for the synthesis of ajmaline/sarpagine indole alkaloids: Enantiospecific total synthesis of (+)-ajmaline, alkaloid $\mathrm{g}$, and norsuaveoline via the asymmetric pictet-spengler reaction. J. Am. Chem. Soc. 1999, 121, 6998-7010. [CrossRef]

71. Li, J. Enantiospecific Total Synthesis of (+)-ajmaline and Alkaloid G as Well as Studies Directed toward the Total Synthesis of 19-hydroxy- $N_{\mathrm{b}}$-methylraumacline via the Asymmetric Pictet-Spengler Reaction. Ph.D. Thesis, University of Wisconsin-Milwaukee, Milwaukee, WI, USA, 1999.

72. Elderfield, R.C.; Gilman, R.E. Alkaloids of Alstonia muelleriana. Phytochemistry 1972, 11, 339-343. [CrossRef]

73. Burke, D.E.; Cook, G.A.; Cook, J.M.; Haller, K.G.; Lazar, H.A.; Le Quesne, P.W. Further alkaloids of Alstonia muelleriana. Phytochemistry 1973, 12, 1467-1474. [CrossRef]

74. Cook, J.M.; Le Quesne, P. Structure of alstonisidine, a novel dimeric indole alkaloid from Alstonia muelleriana. J. Org. Chem. 1971, 36, 582-586. [CrossRef]

75. Burke, D.E.; Cook, J.M.; Le Quesne, P. Biomimetic synthesis and structure of the bisindole alkaloid alstonisidine. J. Chem. Soc. Chem. Commun. 1972, 697. [CrossRef]

76. Hoard, L.G. The Crystal Structures of Altstonisidine, $\mathrm{C}_{42} \mathrm{H}_{48} \mathrm{~N}_{4} \mathrm{O}_{4}$, and Anhydrous Cholesterol, $\mathrm{C}_{27} \mathrm{H}_{46} \mathrm{O}$. Ph.D. Thesis, University of Michigan, Ann Arbor, MI, USA, 1977.

77. Cook, J.M.; Le Quesne, P.; Elderfield, R. Alstonerine, a new indole alkaloid from Alstonia muelleriana. J. Chem. Soc. Chem. Commun. 1969, 1306-1307. [CrossRef]

78. Kishi, T.; Hesse, M.; Gemenden, C.; Taylor, W.; Schmid, H. Alstophyllin, ein neues Indolalkaloid aus Alstonia macrophylla WALL. Helv. Chim. Acta 1965, 48, 1349-1362. [CrossRef] [PubMed]

79. Aynilian, G.; Farnsworth, N. Alkaloids of Vinca species. 3. Isolation and characterization of indole alkaloids from Vinca libanotica. Lloydia 1974, 37, 299. [PubMed]

80. Salim, A.A.; Garson, M.J.; Craik, D.J. New indole alkaloids from the roots of Ochrosia a cuminata. J. Nat. Prod. 2004, 67, 1719-1721. [CrossRef] [PubMed]

81. Lyon, R.; Fong, H.; Farnsworth, N.; Svoboda, G. Biological and phytochemical evaluation of plants XI: Isolation of aspidospermine, quebrachidine, rhazinilam, (-)-pyrifolidine, and akuammidine from Aspidosperma quebracho-blanco (apocynaceae). J. Pharm. Sci. 1973, 62, 218-221. [CrossRef] [PubMed]

82. Gorman, M.; Burlingame, A.; Biemann, K. Application of mass spectrometry to structure problems. The structure of quebrachidine. Tetrahedron Lett. 1963, 4, 39-46. [CrossRef]

83. Burke, D.E.; Cook, J.M.; Le Quesne, P. Biomimetic synthesis of the bisindole alkaloids villalstonine and alstonisidine. J. Am. Chem. Soc. 1973, 95, 546-552. [CrossRef]

84. Hesse, M.; Bodmer, F.; Gemenden, C.; Joshi, B.; Taylor, W.; Schmid, H. Die struktur des Alstonia-alkaloides villalstonin. Helv. Chim. Acta 1966, 49, 1173-1182. [CrossRef]

85. Bi, Y.; Cook, J.M. General approach for the synthesis of macroline/sarpagine alkaloids. The total synthesis of (+)-macroline. Tetrahedron Lett. 1993, 34, 4501-4504. [CrossRef] 
86. Bi, Y.; Zhang, L.-H.; Hamaker, L.K.; Cook, J.M. Enantiospecific Synthesis of (-)-Alstonerine and (+)-Macroline as Well as a Partial Synthesis of (+)-Villalstonine. J. Am. Chem. Soc. 1994, 116, 9027-9041. [CrossRef]

87. Liao, X.; Zhou, H.; Yu, J.; Cook, J.M. An improved total synthesis of (+)-macroline and alstonerine as well as the formal total synthesis of (-)-talcarpine and (-)-anhydromacrosalhine-methine. J. Org. Chem. 2006, 71, 8884-8890. [CrossRef] [PubMed]

88. Yu, J.; Wang, T.; Liu, X.; Deschamps, J.; Flippen-Anderson, J.; Liao, X.; Cook, J.M. General approach for the synthesis of sarpagine indole alkaloids. Enantiospecific total synthesis of (+)-vellosimine, (+)-normacusine B, (-)-alkaloid Q3, (-)-panarine, (+)-Na-methylvellosimine, and (+)-Na-methyl-16-epi-pericyclivine. J. Org. Chem. 2003, 68, 7565-7581. [CrossRef] [PubMed]

89. Liu, X.; Zhang, C.; Liao, X.; Cook, J.M. Enantiospecific total synthesis of the enantiomer of the indole alkaloid intermediate macroline. Tetrahedron Lett. 2002, 43, 7373-7377. [CrossRef]

90. Yu, J.; Wearing, X.Z.; Cook, J.M. A general strategy for the synthesis of vincamajine-related indole alkaloids: Stereocontrolled total synthesis of (+)-dehydrovoachalotine, (-)-vincamajinine, and (-)-11-methoxy-17-epivincamajine as well as the related quebrachidine diol, vincamajine diol, and vincarinol. J. Org. Chem. 2005, 70, 3963-3979. [PubMed]

91. Neukomm, G.; Kletzhäundler, E.; Hesse, M. Die absolute konfiguration von macrolin, einem abbauprodukt des alkaloides villalstonin 179. Mitteilung über organische naturstoffe. Helv. Chim. Acta 1981, 64, 90-96. [CrossRef]

92. Gorman, M.; Sweeny, J. Perivine. Tetrahedron Lett. 1964, 5, 3105-3111. [CrossRef]

93. Zhang, L.-H.; Cook, J.M. Pictet-Spengler reactions in aprotic media. Stereospecific conversion of optically active cis-1, 3-disubstituted 1,2,3,4-tetrahydro- $\beta$-carbolines into their corresponding trans diastereomers. Heterocycles 1988, 27, 1357-1363. [CrossRef]

94. Yu, P.; Wang, T.; Yu, F.; Cook, J.M. General approach for the synthesis of macroline/sarpagine related indole alkaloids via the asymmetric pictet-spengler reaction: The enantiospecific synthesis of the $N_{\mathrm{a}}-\mathrm{H}$, azabicyclo[3.3.1]nonone template. Tetrahedron Lett. 1997, 38, 6819-6822. [CrossRef]

95. Zhang, L.-H.; Bi, Y.-Z.; Yu, F.-X.; Menzia, G.; Cook, J.M. Stereospecificity in the Pictet-Spengler reaction. Enantiospecific synthesis of (6S, 10S)-5\#75)-5-methyl-9-oxo-12-benzyl-6,7,8,9,10,11-hexahydro6,10-imino-5H-cyclooct[b]indole, a template for preparation of macroline/sarpagine alkaloids. Heterocycles 1992, 34, 517-547.

96. Trudell, M.L.; Cook, J.M. Total synthesis of ( \pm )-suaveoline. J. Am. Chem. Soc. 1989, 111, 7504-7507. [CrossRef]

97. Bornack, W.K.; Bhagwat, S.S.; Ponton, J.; Helquist, P. Preparation of lactone systems. Total synthesis of ( \pm )-quadrone. J. Am. Chem. Soc. 1981, 103, 4647-4648. [CrossRef]

98. Amer, M.A.; Court, W.E. Alkaloids of Rauwolfia nitida root bark. Phytochemistry 1981, 20, $2569-2573$. [CrossRef]

99. Banerji, A.; Chakrabarty, M.; Mukherjee, B. Minor indole alkaloids of Alstonia macrophylla. Phytochemistry 1972, 11, 2605-2607. [CrossRef]

100. Tran, Y.S.; Kwon, O. An application of the phosphine-catalyzed [4 + 2] annulation in indole alkaloid synthesis: Formal syntheses of $( \pm)$-alstonerine and ( \pm -macroline. Org. Lett. 2005, 7, 4289-4291. [CrossRef] [PubMed]

101. Fukuyama, T.; Cheung, M.; Kan, T. N-carboalkoxy-2-nitrobenzenesulfonamides: A practical preparation of N-Boc-, N-Alloc-, and N-Cbz-protected primary amines. Synlett 1999, 1999, 1301-1303. [CrossRef]

102. Eschweiler, W. Ersatz von an stickstoff gebundenen wasserstoffatomen durch die methylgruppe mit hülfe von formaldehyd. Ber. Dtsch. Chem. Ges. 1905, 38, 880-882. [CrossRef]

103. Clarke, H.; Gillespie, H.; Weisshaus, S. The action of formaldehyde on amines and amino acids1. J. Am. Chem. Soc. 1933, 55, 4571-4587. [CrossRef]

104. Achenbach, H.; Schaller, E. Alkaloide in Tabernaemontana-Arten, VII. Über einige Bisindolalkaloide aus Tabernaemontana accedens. Chem. Ber. 1976, 109, 3527-3536. [CrossRef]

105. Azoug, M.; Loukaci, A.; Richard, B.; Nuzillard, J.-M.; Moreti, C.; Zèches-Hanrot, M.; Le Men-Olivier, L. Alkaloids from stem bark and leaves of Peschiera buchtieni. Phytochemistry 1995, 39, 1223-1228. [CrossRef]

106. Yang, J.; Sarma, P.; Cook, J.M. Progress toward the enantiospecific total synthesis of accedinisine and $N^{\prime}$-demethylaccedinisine. In Proceedings of the 235th American Chemical Society National Meeting, New Orleans, LA, USA, 6-10 April 2008; p. ORGN 648. 
107. Rallapalli, S.K.; Cook, J.M. Progress toward the total synthesis of the sarpagine related alkaloids amervolfine and ervincidine. In Proceedings of the 237th American Chemical Society National Meeting, Salt Lake City, UT, USA, 22-26 March 2009; p. ORGN 517.

108. Edwankar, C.R.; Edwankar, R.V.; Namjoshi, O.A.; Rallapalli, S.K.; Yang, J.; Cook, J.M. Recent progress in the total synthesis of indole alkaloids. Curr. Opin. Drug Discov. Devel. 2009, 12, 752-771. [PubMed]

109. Edwankar, C.R.; Edwankar, R.V.; Rallapalli, S.; Cook, J.M. General approach to the total synthesis of macroline-related sarpagine and ajmaline alkaloids. Nat. Prod. Commun. 2008, 3, 1839-1870.

110. Yin, W.; Ma, J.; Rivas, F.M.; Cook, J.M. First enantiospecific total synthesis of the important biogenetic intermediates, (+)-polyneuridine and (+)-polyneuridine aldehyde, as well as 16-epi-vellosimine and macusine A. Org. Lett. 2007, 9, 295-298. [CrossRef] [PubMed]

111. Wang, T.; Cook, J.M. General approach for the synthesis of sarpagine/ajmaline indole alkaloids. stereospecific total synthesis of the sarpagine alkaloid (+)-vellosimine. Org. Lett. 2000, 2, 2057-2059. [CrossRef] [PubMed]

112. Warmuth, R.; Munsch, T.E.; Stalker, R.A.; Li, B.; Beatty, A. Enantioselective synthesis of benzocyclic $\alpha$, $\alpha$-dialkyl-amino acids: New insight into the solvent dependent stereoselectivity of the TMSCN addition to phenylglycinol derived imines. Tetrahedron 2001, 57, 6383-6397. [CrossRef]

113. Wender, P.A.; Schaus, J.M.; White, A.W. General methodology for cis-hydroisoquinoline synthesis: Synthesis of reserpine. J. Am. Chem. Soc. 1980, 102, 6157-6159. [CrossRef]

114. Bonjoch, J.; Fernàndez, J.-C.; Valls, N. Total syntheses of $( \pm)$-deethylibophyllidine using a crisscross annulation: Ring cleavage of octahydroindolo[2,3-a]quinolizines followed by tandem cyclizations of octahydroazecino[5,4-b]indoles. J. Org. Chem. 1998, 63, 7338-7347. [CrossRef] [PubMed]

115. Schill, G.; Löwer, H.; Priester, C.U.; Windhövel, U.F.; Fritz, H. Eine neue synthese von vinblastin-derivaten II: Synthesekonzept und modelluntersuchungen. Tetrahedron 1987, 43, 3729-3745. [CrossRef]

116. Schill, G.; Priester, C.U.; Windhovel, U.F.; Fritz, H. Eine neue synthese von vinblastin-derivaten v. konzept und untersuchungen zur synthese von $20^{\prime}$-desethyl-20'-desoxy-c'-homovinblastin-octahydro- $3 \mathrm{H}$ azecino[5,4-b]inidol-derivate. Tetrahedron 1990, 46, 1211-1220. [CrossRef]

117. Calverley, M.; Harley-Mason, J.; Quarrie, S.; Edwards, P. On the stereochemistry of the solvolytic c/d ring cleavage of the 1,2,3,4,6,7,12,12b-octahydroindolo[2,3-a]quinolizine system. Tetrahedron 1981, 37, 1547-1556. [CrossRef]

118. Liu, C.T.; Sun, S.C.; Yu, Q.S. Synthesis and photooxidation of the condensation products of tryptamine and catechol derivatives. An approach to the synthesis of a probable precursor of koumine. J. Org. Chem. 1983, 48, 44-47. [CrossRef]

119. Takayama, H.; Masubuchi, K.; Kitajima, M.; Aimi, N.; Sakai, S.-I. A biomimetic construction of humantenine skeleton. Tetrahedron 1989, 45, 1327-1336. [CrossRef]

120. Takayama, H.; Tominaga, Y.; Kitajima, M.; Aimi, N.; Sakai, S.-I. First synthesis of the novel Gelsemium alkaloids, gelselegine, gelsenicine, and gelsedine using a biomimetic approach. J. Org. Chem. 1994, 59, 4381-4385. [CrossRef]

121. Banks, B.; Calverley, M.; Edwards, P.; Harley-Mason, J. A new synthesis of indolo[2,3- $\alpha$ ]quinolizidine derivatives: A formal total synthesis of $( \pm$ )-geissoschizine. Tetrahedron Lett. 1981, 22, 1631-1634. [CrossRef]

122. Weisbach, J.A.; Raffauf, R.F.; Ribeiro, O.; Macko, E.; Douglas, B. Problems in chemotaxonomy I. Alkaloids of Peschiera affinis. J. Pharm. Sci. 1963, 52, 350-353. [CrossRef] [PubMed]

123. Clivio, P.; Richard, B.; Deverre, J.-R.; Sevenet, T.; Zeches, M.; Le Men-Oliver, L. Alkaloids from leaves and root bark ofErvatamia hirta. Phytochemistry 1991, 30, 3785-3792. [CrossRef]

124. Liu, X.; Wang, T.; Xu, Q.; Ma, C.; Cook, J.M. Enantiospecific total synthesis of the enantiomer of the indole alkaloid affinisine. Tetrahedron Lett. 2000, 41, 6299-6303. [CrossRef]

125. Buchi, G.; Manning, R.; Monti, S. Voacamine and voacorine. J. Am. Chem. Soc. 1964, 86, 4631-4641. [CrossRef]

126. Buchi, G.; Manning, R.; Monti, S. Voacamine. J. Am. Chem. Soc. 1963, 85, 1893-1894. [CrossRef]

127. Sharp, T.M. 265. The alkaloids of Alstonia barks. Part II. A. macrophylla, wall., A. somersetensis, FM Bailey, A. verticillosa, F. Muell., A. villosa, blum. J. Chem. Soc. 1934, 1227-1232. [CrossRef]

128. Kishi, T.; Hesse, M.; Vetter, W.; Gemenden, C.; Taylor, W.; Schmid, H. Macralstonin. Helv. Chim. Acta 1966, 49, 946-964. [CrossRef]

129. Lim, S.-H.; Low, Y.-Y.; Tan, S.-J.; Lim, K.-H.; Thomas, N.F.; Kam, T.-S. Perhentidines A-C: Macroline-macroline bisindoles from Alstonia and the absolute configuration of perhentinine and macralstonine. J. Nat. Prod. 2012, 75, 942-950. [CrossRef] [PubMed] 
130. Changwichit, K.; Khorana, N.; Suwanborirux, K.; Waranuch, N.; Limpeanchob, N.; Wisuitiprot, W.; Suphrom, N.; Ingkaninan, K. Bisindole alkaloids and secoiridoids from Alstonia macrophylla Wall. ex G. Don. Fitoterapia 2011, 82, 798-804. [CrossRef] [PubMed]

131. Ghedira, K.; Zeches-Hanrot, M.; Richard, B.; Massiot, G.; Le Men-Olivier, L.; Sevenet, T.; Goh, S. Alkaloids of Alstonia angustifolia. Phytochemistry 1988, 27, 3955-3962. [CrossRef]

132. Cook, J.; Le Quesne, P. Macralstonine from Alstonia muelleriana. Phytochemistry 1971, 10, 437-439. [CrossRef]

133. Hart, N.; Johns, S.; Lamberton, J. Tertiary alkaloids of Alstonia spectabilis and Alstonia glabriflora (Apocynaceae). Aust. J. Chem. 1972, 25, 2739-2741. [CrossRef]

134. Schmid, H. 4. Internationales Symposium Biochemie und Physiologie der Alkaloide (1969); Akademie Verlag: Berlin, Germany, 1972; p. 348.

135. Burke, D.E.; DeMarkey, C.A.; Le Quesne, P.; Cook, J.M. Biomimetic synthesis of the bis-indole alkaloid macralstonine. J. Chem. Soc. Chem. Commun. 1972, 1346-1347. [CrossRef]

136. Liu, X. The Enantiospecific Stereospecific Total Synthesis of the Enantiomers of the Indole Alkaloids Na-methylvellosimine, Affinisine and Macroline as Well as the Total Synthesis of the Indole Alkaloids Trinervine, Alstophylline and the Antimalarial Bisindole Macralstonine. Ph.D. Thesis, University of Wisconsin-Milwaukee, Milwaukee, WI, USA, 2002.

137. Allen, M.S.; Hamaker, L.K.; La Loggia, A.J.; Cook, J.M. Entry into 6-methoxy-D(+)-tryptophans. Stereospecific synthesis of 1-benzenesulfonyl-6-methoxy-D(+)-tryptophan ethyl ester. Synth. Commun. 1992, 22, 2077-2102. [CrossRef]

138. Ma, C.; Liu, X.; Li, X.; Flippen-Anderson, J.; Yu, S.; Cook, J.M. Efficient asymmetric synthesis of biologically important tryptophan analogues via a palladium-mediated heteroannulation reaction. J. Org. Chem. 2001, 66, 4525-4542. [CrossRef] [PubMed]

139. Liu, X.; Deschamp, J.R.; Cook, J.M. Regiospecific, enantiospecific total synthesis of the alkoxy-substituted indole bases, 16-epi-Na-methylgardneral, 11-methoxyaffinisine, and 11-methoxymacroline as well as the indole alkaloids alstophylline and macralstonine. Org. Lett. 2002, 4, 3339-3342. [CrossRef] [PubMed]

140. Garnick, R.L.; Le Quesne, P.W. Biomimetic transformations among monomeric macroline-related indole alkaloids. J. Am. Chem. Soc. 1978, 100, 4213-4219. [CrossRef]

141. Liao, X.; Zhou, H.; Wearing, X.Z.; Ma, J.; Cook, J.M. The first regiospecific, enantiospecific total synthesis of 6-oxoalstophylline and an improved total synthesis of alstonerine and alstophylline as well as the bisindole alkaloid macralstonine. Org. Lett. 2005, 7, 3501-3504. [CrossRef] [PubMed]

142. Nicolaou, K.; Baran, P.S.; Zhong, Y.-L. Selective oxidation at carbon adjacent to aromatic systems with IBX. J. Am. Chem. Soc. 2001, 123, 3183-3185. [PubMed]

143. Tsuji, J.; Nagashima, H.; Hori, K. A new preparative method for 1,3-dicarbonyl compounds by the regioselective oxidation of alpha, beta-unsaturated carbonyl compounds, catalyzed by $\mathrm{PdCl}_{2}$ using hydroperoxides as the reoxidant of Pd0. Chem. Lett. 1980, 257-260. [CrossRef]

144. Zhao, S.; Liao, X.; Cook, J.M. Enantiospecific, stereospecific total synthesis of (+)-majvinine, (+)-10-methoxyaffinisine, and (+)-Na-methylsarpagine as well as the total synthesis of the alstonia bisindole macralstonidine. Org. Lett. 2002, 4, 687-690. [CrossRef] [PubMed]

145. Zhao, S.; Liao, X.; Wang, T.; Flippen-Anderson, J.; Cook, J.M. The enantiospecific, stereospecific total synthesis of the ring-A oxygenated sarpagine indole alkaloids (+)-majvinine, (+)-10-methoxyaffinisine, and (+)-Na-methylsarpagine, as well as the total synthesis of the Alstonia bisindole alkaloid macralstonidine. J. Org. Chem. 2003, 68, 6279-6295. [CrossRef] [PubMed]

146. Heath-Brown, B.; Philpott, P. Studies in the indole series. Part III. The Japp-Klingemann reaction. J. Chem. Soc. 1965, 7185-7193. [CrossRef]

147. Liao, X. The First Total Synthesis of the Indole Alkaloids, Macralstonidine, 6-oxoalstophylline, 10-methoxyvellosimine, Lochnerine, Sarpagine and an Improved Total Synthesis of Macralstonine and Macroline, as Well as the Formal Total Synthesis of Dispegatrine. Ph.D. Thesis, University of Wisconsin-Milwaukee, Milwaukee, WI, USA, 2007.

148. Hesse, M.; Hürzeler, H.; Gemenden, C.; Joshi, B.; Taylor, W.; Schmid, H. Die Struktur des Alstonia-Alkaloides Villalstonin Vorläufige Mitteilung. Helv. Chim. Acta 1965, 48, 689-704. [CrossRef] [PubMed]

149. Pan, L.; Terrazas, C.; Acuña, U.M.; Ninh, T.N.; Chai, H.; de Blanco, E.J.C.; Soejarto, D.D.; Satoskar, A.R.; Kinghorn, A.D. Bioactive indole alkaloids isolated from Alstonia angustifolia. Phytochem. Lett. 2014, 10, 54-59. [CrossRef] [PubMed] 
150. Nordman, C.; Kumra, S. The structure of villalstonine1. J. Am. Chem. Soc. 1965, 87, 2059-2060. [CrossRef]

151. Kump, W.; Schmid, H. Über die alkaloide von Pleiocarpa mutica BENTH. Helv. Chim. Acta 1961, 44, 1503-1516. [CrossRef]

152. Kam, T.-S.; Subramaniam, G.; Chen, W. Alkaloids from Kopsia dasyrachis. Phytochemistry 1999, 51, $159-169$. [CrossRef]

153. Bartlett, M.; Sklar, R.; Smith, A.; Taylor, W. The alkaloids of Hunteria eburnea Pichon. III. 1 The tertiary bases. J. Org. Chem. 1963, 28, 2197-2199. [CrossRef]

154. Hesse, M.; Philipsborn, W.; Schumann, D.; Spiteller, G.; Spiteller-Friedmann, M.; Taylor, W.; Schmid, H.; Karrer, P. Die strukturen von C-fluorocurin, C-mavacurin und pleiocarpamin. 57. Mitteilung über Curare-alkaloide. Helv. Chim. Acta 1964, 47, 878-911. [CrossRef]

155. Mayerl, F.; Hesse, M. Macrocarpamin, ein neues bisindolalkaloid aus Alstonia macrophylla WALL. 167. Mittelung über organische naturstoffe. Helv. Chim. Acta 1978, 61, 337-351. [CrossRef]

156. Said, I.M.; Din, L.B.; Yusoff, N.I.; Wright, C.W.; Cai, Y.; Phillipson, J.D. A new alkaloid from the roots of Alstonia angustifolia. J. Nat. Prod. 1992, 55, 1323-1324. [CrossRef]

157. Khan, Z.M.; Hesse, M.; Schmid, H. Die Struktur des quartären Alkaloides Macrosalhin. Helv. Chim. Acta 1967, 50, 1002-1010. [CrossRef] [PubMed]

158. Gan, T.; Cook, J.M. General approach for the synthesis of macroline/sarpagine related indole alkaloids via the asymmetric Pictet-Spengler reaction: The enantiospecific synthesis of (-)-anhydromacrosalhine-methine. Tetrahedron Lett. 1996, 37, 5033-5036. [CrossRef]

159. Gan, T.; Cook, J.M. Partial synthesis of the antiamoebic bisindole alkaloid (-)-macrocarpamine. Tetrahedron Lett. 1996, 37, 5037-5038. [CrossRef]

160. Gan, T.; Cook, J.M. Enantiospecific total synthesis of (-)-anhydromacrosalhine-methine and partial synthesis of the antiamoebic bisindole alkaloid (-)-macrocarpamine. J. Org. Chem. 1998, 63, 1478-1483. [CrossRef]

161. Takayama, H.; Phisalaphong, C.; Kitajima, M.; Aimi, N.; Sakai, S.-I. An efficient synthetic pathway to the macroline-type indole alkaloids, talcarpine and alstonerine from ajmaline. Tetrahedron 1991, 47, 1383-1392. [CrossRef]

162. Wearing, X.Z. Enantiospecific Stereospecific Total Synthesis of the Oxindole Alkaloid (+)-alstonisine and Stereocontrolled Total Synthesis of (-)-11-methoxy-17-epivincamajine as Well as Studies Directed toward the Total Synthesis of $N_{\mathrm{b}}$-demethylalstophylline Oxindole. Ph.D. Thesis, Univeristy of Wisconsin-Milwaukee, Milwaukee, WI, USA, 2004.

163. Zhang, L.; Cook, J. General approach to the synthesis of macroline-related alkaloids. Stereospecific total synthesis of (-)-alstonerine. J. Am. Chem. Soc. 1990, 112, 4088-4090. [CrossRef]

164. Lin, M.; Yang, B.-Q.; Yu, D.-Q. Studies on the quaternary alkaloids of Rauvolfia verticillata (lour.) Baill var. Hainanensis Tsiang. Acta Pharmacol. Sin. 1986, 21, 114-118.

165. Lin, M.; Yu, D.-Q.; Liu, X.; Fu, F.; Zheng, Q.; He, C.; Bao, G.; Xu, C. Chemical studies on the quaternary alkaloids of Rauvolfia verticillata (Lour.) Baill. F. ruberocarpa HT Chang. mss. Acta Pharmacol. Sin. 1985, 20, 198-202.

166. Arbain, D.; Dachriyanus, F.; Sargent, M.V.; Skelton, B.W.; White, A.H. Unusual indole alkaloids from Ophiorrhiza blumeana Korth. J. Chem. Soc. Perkin Trans. 1998, 1, 2537-2540. [CrossRef]

167. Orazi, O.O.; Corral, R.A.; Stoichevich, M.E. Studies on plants: XI. Alkaloids of Aspidosperma spegazzinii. Can. J. Chem. 1966, 44, 1523-1529. [CrossRef]

168. Madinaveitia, A.; Valencia, E.; Bermejo, J.; Gonzalez, A. Indole alkaloids from Rauwolfia sprucei. Biochem. Syst. Ecol. 1995, 23, 877. [CrossRef]

169. Edwankar, C.R.; Edwankar, R.V.; Deschamps, J.R.; Cook, J.M. Nature-inspired stereospecific total synthesis of $P$-(+)-dispegatrine and four other monomeric sarpagine indole alkaloids. Angew. Chem. Int. Ed. 2012, 51, 11762-11765. [CrossRef] [PubMed]

170. Edwankar, C.R.; Edwankar, R.V.; Namjoshi, O.A.; Liao, X.; Cook, J.M. Stereospecific approach to the synthesis of ring-A oxygenated sarpagine indole alkaloids. Total synthesis of the dimeric indole alkaloid P-(+)-dispegatrine and six other monomeric indole alkaloids. J. Org. Chem. 2013, 78, 6471-6487. [CrossRef] [PubMed]

171. Tohma, H.; Morioka, H.; Takizawa, S.; Arisawa, M.; Kita, Y. Efficient oxidative biaryl coupling reaction of phenol ether derivatives using hypervalent iodine (III) reagents. Tetrahedron 2001, 57, 345-352. [CrossRef] 
172. Larock, R.C.; Yum, E.K. Synthesis of indoles via palladium-catalyzed heteroannulation of internal alkynes. J. Am. Chem. Soc. 1991, 113, 6689-6690. [CrossRef]

173. Larock, R.; Yum, E.; Refvik, M. Synthesis of 2,3-disubstituted indoles via palladium-catalyzed annulation of internal alkynes. J. Org. Chem. 1998, 63, 7652-7662. [CrossRef]

174. Schollkopf, U. Asymmetric syntheses of amino acids via metalated bis-lactim ethers of 2,5-diketopiperazines. Pure Appl. Chem. 1983, 55, 1799-1806. [CrossRef]

175. Schöllkopf, U.; Groth, U.; Deng, C. Enantioselective syntheses of (R)-amino acids using L-valine as chiral agent. Angew. Chem. Int. Ed. 1981, 20, 798-799. [CrossRef]

176. Ma, J.; Yin, W.; Zhou, H.; Cook, J.M. Total synthesis of the opioid agonistic indole alkaloid mitragynine and the first total syntheses of 9-methoxygeissoschizol and 9-methoxy- $N_{\mathrm{b}}$-methylgeissoschizol. Org. Lett. 2007, 9, 3491-3494. [CrossRef] [PubMed]

177. Kondo, Y.; Kojima, S.; Sakamoto, T. General and facile synthesis of indoles with oxygen-bearing substituents at the benzene moiety. J. Org. Chem. 1997, 62, 6507-6511. [CrossRef]

178. Lizos, D.E.; Murphy, J.A. Concise synthesis of $( \pm)$-horsfiline and $( \pm)$-coerulescine by tandem cyclisation of iodoaryl alkenyl azides. Org. Biomol. Chem. 2003, 1, 117-122. [CrossRef] [PubMed]

179. Snieckus, V. Directed ortho metalation. Tertiary amide and O-carbamate directors in synthetic strategies for polysubstituted aromatics. Chem. Rev. 1990, 90, 879-933. [CrossRef]

180. Zhou, H.; Liao, X.; Cook, J.M. Regiospecific, enantiospecific total synthesis of the 12-alkoxy-substituted indole alkaloids, (+)-12-methoxy-Na-methylvellosimine, (+)-12-methoxyaffinisine, and (-)-fuchsiaefoline. Org. Lett. 2004, 6, 249-252. [CrossRef] [PubMed]

181. Abramovitch, R.; Shapiro, D. 880. Tryptamines, carbolines, and related compounds. Part II. A convenient synthesis of tryptamines and $\beta$-carbolines. J. Chem. Soc. 1956, 4589-4592. [CrossRef]

182. Robinson, B. The Fischer Indole Synthesis; John Wiley \& Sons Ltd.: New York, NY, USA, 1982.

183. Nelson, T.D.; Crouch, R.D. $\mathrm{Cu}, \mathrm{Ni}$, and $\mathrm{Pd}$ mediated homocoupling reactions in biaryl syntheses: The Ullmann reaction. Org. React. 2004. [CrossRef]

184. Cox, E.D.; Cook, J.M. The Pictet-Spengler condensation: A new direction for an old reaction. Chem. Rev. 1995, 95, 1797-1842. [CrossRef]

185. Klausen, R.S.; Jacobsen, E.N. Weak Brønsted acid-thiourea co-catalysis: Enantioselective, catalytic Protio-Pictet-Spengler reactions. Org. Lett. 2009, 11, 887-890. [CrossRef] [PubMed]

186. Stöckigt, J.; Antonchick, A.P.; Wu, F.; Waldmann, H. The Pictet-Spengler reaction in nature and in organic chemistry. Angew. Chem. Int. Ed. 2011, 50, 8538-8564. [CrossRef] [PubMed]

187. Yang, J.; Rallapalli, S.K.; Cook, J.M. The first enantiospecific total synthesis of the 3-oxygenated sarpagine indole alkaloids affinine and 16-epiaffinine, as well as vobasinediol and 16-epivobasinediol. Tetrahedron Lett. 2010, 51, 815-817. [CrossRef]

188. Solé, D.; Urbaneja, X.; Bonjoch, J. Palladium-catalyzed intramolecular coupling of amino-tethered vinyl halides with ketones, esters, and nitriles using potassium phenoxide as the base. Adv. Synth. Catal. 2004, 346, 1646-1650. [CrossRef]

189. Keller, P.A.; Yepuri, N.R.; Kelso, M.J.; Mariani, M.; Skelton, B.W.; White, A.H. Oxidative coupling of indoles using thallium (III) trifluoroacetate. Tetrahedron 2008, 64, 7787-7795. [CrossRef]

190. McKillop, A.; Turrell, A.G.; Young, D.W.; Taylor, E.C. Thallium in organic synthesis. 58. Regiospecific intermolecular oxidative dehydrodimerization of aromatic compounds to biaryls using thallium (III) trifluoroacetate. J. Am. Chem. Soc. 1980, 102, 6504-6512. [CrossRef]

191. Mckillop, A.; Taylor, E.C. Recent advances in organothallium chemistry. Adv. Organomet. Chem. 1973, 11, 147-206.

192. Elson, I.H.; Kochi, J.K. Thallium (III) in one-electron oxidation of arenes by electron spin resonance. J. Am. Chem. Soc. 1973, 95, 5060-5062. [CrossRef]

193. Lau, W.; Kochi, J. Kinetics and mechanism of aromatic thallation. Identification and proof of competing electrophilic and electron-transfer pathways. J. Am. Chem. Soc. 1984, 106, 7100-7112. [CrossRef]

(C) 2016 by the authors; licensee MDPI, Basel, Switzerland. This article is an open access article distributed under the terms and conditions of the Creative Commons Attribution (CC-BY) license (http://creativecommons.org/licenses/by/4.0/). 